ANL-6442

ANL-6442

97599

MASTER

Argonne hational Laboratorn

COST FUNCTION STUDIES

FOR POWER REACTORS

by

J. Heestand and L. T. Wos 


\section{DISCLAIMER}

This report was prepared as an account of work sponsored by an agency of the United States Government. Neither the United States Government nor any agency Thereof, nor any of their employees, makes any warranty, express or implied, or assumes any legal liability or responsibility for the accuracy, completeness, or usefulness of any information, apparatus, product, or process disclosed, or represents that its use would not infringe privately owned rights. Reference herein to any specific commercial product, process, or service by trade name, trademark, manufacturer, or otherwise does not necessarily constitute or imply its endorsement, recommendation, or favoring by the United States Government or any agency thereof. The views and opinions of authors expressed herein do not necessarily state or reflect those of the United States Government or any agency thereof. 


\section{DISCLAIMER}

Portions of this document may be illegible in electronic image products. Images are produced from the best available original document. 
This report was prepared as an account of Government sponsored work. Neither the United States, nor the Commission, nor any person acting on behalf of the Commission:

A. Makes any warranty or representation, expressed or implied. with respect to the accuracy, completeness, or usefulness of the information contained in this report, or that the use of any information, apparatus, method, or process disclosed in this report may not infringe privately owned rights; or

B. Assumes any liabilities with respect to the use of, or for damages resulting from the use of any information, apparatus, method, or process disclosed in this report.

As used in the above, "person acting on behalf of the Commission" includes any employee or contractor of the Commission, or employee of such contractor, to the extent that such employee or contractor of the Commission, or employee of such contractor prepares, disseminates, or provides access to, any information pursuant to his employment or contract with the Commission, or his employment with such contractor.

Price $\$ 1.50$. Available from the Office of Technical Services, Department of Commerce, Washington 25, D.C. 
ANL-6442

Reactor Technology

(TID-4500, 16th Ed., Amended)

AEC Research and

Development Report

\section{ARGONNE NATIONAL LABORATORY \\ 9700 South Cass Avenue \\ Argonne, Illinois}

\section{COST FUNCTION STUDIES FOR POWER REACTORS}

by

J. Heestand and L. T. Wos

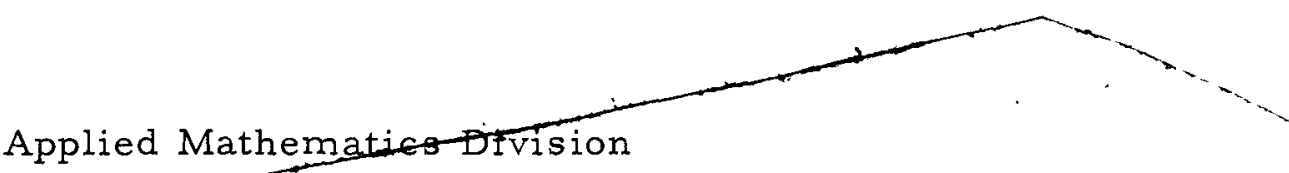

Applied Mathematie Division

November 1961

Operated by The University of Chicago

under

Contract W-3I-109-eng-38 
TABLE OF CONTENTS

$\underline{\text { Page }}$

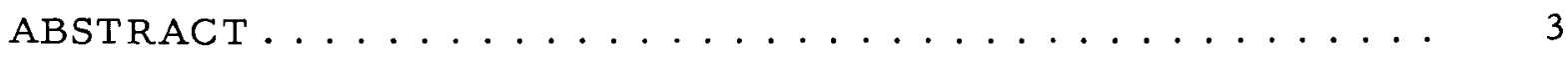

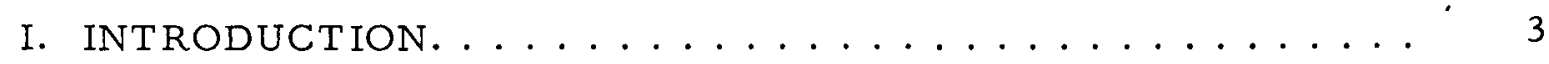

II. DEVELOPMENT OF COST FUNCTION. ............ 3

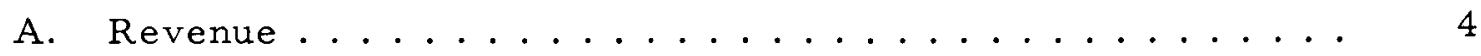

B. Capital Charges.................... 4

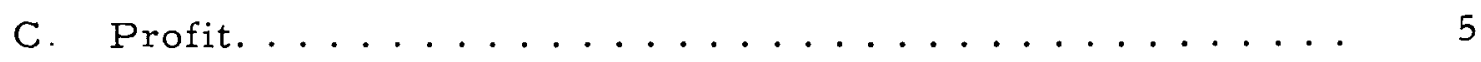

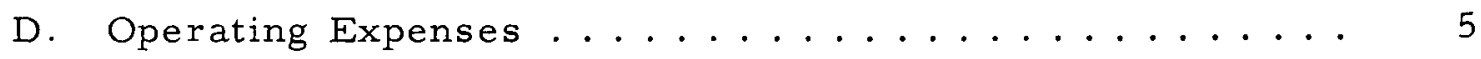

1. Ad valorem Charges.................... 5

2. Operation and Maintenance Costs ........... 5

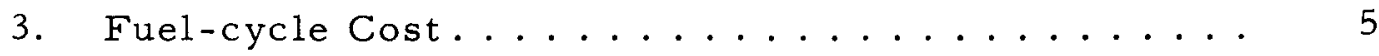

4. Liability Insurance................ 6

5. Taxes........................... 7

III. CONCLUDING REMARKS. ................. 8

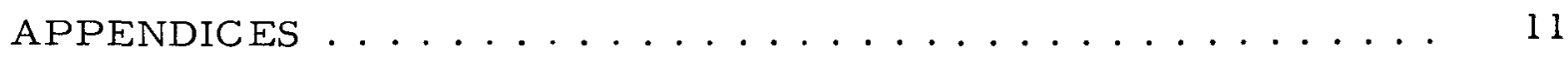

A. Description of the IBM 704 Program 0908/RE224...... 11

B. Fast Reactor Fuel Cycle Cost Analysis. . . . . . . . . . 20

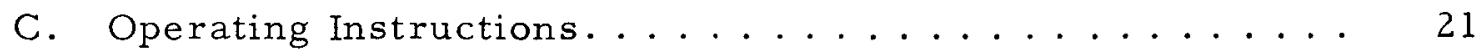

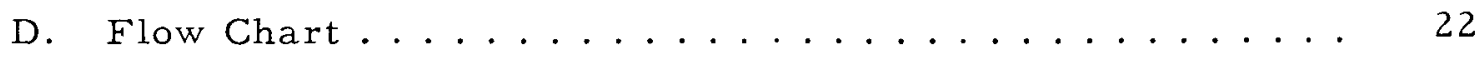

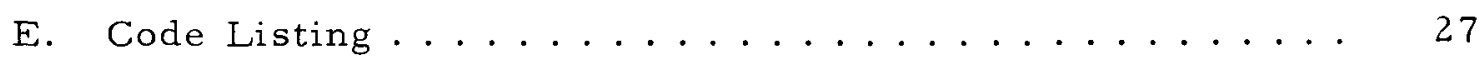

F. Sample Problem Input and Output ............. 53

G. Sample Work Sheet................. 60

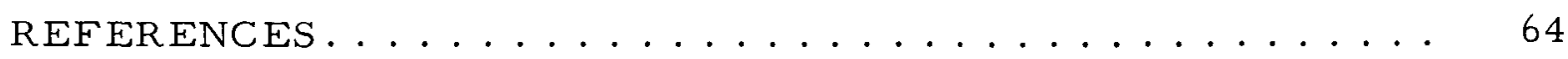

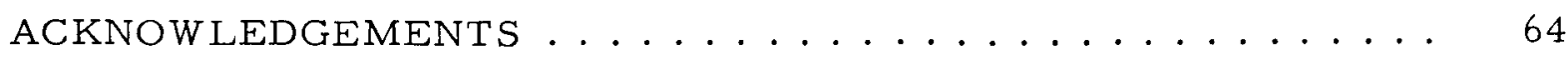




\title{
COST FUNCTION STUDIES FOR POWER REACTORS
}

by

J. Heestand and L. T. Wos

\begin{abstract}
A function to evaluate the cost of electricity produced by a nuclear power reactor is developed. The basic equation, revenue = capital charges + profit + operating expenses, is expanded in terms of various cost parameters to enable analysis of multiregion nuclear reactors with uranium and/or plutonium for fuel. A corresponding IBM 704 computer program, which will compute either the price of electricity or the value of plutonium, is presented in detail in the appendices.
\end{abstract}

\section{INTRODUCTION}

The industrial application of any large engineering system requires a critical examination of the economic factors involved in its use. Following the suggestion of the use of nuclear reactors for the generation of electric power, there has arisen an interest in examining the economic aspects of the operation of such a reactor power station. For this purpose a program directed toward carrying out a rather thorough analysis of reactor power stations has been initiated, the first step of which is the development of an appropriate cost function for the system. The purpose of this paper is to discuss the development of the cost function, which in this case gives the cost in mills per kilowatt hour of generated electricity as a function of the various cost parameters. The cost function contains minor simplifications whose effect on mills per kilowatt hour is insignificant; it is not intended to serve as an accounting technique. This work bears a close resemblance to that of J. M. McCampbell, (a) with revisions to incorporate recent changes in insurance laws, elaboration of the treatment of fuel cycle cost, and refinements to give access to more detailed information and to permit further studies which are contemplated.

\section{DEVELOPMENT OF COST FUNCTION}

The basis for the analysis is contained in the equation

$$
\text { revenue = capital charges }+ \text { profit + operating expenses },
$$

which is assumed to hold true for each period of time (one year in this program) in which the reactor is operated to produce electricity. 
A. Revenue

There are two sources of revenue, the sale of electricity and the sale of plutonium (or $\mathrm{U}^{233}$ ). We ignore all other fission byproducts as sources of revenue.

Annual electric revenue $(\$)=8.76 \times 10^{3} \mathrm{P} \eta \in \mathrm{m}$,

where $P$ is the thermal power rating of the reactor in megawatts, $\eta$ is the net thermal efficiency, $\epsilon$ is the plant factor, and $m$ is the cost of electricity to the user in mills per kilowatt hour.

Annual revenue $(\$)$ from sale of plutonium $=10^{3} \mathrm{Av} / \mathrm{T}$,

where $A$ is the amount in kilograms of plutonium produced by one fuel charge in exposure time $\tau$ years and $v$ is the value in dollars of one gram of plutonium.

\section{B. Capital Charges}

Capital charges are just those charges needed to redeem capital spent on construction, research and development, the corresponding interest, and the interest on capital spent for land. We wish to redeem interest on the various sums involved, whether it occurs as a result of actually borrowing capital or as a result of interest lost by utilizing available funds in these connections instead of investing them. We make the assumptions that the value of land is a constant and that available interest on sinking funds is equal percentagewise to those interests referred to above. We then have

(capital charges) $\left(\frac{(1+i)^{n}-1}{i}\right)+I_{\ell}=\frac{1}{\beta} I_{d}(1+i)^{n_{d}+n}+\left(I_{c}+I_{\ell}\right)(1+i)^{n_{c}+n}$,

where, remembering that the assumption with sinking funds is that the payment is made at the end of each period, $\left[(1+i)^{n}-1\right] / i$ is the sinking fund factor which gives the value of a sinking fund consisting of $n$ equal payments at interest $i, n$ is the life of the plant in years, $\beta$ is the number of plants over which research and development costs are distributed, $I_{d}$ is the research and development cost, $n_{d}$ is the average lead time in years for research and development, $I_{C}$ and $I_{\ell}$ are the respective costs for construction and land, and $n_{C}$ is the number of years capital is tied up in land and construction prior to startup. By transposing the cost of land and dividing by $(1+i)^{n}$, we have an equation stating that the present value of the sinking fund resulting from annual capital charges is equal to the present net value of the capital transaction. In other words, capital charges refer to that amount of money deposited in equal payments at the 
end of each operating year in a sinking fund such that the value of that fund when the plant has zero salvage value is precisely the difference between the value of the invested capital at that time and the value of land; the value of invested capital at the end of the life of the plant is expressed by the right side of Equation (4).

C. Profit

The profit parameter $\omega$ is given as a percentage of the value of invested capital at startup, and is not to be confused with the present value of all capital transactions. The value of $\omega$ is obtained by levelizing the desired profit over the lifetime of the plant. The profit in dollars is thus $\omega\left[\frac{1}{\beta} I_{d}(1+i)^{n_{d}}+\left(I_{c}+I_{l}\right)(1+i)^{n_{c}}\right]$. At present, the value of $\omega$ is supplied to, rather than computed by, the program.

D. Operating Expenses

Operating expenses consist of: ad valorem charges, operation and maintenance, fuel-cycle costs, and insurance and taxes not proportional to the value of the plant.

1. Ad valorem Charges. Ad valorem charges (plant insurance, property damage insurance, and property taxes) are assessed against the appraised value of the property. The sum of these charges is given by

$$
(\phi+\chi+\psi) \delta\left(I_{C}+I_{\ell}\right)
$$

where $\phi, \chi$, and $\psi$ are the respective rates, and $\delta$ is the ratio of appraised value to actual.

2. Operation and Maintenance Costs. Operation and maintenance costs are estimated by the user of the program. They include salaries, equipment, supplies, and overhead.

3. Fuel-cycle Cost. Fuel-cycle cost is computed from supplied cost parameters; there is no attempt at this time to include any core design study or any technique for minimization of this cost. We are able to consider a multiregion core, a multiregion blanket, and, as fuel, enriched uranium, plutonium, or some combination of these fuels restricted to separate regions. The fuel-cycle cost is, therefore, the sum of the costs for the various regions. Any credit for plutonium production is added as revenue and not placed against fuel-cycle cost directly. For any one region, the fuel-cycle cost has four components: first, the product of the throughput of fuel, adjusted to compensate for various losses, and the sum of the unit costs for conversion, fabrication, reprocessing, shipping, and 
waste disposal; second, a use-charge proportional to the use-charge rate, value of fuel at the appropriate enrichment, and the time in which the fuel is not in AEC possession; third, a burnup charge from the los $s$ in value of the fuel; fourth, the cost of reducing produced plutonium to metal buttons. Since annual loading equals initial loading divided by residence time, fuelcycle cost is given by the equation

$$
\begin{aligned}
& f_{c}= \sum_{k}\left[u L_{3 k} V\left(e_{1}\right)_{k}+\frac{1}{\tau_{k}}\left\{\left[c_{c k}\left(1+\ell_{c k}+l_{f k}\right)+c_{f k}\left(1+l_{f k}\right)+c_{r k}+c_{s k}+c_{s}{ }_{k}+c_{w k} \ell_{w k}\right] L_{1 k}\right.\right. \\
&+ {\left[\left(t_{c k}+t_{f k}+t_{s k}\right) V\left(e_{1}\right)_{k}+\tau_{k}\left(\frac{V\left(e_{1}\right)_{k}+V\left(e_{2}\right)_{k}}{2}\right)+\left(t_{d k}+t_{r k}+t_{s^{\prime} k}\right) V\left(e_{2}\right)_{k}\right] u L_{1 k}\left(1+l_{c k}+\ell_{f k}\right) } \\
&+ {\left.\left.\left[V\left(e_{1}\right)_{k} L_{1 k}\left(1+\ell_{c k}+l_{f k}\right)-V\left(e_{2}\right)_{k} L_{2 k}\right]+A_{k} c_{p k} 10^{3}\right\}\right], } \\
& \text { (the subscript } k \text { designates the region) }
\end{aligned}
$$

where: $c_{C}, c_{f}, c_{r}, c_{S}, c_{S}{ }^{\prime}$, and $c_{W}$ are unit costs per kilogram of conversion, fabrication, reprocessing, shipping of new and irradiated fuel, and radioactive waste disposal, respectively; $t_{c}, t_{f}, t_{r}, t_{s}$ and $t_{s}$ are the corresponding times required for the processes; $t_{d}$ is the time necessary for radioactive decay of spent fuel before reprocessing; $T$ is the residence time; $u$ is the use-charge rate; $V\left(e_{1}\right)$ denotes the value at initial enrichment $e_{1}$, and $V\left(e_{2}\right)$ the value at enrichment $e_{2}$ at discharge; $L_{1}, L_{2}$, and $L_{3}$ are the weights of fuel at initial loading, after reprocessing and for the inventory; $l_{\mathrm{c}}$ and $\ell_{\mathrm{f}}$ are those percentages by which $L_{1}$ must be increased to compensate for losses in conversion and fabrication, respectively*; $l_{\mathrm{W}}$ is the percentage of $L_{1}$ to be disposed of as radioactive waste; $A$ is the amount of plutonium produced by one loading; and $c_{p}$ is the cost per gram of reducing plutonium to metal buttons.

4. Liability Insurance. According to the latest law on liability insurance for power reactors, the required coverage is determined in the following manner. If the maximum allowable power does not exceed $10 \mathrm{kw}$ (thermal), the required coverage is 1 million dollars; if greater than $10 \mathrm{kw}(\mathrm{t})$ but does not exceed $1 \mathrm{mw}(\mathrm{t}), 1.5 \mathrm{million}$; if greater than $1 \mathrm{mw}(\mathrm{t})$ but does not exceed $10 \mathrm{mw}(\mathrm{t}), 2.5$ million. If the power rating in mw(electrical) exceeds 100 , the required coverage is 60 million. For those reactors not yet covered, apply the formula $\mathrm{x}=\mathrm{Bp}$, where $\mathrm{x}$ is coverage in dollars rounded up to the nearest hundred thousand, $B$ is the base amount of financial protection, and $\mathrm{p}$ is the population factor. The coverage $x$ must be between 3.5 and 60 million; $B$ equals 150 dollars times maximum allowable power in $\mathrm{kw}(\mathrm{t}) ; \mathrm{p}$ is between $\mathrm{l}$ and 1.5 and is determined by the magnitude of the nearby population.

* To avoid confusion it should be understood that $l_{C}$ equals 0.15 if, for example, the loss from conversion is $15 \%$. 
The parameter of interest, however, is the amount of premium. Not allowing a premium rate to be less than 1,000 dollars per million of coverage, the premium schedule is: the base premium for the first million, 0.5 of base for each of the next 4 million, 0.2 of base for each of next $5,0.1$ for each of next $10,0.05$ for each of next 20 , and 0.025 for each million of coverage above 40 million. Annual cost of liability insurance $\mathrm{Pl}$ is given by

$$
P \ell=a_{1} \kappa+0.5 a_{1} \lambda+0.2 a_{1} \mu+0.1 a_{1} \nu+0.05 a_{1} \xi+0.025 a_{1} \zeta,(6)
$$

where $\mathrm{a}_{1}$ is the base premium and $\kappa, \lambda, \mu, \nu, \xi$, and $\zeta$ are the number of millions at the corresponding premium.

5. Taxes. The taxes are of two kinds: state income and federal income. State $\operatorname{tax} S$ is assessed at the rate $\mathrm{j}_{S}$ on the difference between gross revenue and the tax deductibles. The tax deductibles consist of ad valorem charges, operation and maintenance cost, fuel-cycle cost, liability insurance, interest on the bonded fraction of invested capital at startup, and depreciation. For the tax calculation the shortest allowable time for straight-line depreciation is taken. The federal income tax $F$ is obtained by taking that revenue taxable by the state, subtracting from it the money paid as state income tax, and taxing this modified revenue at the rate $j_{F}$. With $b$ the bonded fraction of capitalization, $\underline{i}$ the interest rate on the bonds, and $n$ 'the depreciation time, the tax equations are

$$
\begin{aligned}
S= & j_{S}\left(8.76 \times 10^{3} P \eta \in m+10^{3}(A v / \tau)-(\phi+\psi+\chi)\left(I_{c}+I_{\ell}\right) \delta-O M-f_{c}-P_{\ell}\right. \\
& \left.-\frac{1}{n^{\prime}}\left[\frac{1}{\beta} I_{d}+I_{C}\right]-b_{\underline{i}}\left[\frac{1}{\beta} I_{d}(1+i)^{n_{d}}+\left(I_{C}+I_{\ell}\right)(1+i)^{n_{c}}\right]\right)
\end{aligned}
$$

and

$$
F=j_{F}\left(1-j_{S}\right) S / j_{S}
$$

If the reactor power station is part of a larger complex and, the refore, its taxes are not computed separately but are instead assigned as a fraction $g$ of the revenue dollar; its reduced revenue, $l-g$ times gross revenue, must equal the sum of capital charges and operating expenses exclusive of taxes. By using the selector $\alpha$, which takes on the value 0 or 1 , we can handle either tax situation. This is accomplished by replacing revenue in Equation (1) by $(1-\alpha g)$ revenue and by replacing the tax contribution in Equation (1) by $(1-\alpha)(F+S)$. Thus, when $\alpha$ is 0 , we are in the first case; and when $\alpha$ is 1 , the tax contribution is nullified and the gross revenue reduced accordingly, and we are in the second. 
Using Equations (1) and (2) and letting I be the present value of all capital transactions and $\left.a_{n}\right]=\left[1-(1+i)^{-n}\right] / i$, we have

$$
a_{n} 7 \text { revenue }=I+a_{n\rceil} \text { profit }+a_{n 7} \text { operating expenses, }
$$

which says that the present value of annual revenue equals the present value of annual capital charges plus the present value of annual profit plus the present annual operating expenses all taken over the life of the plant. By expanding Equation (9) in the parameters discussed above, we can solve for $m$, obtaining

$$
\begin{aligned}
& \mathrm{m}=\frac{1}{8.76 \times 10^{3} \mathrm{P} \eta \in[(1-\alpha g)-(1-\alpha) \mathrm{j}]} x \\
& \left\{I / a_{n} 7+[1-(1-\alpha) j][\phi+\chi+\psi) \delta\left(I_{C}+I_{\ell}\right)+O M+f_{c}+P_{\ell}\right] \\
& +\left[\frac{1}{\beta} I_{d}(1+i)^{n_{d}}+\left(I_{c}+I \ell\right)(1+i)^{n_{c}}\right][\omega-(1-\alpha) j b \underline{i}] \\
& \left.-(1-\alpha) j \frac{1}{n^{\prime}}\left[\frac{1}{\beta} I_{d}+I_{C}\right]+[(1-\alpha) j-(1-\alpha g)]\left[10^{3} \mathrm{Av} / T\right]\right\} \text {, }
\end{aligned}
$$

where $j=j_{S}+j_{F}-j_{S} j_{F}$. Thus, if we are given average values for the parameters involved, we can determine the average price to be charged for the electricity produced by the power reactor in order to cover the various costs and still yield the desired average profit. For the public power station operating on a nonprofit basis, we just set the profit parameter $\omega$ to 0 and follow our usual procedure. The question of a year with unusual operating conditions may be of interest to the utility - for example, the first year with its attendant startup problems and, therefore, costs. To compute the corresponding charge for electricity necessary to maintain the desired revenue cost balance when viewed as a one-year problem, we need only adjust the affected cost parameters accordingly, since the value of fixed charges is not changed by such considerations.

\section{CONCLUDING REMARKS}

Since the selling price of electricity produced by power reactors may be very dependent on the value placed on the simultaneously produced plutonium, the pricing of plutonium is a very relevant consideration. We have applied the analysis above to this problem, interchanging the roles of electricity cost and plutonium value, and thus developed an IBM 704 program to yield the value of plutonium when assigning a selling price for electricity therein produced. 
By use of the cost function discussed in this paper, or the corresponding IBM 704 program, one can gain information about the economic competitiveness of a given reactor with other means of producing electricity. By a differential analysis of such cost functions, the importance of the various cost parameters can be seen. Thus, for example, the effect of a small change in use-charge rate or a change in tax rate can easily be assessed. Differentiating with respect to $u$, the use-charge, we have

$$
\begin{aligned}
\frac{\partial \mathrm{m}}{\partial \mathrm{u}}= & \frac{[(1-\alpha g)-(1-\alpha) j]^{-1}}{8.76 \times 10^{3} \mathrm{P} \eta \epsilon} x \\
& \sum_{\mathrm{k}}\left\{\mathrm{L}_{3 \mathrm{k}} \mathrm{V}\left(\mathrm{e}_{1}\right)_{\mathrm{k}}+\frac{1}{T_{\mathrm{k}}}\left[\left(\mathrm{t}_{\mathrm{ck}}+\mathrm{t}_{\mathrm{fk}}+\mathrm{t}_{\mathrm{sk}}\right) \mathrm{V}\left(\mathrm{e}_{1}\right)_{\mathrm{k}}+\tau_{\mathrm{k}}\left(\frac{\mathrm{V}\left(\mathrm{e}_{1}\right)_{\mathrm{k}}+\mathrm{V}\left(\mathrm{e}_{2}\right)_{\mathrm{k}}}{2}\right)\right.\right. \\
& \left.\left.+\left(t_{\mathrm{dk}}+t_{\mathrm{rk}}+t_{\mathrm{s} / \mathrm{k}}\right) \mathrm{V}\left(\mathrm{e}_{2}\right)_{\mathrm{k}}\right] \mathrm{L}_{\mathrm{xk}}\left(1+l_{\mathrm{ck}}+l_{\mathrm{fk}}\right)\right\}
\end{aligned}
$$

which shows that a doubling of the use-charge would cause the cost in mills per kilowatt hour to increase by

$$
\begin{aligned}
& \frac{u[(1-\alpha g)-(1-\alpha) j]^{-1}}{8.76 \times 10^{3} P \eta \epsilon} \times \\
& \sum_{k}\left\{L_{3 k} V\left(e_{1}\right)_{k}+\frac{1}{\tau_{k}}\left[\left(t_{c k}+t_{f k}+t_{s k}\right) V\left(e_{1}\right)_{k}+\tau_{k}\left(\frac{V\left(e_{1}\right)_{k}+V\left(e_{2}\right)_{k}}{2}\right)\right.\right. \\
& \left.\left.+\left(t_{d k}+t_{r k}+t_{s / k}\right) V\left(e_{2}\right)_{k}\right] L_{1 k}\left(1+l_{c k}+l_{f k}\right)\right\} .
\end{aligned}
$$

Another partial, perhaps of equal interest, is that with respect to $j$, the tax rate:

$$
\begin{aligned}
\frac{\partial m}{\partial j}= & (1-\alpha)\left\{I / a_{n}+[1-(1-\alpha g)]\left[(\phi+\psi+\chi) \delta\left(I_{C}+I_{\ell}\right)+O M+f_{C}+P_{\ell}\right]\right. \\
& +[\omega-(1-\alpha g) b \underline{i}]\left[\frac{1}{\beta} I_{d}(1+i)^{n_{d}}+\left(I_{C}+I_{L}\right)(1+i)^{n_{C}}\right] \\
& \left.-(1-\alpha g) \frac{1}{n^{\prime}}\left[\frac{1}{\beta} I_{d}+I_{c}\right]\right\} \div\left\{8.76 \times 10^{3} P \eta \in[(1-\alpha g)-(1-\alpha) j]^{2}\right\}
\end{aligned}
$$

Such an analysis can indicate those areas in which, from an economic viewpoint, technological progress is needed. 


\section{APPENDIX A}

\section{DESCRIPTION OF THE IBM 704 PROGRAM 0908/RE224}

STATEMENT OF THE PROBLEM: RE224 is a program for the IBM 704 that will evaluate $m$, the cost of electricity (mills/kwhr), or $v$, the value of plutonium $(\$ / \mathrm{gm})$, for a nuclear power plant, given various cost parameters as input.

The cost of electricity, $m$, can be evaluated for eithe $r$ a nuclear power plant or a fossil-fueled power plant by the following equation:

$$
\begin{aligned}
\mathrm{m}= & \frac{1}{8.76 \times 10^{3} \mathrm{P} \eta \in[(1-\alpha \mathrm{g})-(1-\alpha) \mathrm{j}]} \\
& \times \quad\left\{\left(1 / \mathrm{a}_{\mathrm{n}}\right)+[1-(1-\alpha) \mathrm{j}]\left[(\phi+\chi+\psi) \delta\left(\mathrm{I}_{\mathrm{c}}+\mathrm{I}_{\ell}\right)+\mathrm{OM}+\mathrm{P}_{\ell}+\mathrm{fc}_{\mathrm{t}}\right]\right. \\
& +\left[\mathrm{I}+\mathrm{I}_{\ell}(1+\mathrm{i})^{-\mathrm{n}}\right][\omega-(1-\alpha) \mathrm{j} \mathrm{b} \underline{\mathrm{i}}]-(1-\alpha) \mathrm{j} \frac{1}{\mathrm{n}^{\prime}}\left(\frac{1}{\beta} \mathrm{I}_{\mathrm{d}}+\mathrm{I}_{\mathrm{c}}\right) \\
& \left.+[(1-\alpha) \mathrm{j}-(1-\alpha \mathrm{g})]\left[10^{3} \mathrm{Av} / \tau\right]\right\},
\end{aligned}
$$

where

$$
\begin{aligned}
& I=\frac{1}{\beta} I_{d}(1+i)^{n_{d}}+\left(I_{c}+I_{\ell}\right)(1+i)^{n_{c}}-I_{\ell}(1+i)^{-n}, \\
& j=j_{S}+j_{F}-j_{S} j_{F} \quad, \\
& a_{n\urcorner}=\frac{1-(1+i)^{-n}}{i} \text {, } \\
& P_{l}=\left\{\begin{array}{l}
0 \text { for fossil-fueled plant } \\
\kappa a_{1}+\lambda 0.5 a_{1}+\mu 0.2 a_{1}+\nu 0.1 a_{1}+\xi 0.05 a_{1}+\zeta 0.025 a_{1} \\
\quad \text { for nuclear power plant, }
\end{array}\right. \\
& \tau_{k}=\left\{\begin{array}{l}
\text { assumed one year for fossil-fueled plant } \\
\frac{2.7397 \times 10^{-3} E_{\mathrm{tk}}}{\in \mathrm{P}} \text { for nuclear power plant }(2)
\end{array}=\begin{array}{l}
\text { residence } \\
\text { time, }
\end{array}\right. \\
& \mathrm{Av} / T=\left\{\begin{array}{l}
0 \text { for fossil-fueled plant } \\
\mathrm{NFCB}+\mathrm{NFCC} \\
\mathrm{v} \sum_{\mathrm{k}=1} \mathrm{~A}_{\mathrm{k}} / \tau_{\mathrm{k}} \text { for nuclear power plant, and }
\end{array}\right.
\end{aligned}
$$

* See notes at end of Appendix A 
$f c_{t}=\left\{\begin{array}{l}\text { input for fossil-fueled plant } \\ Q_{1}+Q_{2}+Q_{3} \vee 10^{3} \text { for nuclear power plant }\end{array}\right.$

In the equation for $f c_{t}$,

$$
\begin{aligned}
& \Omega_{1}=\sum_{k=1}^{N F C B+N F C C} 1 / \tau_{k}\left\{\left[c_{c k}\left(1+\ell_{c k}+\ell_{f k}\right)+c_{f k}\left(1+\ell_{f k}\right)+c_{r k}+c_{s k}+c_{s}{ }^{\prime k}+c_{w k} \ell_{w k}\right] L_{1 k}+A_{k} c_{p k} 10^{3}\right\} \\
& Q_{2}=\sum_{k=1}^{N F C B} u_{k} L_{3 k} V\left(e_{1}\right)_{k}+\frac{1}{T_{k}}\left\{\left[\left(t_{c k}+t_{f k}+t_{s k}\right) v\left(e_{1}\right)_{k}+\tau_{k}\left(\frac{V\left(e_{1}\right)_{k}+V\left(e_{2}\right)_{k}}{2}\right)\right.\right. \\
& \left.\left.+\left(t_{d k}+t_{r k}+t_{s}{ }^{\prime}\right) \quad v\left(e_{2}\right)_{k}\right] u_{k} L_{1 k}\left(1+\ell_{c k}+\ell_{f k}\right)+\left[v\left(e_{1}\right)_{k} L_{1 k}\left(1+\ell_{c k}+\ell_{f k}\right)-v\left(e_{2}\right)_{k} L_{2 k}\right]\right\} \text {, }
\end{aligned}
$$

and

$$
Q_{3}=\sum_{k=N F C B+1}^{N F C B+N F C C} u_{k} L_{3 k}+1 / \tau_{k}\left\{\left[\left(t_{c k}+t_{f k}+\tau_{k}+t_{d k}+t_{r k}+t_{s k}+t_{s} k_{k}\right) u_{k}+1\right] \quad L_{i k}\left(1+l_{c k}+\ell_{f k}\right)-L_{2 k}\right\}
$$

with

$$
V\left(e_{p}\right)=\left\{C_{F}\left(\frac{e_{p}-e_{w}}{e_{F}-e_{w}}\right)+C_{\Delta}\left[v_{p}+\left(\frac{e_{p}-e_{F}}{e_{F}-e_{w}}\right) v_{w}-\left(\frac{e_{p}-e_{w}}{e_{F}-e_{w}}\right) v_{F}\right]\right\}
$$

defined as the value of the product fuel at enrichment $e_{p}, p=1,2$, and

$$
v_{\zeta}=\left(2 e_{\zeta}-1\right) \ln \left(\frac{e_{\zeta}}{1-e_{\zeta}}\right)
$$

defined as the separation potential of the $\zeta^{\text {th }}$ stream, $\zeta=p, w, F^{(c)}$

The parameter NFCB designates the number of uranium fuel regions in the reactor and NFCC, the number of plutonium fuel regions.

The value of plutonium, $v$, can be evaluated for a uranium- or a plutonium-fueled plant by the following equation:

$$
\begin{aligned}
\mathrm{v}= & \frac{1}{\left[(1-\alpha g)-(1-\alpha)_{J}\right] 10^{3}(\mathrm{~A} / \tau)-\left[1-(1-\alpha)_{j}\right] Q_{3} \times 10^{3}} \\
& \times\left\{\left(\mathrm{I} / \mathrm{a}_{\mathrm{n} 7}\right)-876 \times 10^{3} \mathrm{P} \eta \in \mathrm{m}\left[(1-\alpha g)-(1-\alpha)_{J}\right]\right. \\
& +\left[\omega-(1-\alpha)_{j} \mathrm{~b}_{1}\right]\left[\mathrm{I}+\mathrm{I}_{\ell}(1+1)^{-\mathrm{n}}\right]-(1-\alpha)_{3} \frac{1}{\mathrm{n}^{1}}\left(\frac{1}{\beta} \mathrm{I}_{\mathrm{d}}+\mathrm{I}_{\mathrm{c}}\right) \\
& \left.+\left[1-(1-\alpha)_{j}\right]\left[(\phi+\psi+\chi) \delta\left(\mathrm{I}_{\mathrm{c}}+\mathrm{I}_{\ell}\right)+O M+\mathrm{P}_{\ell}+Q_{1}+Q_{2}\right]\right\},
\end{aligned}
$$

where $I, J, a_{n}, P_{\ell}, \tau, Q_{1}, Q_{2}$, and $Q_{3}$ are as defıned above for uranıum-fueled plants and

$$
A / T=\sum_{k=1}^{N F C B+N F C C} A_{k} / \tau_{k}
$$


Further analysis of the fuel cycle cost equation can be found in Appendix B.

MACHINE: This program is written in FORTRAN for an IBM 704 with core storage of at least $8 \mathrm{~K}$, an on-line card reader, and an on-line printer or one magnetic tape unit.

RUNNING TIME: A problem takes less than one-minute running time with tape output.

INPUT INFORMATION REQUIRED: The input parameters, together with the values of the associated index $J$ (to be explained later), are as follows:

\begin{tabular}{|c|c|c|}
\hline $\mathrm{J}$ & $\begin{array}{l}\text { Param- } \\
\quad \text { eter }\end{array}$ & Description \\
\hline 1 & MCALC & $\left\{\begin{array}{l}0-v-c a l c u l a t i o n \\
l-m-c a l c u l a t i o n\end{array}\right.$ \\
\hline 2 & NFCB & number of uranium regions $\left\{\begin{array}{l}0 \leq N F C B \leq 10 \\
0 \leq N F C C \leq 10\end{array}\right.$ \\
\hline 3 & NFCC & number of plutonium regions $\left\{\begin{array}{c}0 \leq \mathrm{NFCB}+\mathrm{NFCC} \leq 10 \\
\text { (both } 0 \text { for fossil-fuel } \\
\text { case) }\end{array}\right.$ \\
\hline 4 & $\beta$ & $\begin{array}{l}\text { number of plants over which design and development } \\
\text { costs are distributed }\end{array}$ \\
\hline 5 & i & interest rate $\left(\% \times 10^{-2}\right)$ \\
\hline 6 & $\mathrm{I}_{\mathrm{c}}$ & investment in construction $(\$)$ \\
\hline 7 & $I_{d}$ & investment in design and development $(\$)$ \\
\hline 8 & $\mathrm{I}_{\ell}$ & investment in land $(\$)$ \\
\hline 9 & $\mathrm{n}$ & plant life (yr) \\
\hline 10 & $\mathrm{n}_{\mathrm{c}}$ & average lead time for construction ( $y r)$ \\
\hline 11 & $\mathrm{n}_{\mathrm{d}}$ & average lead time for design (yr) \\
\hline 12 & $\epsilon$ & plant factor $\left(\% \times 10^{-2}\right)$ \\
\hline 13 & $\eta$ & plant net thermal efficiency $\left(\% \times 10^{-2}\right)$ \\
\hline 14 & $\mathrm{P}$ & thermal power rating of reactor ( $T M W)$ \\
\hline 15 & $\mathrm{v}$ & value of plutonium as metal buttons $(\$ / \mathrm{gm})$ \\
\hline 16 & $\mathrm{~m}$ & cost of generating electric power (mills/kwhr) \\
\hline 17 & OM & operating and maintenance cost $(\$ / y r)$ \\
\hline 18 & $\omega$ & annual levelized return on investment $\left(\% \times 10^{-2}\right)$ \\
\hline
\end{tabular}




\begin{tabular}{|c|c|c|}
\hline $\mathrm{J}$ & $\begin{array}{l}\text { Param- } \\
\quad \text { eter }\end{array}$ & Description \\
\hline 19 & $\chi$ & ad valorem rate for property taxes $\left(\% \times 10^{-2}\right)$ \\
\hline 20 & $\delta$ & appraisal fraction $\left(\% \times 10^{-2}\right)$ \\
\hline 21 & $\phi$ & ad valorem rate for plant insurance $\left(\% \times 10^{-2}\right)$ \\
\hline 22 & $\psi$ & $\begin{array}{l}\text { ad valrem rate for property damage insurance } \\
\left(\% \times 10^{-2}\right)\end{array}$ \\
\hline 23 & $a_{1}$ & $\begin{array}{l}\text { base rate of premium on liability insurance } \\
\text { ( } \$ \text { per } \$ \text { million })\end{array}$ \\
\hline 24 & PF & population factor \\
\hline 25 & $\alpha$ & $\left\{\begin{array}{l}0 \text { - calculation for individual plant } \\
1 \text { - calculation for company as a whole }\end{array}\right.$ \\
\hline 26 & $\mathrm{~b}$ & fraction of capitalization by bonds $\left(\% \times 10^{-2}\right)$ \\
\hline 27 & $\underline{\mathrm{i}}$ & interest on bonds $\left(\% \times 10^{-2}\right)$ \\
\hline 28 & $j_{F}$ & federal income tax rate $\left(\% \times 10^{-2}\right)$ \\
\hline 29 & $\mathrm{j}_{\mathrm{S}}$ & state income tax rate $\left(\% \times 10^{-2}\right)$ \\
\hline 30 & $\mathrm{n}^{\prime}$ & $\begin{array}{l}\text { shortest period allowed for straight line depreciation } \\
\quad \text { for tax deduction (yr) }\end{array}$ \\
\hline 31 & $\mathrm{~g}$ & $\begin{array}{l}\text { average ratio of annual income tax payments to an- } \\
\text { nual gross revenue }\left(\% \times 10^{-2}\right)\end{array}$ \\
\hline 32 & $\mathrm{fc}_{t}$ & $\left\{\begin{array}{l}0 \text { for nuclear power case } \\
\text { "fuel cycle cost" for fossil-fueled case }(\$ / y r)\end{array}\right.$ \\
\hline $33-42$ & $\mathrm{~L}_{1}$ & initial fuel loading $(\mathrm{kg})$ \\
\hline $43-52$ & $\mathrm{~L}_{2}$ & amount of fuel after reprocessing $(\mathrm{kg})$ \\
\hline $53-62$ & $\mathrm{~L}_{3}$ & amount of inventory fuel $(\mathrm{kg})$ \\
\hline $63-72$ & $\ell_{\mathrm{c}}$ & $\begin{array}{l}\text { percent by which } L_{1} \text { must be increased to compensate } \\
\text { for loss due to conversion }\left(\% \times 10^{-2}\right)\end{array}$ \\
\hline $73-82$ & $\ell_{F}$ & $\begin{array}{l}\text { percent by which } L_{1} \text { mustbe increased to compensate } \\
\text { for loss due to fabrication }\left(\% \times 10^{-2}\right)\end{array}$ \\
\hline $83-92$ & $\ell_{\mathrm{w}}$ & $\begin{array}{l}\text { percent of } L_{1} \text { to be disposed of as radioactive waste } \\
\left(\% \times 10^{-2}\right)\end{array}$ \\
\hline $93-102$ & $c_{c}$ & cost of conversion to fuel meat material $(\$ / \mathrm{kg})$ \\
\hline $103-112$ & $c_{f}$ & cost of fabricating fuel elements $(\$ / \mathrm{kg})$ \\
\hline $113-122$ & $c_{r}$ & cost of reprocessing fuel $(\$ / \mathrm{kg})$ \\
\hline
\end{tabular}




\begin{tabular}{|c|c|c|}
\hline $\mathrm{J}$ & $\begin{array}{l}\text { Param- } \\
\quad \text { eter }\end{array}$ & Description \\
\hline $123-132$ & $c_{w}$ & cost of radioactive waste disposal $(\$ / \mathrm{kg})$ \\
\hline $133-142$ & $c_{s}$ & cost of shipping new fuel $(\$ / \mathrm{kg})$ \\
\hline $143-152$ & $c_{s}{ }^{\prime}$ & cost of shipping irradiated fuel $(\$ / \mathrm{kg})$ \\
\hline $153-162$ & $t_{c}$ & conversion time (yr) \\
\hline $163-172$ & $t_{f}$ & fabrication time (yr) \\
\hline $173-182$ & $t_{\mathbf{r}}$ & reprocessing time (yr) \\
\hline $183-192$ & $t_{\mathrm{d}}$ & radioactive decay time for "cooling" (yr) \\
\hline $193-202$ & $t_{s}$ & shipping time for new fuel (yr) \\
\hline $203-212$ & $\mathrm{t}_{\mathrm{s}}$ & shipping time for irradiated fuel (yr) \\
\hline $213-222$ & $e_{1} *(3)$ & initial uranium fuel enrichment (wt $\% \times 10^{-2}$ ) \\
\hline $223-232$ & $\mathrm{e}_{2}^{*}$ & discharge uranium fuel enrichment (wt $\% \times 10^{-2}$ ) \\
\hline $233-242$ & $C_{\triangle}{ }^{*}$ & cost of separative work $(\$ / \mathrm{kg})$ \\
\hline $243-252$ & $C_{F}^{*}$ & cost of feed material $(\$ / \mathrm{kg})$ \\
\hline $253-262$ & $e_{F}^{*}$ & $\begin{array}{l}\text { feed stream enrichment in separation plant } \\
\qquad\left(w t \% \times 10^{-2}\right)\end{array}$ \\
\hline $263-272$ & $\mathrm{e}_{\mathrm{w}}{ }^{*}$ & $\begin{array}{l}\text { waste stream enrichment in separation plant } \\
\quad\left(\text { wt } \% \times 10^{-2}\right)\end{array}$ \\
\hline $273-282$ & $A$ & $\begin{array}{l}\text { amount of plutonium produced with one fuel charge } \\
(\mathrm{kg})\end{array}$ \\
\hline $283-292$ & $c_{p}$ & $\begin{array}{l}\text { cost of reducing plutonium nitrate to metal buttons } \\
(\$ / \mathrm{gm})\end{array}$ \\
\hline $293-302$ & $E_{t}$ & integrated fission energy (TMW day) \\
\hline $303-312$ & $\mathrm{u}$ & use charge rate $\left(\% \times 10^{-2} / \mathrm{yr}\right)$. \\
\hline
\end{tabular}

The input format is as follows:

Card 1 title card of up to 72 Hollerith characters including a 1 in column 1

Card 2 $3 \mathrm{I} 12^{(4)}$

MCALC, NFCB, NFCC

Card 3

$6 \mathrm{E} 12.5$

$\beta, i, I_{C}, I_{d}, I_{\ell}, n$

Card 4

$2 \mathrm{E} 12.5$

$\mathrm{n}_{\mathrm{C}}, \mathrm{n}_{\mathrm{d}}$

Card 5

$5 \mathrm{E} 12.5$

$\epsilon, \eta, \mathrm{p}, \mathrm{v}, \mathrm{m}$ 


\begin{tabular}{|c|c|c|c|}
\hline Card & 6 & $1 E 12.5$ & $\mathrm{OM}$ \\
\hline Card & 7 & $1 \mathrm{E} 12.5$ & $\omega$ \\
\hline Card & 8 & $4 \mathrm{E} 12.5$ & $\chi, \delta, \phi, \psi$ \\
\hline Card & 9 & $2 \mathrm{E} 12.5$ & $a_{1}, P F$ \\
\hline Card & 10 & $6 \mathrm{E} 12.5$ & $\alpha, b, \underline{i}, j_{F}, j_{S}, n^{\prime}$ \\
\hline Card & 11 & $1 \mathrm{E} 12.5$ & $\mathrm{~g}$ \\
\hline Card & 12 & $1 \mathrm{E} 12.5$ & $\mathrm{fc}_{\mathrm{t}}$ \\
\hline Card & 13 & $6 \mathrm{E} 12.5$ & $L_{1}, L_{2}, L_{3}, l_{c}, l_{f}, l_{w}$ \\
\hline Card & 14 & $6 \mathrm{E} 12.5$ & $c_{c}, c_{f}, c_{r}, c_{w}, c_{s}, c_{s^{\prime}}$ \\
\hline Card & 15 & $6 \mathrm{E} 12.5$ & $t_{c}, t_{f}, t_{r}, t_{d}, t_{s}, t_{s}{ }^{\prime}$ \\
\hline Card & 16 & $6 \mathrm{E} 12.5$ & $\mathrm{e}_{1}, \mathrm{e}_{2}, \mathrm{C}_{\triangle}, \mathrm{C}_{\mathrm{F}}, \mathrm{e}_{\mathrm{F}}, \mathrm{e}_{\mathrm{W}}$ \\
\hline Card & 17 & $4 \mathrm{E} 12.5$ & $A, c_{p}, E_{t}, u$ \\
\hline
\end{tabular}

There must be NFCB + NFCC sets of cards number 13 through 17, and the data for all the uranium regions (NFCB sets) must precede the data for the plutonium regions (NFCC sets).

To facilitate parameter studies, as many sets of the following $N P C+1$ cards as desired (including 0 ) may follow the above data:

Card "1" Il 2 NPC the number of parameter changes in the next case

Card "2" I $2, E 12.5 \quad \mathrm{~J}_{1}, \mathrm{PA}\left(\mathrm{J}_{1}\right)-$ the index of the parameter to be changed and the new value of that parameter

Card "NPC +1" Il 2,El2.5 $\mathrm{J}_{\mathrm{NPC}}, \mathrm{PA}\left(\mathrm{J}_{\mathrm{NPC}}\right)$

A blank card must be the last card for each problem.

Any desired number of problems can be run consecutively.

POSSIBLE OUTPUT: Output from an m-calculation consists of:

$\mathrm{m}$ (mills -kwhr)

Capital charges $=\mathrm{I}(\$ / \mathrm{yr})$

Ad valorem charges $=(\phi+\psi+\chi) \delta\left(\mathrm{I}_{\mathrm{C}}+\mathrm{I}_{\ell}\right)(\$ / \mathrm{yr})$

Liability insurance premium $=\mathrm{P}_{\ell}(\$ / \mathrm{yr})$ 


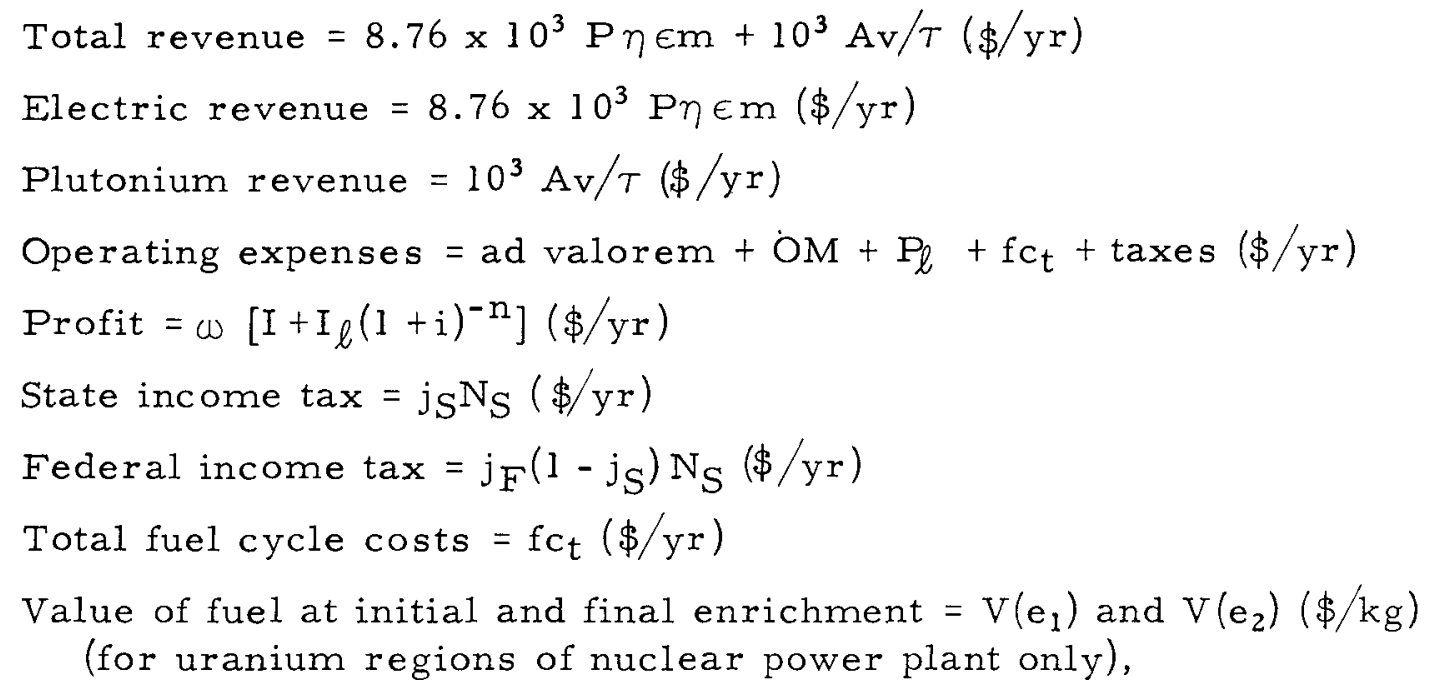

where

Taxes $=$ federal income tax + state income tax

and

$$
\begin{aligned}
N_{S}= & \text { revenue }-f c_{t}-O M-\text { ad valorem charges }-P_{\ell} \\
& -\frac{1}{n^{\prime}}\left[\frac{1}{\beta} I_{d}+I_{c}\right]-b_{-}\left[\frac{1}{\beta} I_{d}(1+i)^{n}+\left(I_{c}+I_{\ell}\right)(1+i)^{n}\right]
\end{aligned}
$$

Output from a v-calculation is the same as that for an m-calculation except that $m$ is replaced by $v$.

SPECIAL FEATURES, RESTRICTIONS, AND PROGRAM LIMITATIONS:

1. In computing federal and state taxes, a negative result is possible if tax deductibe expenses exceed the revenue. In this case the taxes are set equal to 0 and $m$ or $v$ appropriately adjusted.

2. Liability insurance coverage required is rounded up to the nearest $\$ 100,000$.

3. Parameter studies are possible without rereading the entire data deck, as is apparent from the description of the input format. To facilitate storage of the new values of changed parameters, an index $\mathrm{J}$ has been assigned to each parameter (see list of input parameters). The index $\mathrm{J}$ associated with a fuel-cycle-cost parameter has 10 possible values, one for each possible fuel cycle. For example, the value of $A$ in the third fuel cycle would have index $J=275$. The values of NFCB and NFCC may be changed to 0 and later restored to their original values to enable a comparison with fossil-fueled plants. No other changes in NFCB and NFCC are permitted. Any parameter changes made will remain in effect in succeeding cases until changed. 
4. Depressing Sense Switch 1 will produce additional output (labelled) for use in debugging. This output consists of: $a_{n}, Q_{1}, Q_{2}$, and $Q_{3}$, which have been defined previously; $I_{p}=I-I_{\ell}(1+i)-n_{;}$and $T_{1}, T_{2}, T_{3}$, and $T_{\mathbf{4}}$ which are intermediate terms defined in the flowchart in boxes 402 and 404 for an $m$ calculation and in box 401 for a $v$ calculation.

NOTES:

(1) See reference (b), table on page 5 of reference (a), and Section II.D.4 of this report for details on liability insurance premiums.

(2) For theoretical physics purposes, $\tau$, the residence time, may be defined as $y \theta / \phi_{100} \epsilon$, where

$$
\begin{aligned}
\theta & =\text { integrated flux time }\left(\mathrm{cm}^{-2}\right), \\
\phi_{100} & =\text { spatial average of neutron flux at } 100 \% \text { power }\left(\mathrm{cm}^{-2} \mathrm{sec}^{-1}\right), \\
\epsilon & =\text { plant factor }\left(\% \times 10^{-2}\right), \text { and } \\
y & =\text { number of years per second }=3.1709 \times 10^{-8} .
\end{aligned}
$$

(3) Starred parameters are defined for uranium regions only. They should be set equal to zero for plutonium regions.

(4) MCALC, NFCB, NFCC, NPC, and J must be written as integers (no decimal point) and right adjusted in their respective card fields. For example, if $\mathrm{NFCC}=4$, the 4 goes in column 36 of card 2 and columns 25-35 must be blank. All other parameters must be written as floating point numbers with format E12.5. For example, the number -0.035 would be written as $-3.50000 \mathrm{E}-02$. 
704 INPUT DATA

FORM I

\begin{tabular}{|c|c|c|c|c|c|c|c|c|}
\hline PROBLEM SAMPLE & INPU & FORM & & 0908/RE & DATE & PAGE & OF & \\
\hline & 1 & 2 & 3 & 4 & 5 & 6 & & 8 \\
\hline 123456789 & 012 & 345567899001234 & \begin{tabular}{llll|llllll}
56 & 68 & 0 & 0 & 1 & 2 & 3 & 4 & 5
\end{tabular} & \begin{tabular}{ll|llllll}
78 & 89 & 0 & 1 & 2 & 3 & 4 & 5
\end{tabular} & 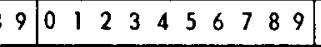 & \begin{tabular}{lllllllll|l|l}
0 & 1 & 2 & 3 & 4 & 5 & 6 & 7 & 8 & 9 & 0
\end{tabular} & 345 & \\
\hline 1 Lriltullel 1 & $\perp \perp 1$ & $11 \perp 1 \perp \perp 1 \perp \perp$ & 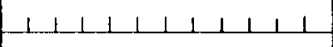 & 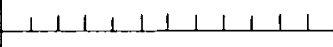 & $|1| \perp|1| 1|1| 1 \mid 1$ & إس & $\mathbf{T}=\mathbf{I} \mid \mathbf{T} \cup \mathbf{E}_{1} \perp$ il & \\
\hline 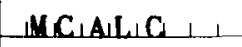 & $1 \ldots$ & $\triangle N\left|F_{1} C_{B}\right| \perp \perp \perp \perp 1$ & $\_\mathbb{N} \mid F_{1} C_{1} C_{1} \perp \perp \perp \perp \perp \perp$ & $\perp 11 \perp \perp \perp \perp \perp \perp \perp \perp$ & $\perp 1,1,1,1,1,1,1$ & $\perp \perp \perp \perp \perp \perp \perp \perp \perp \perp \perp \perp$ & $D_{\perp A} R_{U} A M_{\perp} S_{\perp}, 2$ & \\
\hline$\beta_{1}, 1,1, \ldots$ & 1,1 & i $\perp \perp \perp \perp \perp \perp \perp \perp \perp \perp$ & $I_{0}, \perp \perp \perp \perp \perp \perp \ldots$ & $\mathbf{I}_{\mathbf{d} \perp \perp}$ & 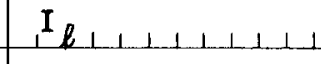 & 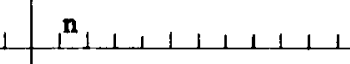 & $F_{1} I_{1} X_{1} E_{1} D_{1} \perp I_{3}$ & \\
\hline $\mathbf{n}_{\mathbf{a} \perp \perp \perp \perp \perp-1}$ & $1 \perp 1$ & $\perp^{\mathbf{n}_{\mathbf{d}}} \perp \perp \perp \perp \perp \perp \perp$ & $\perp \perp \perp \perp \_\perp \perp \perp \perp \perp \perp$ & $\mid \perp \perp \perp \perp \perp \perp \perp \perp \perp \perp$. & $\perp 1 \ldots 11111 \ldots 1 \ldots$ & $1 \perp 1,1 \mid 1,1,11$ & $C_{\perp} H_{\perp} A_{1} B_{1} G_{1} \mathbf{R}_{1} S_{14}$ & \\
\hline $\mid \epsilon_{1} \perp \perp \ldots \perp \ldots$ & 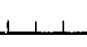 & 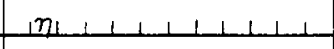 & 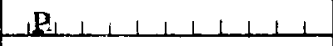 & $1,1,1,1$ & $1 m_{\perp} \perp$ & & $R_{1} E_{1} V_{1} E_{1} N_{1} U_{1} E_{1} 5$ & \\
\hline$O M, 1,1,1$ & 11.1 & $1,1 \perp \ldots \perp \perp \perp 111$ & $1,1,111111.11 .1$ & $\mid-1,1,1,1,1,1,1,1,1$ & 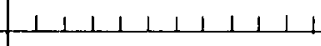 & $1,1,1,1,1,1,1$ & buML $\perp \perp \perp 16$ & \\
\hline$|\omega| \perp \perp \perp \perp L 1$ & $1 \perp 1$ & $1 \perp \perp \perp 1 \perp \perp 1 \perp \perp$ & $1 \perp 1+11 \ldots \perp \perp \perp 1$ & 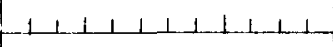 & $|1| 1|1| 1|1| 1 \mid$ & $1,11,1,1,1,11$ & $P_{\perp} R_{\perp} O_{L} E_{\perp} I / T \backslash 17$ & \\
\hline$x_{1}+\ldots \ldots+\ldots$ & 1,1 & $\perp \delta_{\perp} \perp \perp \perp \perp \perp \perp \perp \perp \perp$ & $1 \phi 1,1,1,1, \ldots$ & $\psi_{\perp} \perp \perp \perp \perp 1,1|1|$ & $\perp \perp \perp \perp \perp \perp$ & $\perp \perp|\perp| \perp \mid \perp \perp \perp \perp \perp \perp$ & $A_{1} D_{\perp}, V_{\perp} A_{1} L_{1}, 18$ & \\
\hline 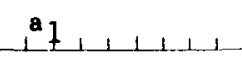 & $\perp$ & PF & 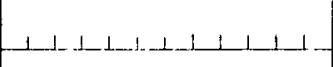 & $\perp 1 \perp \perp \perp \perp$ & $1|1| 1|1| \perp \mid \perp \perp$ & $\perp \perp \perp \perp \perp \perp \perp \perp$ & IN S S D W & \\
\hline$\stackrel{a}{1}+1,1,1$, & Lـــ & 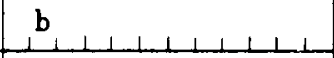 & $\underline{\underline{i}}, \ldots, \perp, 1,1$ & 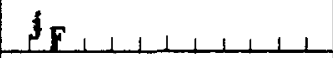 & $\dot{\mathbf{j}}_{\mathbf{S}}, \ldots$ & $n_{\perp}^{\prime}$ & $T_{\perp} A_{\perp} X_{1} \mathbf{E} S_{i}, \perp 0$ & \\
\hline $18+1,1+1,1$ & 1,1 & $\perp \perp \perp \perp|\perp| 1|\perp| \perp \mid 1$ & $\mid \perp<\perp<\perp \perp \perp \perp \perp 1$ & $\perp \perp \perp \perp \perp 1 \perp \perp \perp \perp \perp$ & $111111111: 1$ & $\perp \perp|1| \perp \perp \perp \perp \mid 1$ & 111111111 & \\
\hline$f_{1} c_{t, 1}, \ldots, 1$, & $\perp \perp \perp$ & $1 \perp|1| 1|1|$ & $-\perp \perp \perp \perp \perp 1 \mid 1 \perp \perp \perp-1$ & $\perp \perp \perp \perp \perp \perp \perp \perp \perp \perp \perp \perp \perp$ & 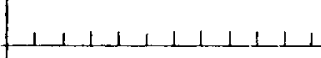 & $1|1| \perp|1| 1|1|$ & $F_{1} C_{1}, 1,112$ & \\
\hline$L_{1 \perp \perp \perp \perp \perp \perp, 1}$ & & $-11+1+1.1$ & $L_{3}$ & $\ell_{-6}$ & $l_{t+1}+1,1$, & $\ell_{* 11}$ & FuUELL & \\
\hline${ }_{1} c_{c}, 1,1,1$ & $\perp \perp \perp$ & 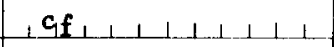 & $\mathbf{c}_{\mathbf{I}} \perp \perp \perp \perp \perp \perp \perp \perp \perp \perp$ & 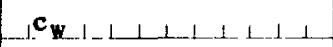 & $\boldsymbol{c}_{\mathbf{g}} \perp 1, \ldots, 1,1$ & $c_{g}^{\prime} \perp \perp \perp \perp \perp \perp \perp \perp$ & 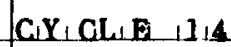 & \\
\hline$t_{c} c_{1} L_{1} L_{1} L_{1}$ & 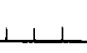 & $t_{f} \perp \perp \perp \perp \perp \perp \perp \perp \perp$ & 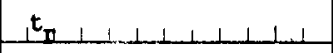 & $t_{d}, 1,1,1,1,1$, & $t_{8}, 1,1,1,1,1$ & $t_{s}^{\prime} \perp \ldots 1,1,1, \ldots$ & 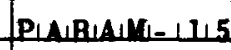 & \\
\hline ej & & 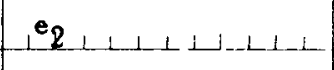 & 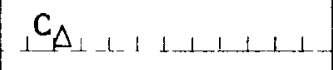 & $\mathrm{C}_{\mathrm{F}}$ & $\perp^{\mathbf{E}} \mathbf{H} \perp \perp \perp \perp \perp \perp \perp \perp$ & 111.1 & 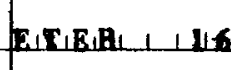 & \\
\hline A $, 1,1,1$, & II & ${ }_{\perp} P_{\perp}, \perp \perp \perp \perp \mid 1,1$ & $E_{t}, \ldots 1, \perp \perp 1 \ldots$ & $u_{1}+1+1$ & $1,1 / 1|1| 1|1| 1,1,1$ & 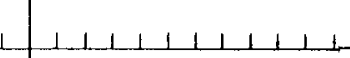 & $S_{1}, T_{\perp}, \perp, \mathbf{l}_{1}$ & \\
\hline $\mathbf{N} \perp \mathbf{P l}_{\mathbf{C}} \perp \perp \perp \perp$ & $\perp \perp \perp$ & $\perp \perp \perp \perp \perp \perp \perp \perp \perp \perp \perp$ & $\mid-1 \perp \perp \perp \perp 1$ & $\perp 1-1 \perp \perp \perp 1-1 \ldots \perp$ & $\perp \perp 1-1|+| 1-1 \_\perp$ & $111,1,1,111$ & $N P_{1} C_{1}-1 M_{1} O_{1} D_{1}$ & \\
\hline$J_{1}\left(1_{1}\right)_{1,1}$ & 111 & 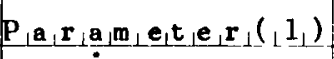 & $\perp 1 \perp 1: \perp 1-1<L$ & $\mid 1 !-\perp \perp \perp \perp \perp \perp \perp \perp \perp$ & 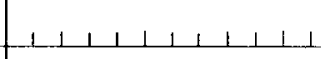 & $1 \ldots \perp \perp|1| \perp|1| \perp|1| \perp$ & $P_{1} C_{1}\left(I_{1}\right)_{1}, \perp$ & \\
\hline$\dot{J}_{1}\left(N_{1} P_{C}\right)_{i}$ & & 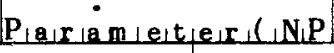 & C) 1,1 & & & $1,111,1111$ & $\operatorname{Pin}_{1}\left(N_{N}\right.$ & \\
\hline blank card & 12 & \begin{tabular}{llllll|lllll}
34 & 5 & 6 & 7 & 89 & 0 & 0 & 1234
\end{tabular} & 567890123456 & 789012345678 & $9\left[\begin{array}{llllllllll}0 & 1 & 2 & 3 & 4 & 5 & 6 & 7 & 8 & 9\end{array}\right.$ & \begin{tabular}{llllllllll|lll|}
0 & 1 & 2 & 3 & 4 & 5 & 6 & 7 & 8 & 9 & 0 & 1 & 2 \\
\end{tabular} & $\begin{array}{l}3445667890 \\
\end{array}$ & \\
\hline & 1 & 2 & 3 & 4 & 5 & 6 & & 8 \\
\hline
\end{tabular}

AMD-8 (8-58) 
APPENDIX B

FAST REACTOR FUEL CYCLE COST ANALYSIS

Consider the reactor divided into up to ten fuel regions of two types - uranium regions and plutonium regions.

The fuel-cycle-cost equation for a uranium region is of the form

$$
\begin{aligned}
& \mathrm{fc}_{\mathrm{U}}=\mathrm{uL} \mathrm{L}_{3} \mathrm{~V}\left(\mathrm{e}_{1}\right)+\frac{1}{\tau}\left\{\left[\mathrm{c}_{\mathrm{c}}\left(1+\ell_{\mathrm{c}}+\ell_{\mathrm{f}}\right)+\mathrm{c}_{\mathrm{f}}\left(1+\ell_{\mathrm{f}}\right)+\mathrm{c}_{\mathrm{r}}+\mathrm{c}_{\mathrm{s}}+\mathrm{c}_{\mathrm{s}^{\prime}}+\mathrm{c}_{\mathrm{w}} \ell_{\mathrm{w}}\right] \mathrm{L}_{1}\right. \\
& +\left[\left(t_{c}+t_{f}+t_{s}\right) V\left(e_{1}\right)+\tau\left(\frac{V\left(e_{1}\right)+V\left(e_{2}\right)}{2}\right)\right. \\
& \left.+\left(t_{d}+t_{r}+t_{s^{\prime}}\right) V\left(e_{2}\right)\right] u L_{1}\left(1+\ell_{c}+l_{f}\right) \\
& \left.+\left[\mathrm{V}\left(\mathrm{e}_{1}\right) \mathrm{L}_{1}\left(1+\ell_{\mathrm{c}}+\ell_{\mathrm{f}}\right)-\mathrm{V}\left(\mathrm{e}_{2}\right) \mathrm{L}_{2}\right]+\mathrm{A} \mathrm{c}_{\mathrm{p}} 10^{3}\right\} \text {, }
\end{aligned}
$$

where all cost and weight variables and the use-charge rate are in terms of uranium.

For plutonium regions we assume that the cost of non-plutonium core materials is negligible and that all isotopes of plutonium are of equal value. Hence all costs and weights are in terms of plutonium only. In equation (1), replace $V\left(e_{1}\right)$ and $V\left(e_{2}\right)$ by $v \cdot 10^{3}$, the value of a kllogram of plutonium, and redefine all cost and weight variables and the use-charge rate in terms of plutonium. This yields

$$
\begin{aligned}
{ }^{f c_{P u}}= & u L_{3} v \cdot 10^{3}+\frac{1}{\tau}\left\{\left[c_{c}\left(1+\ell_{c}+\ell_{f}\right)+c_{f}\left(1+\ell_{f}\right)+c_{r}+c_{s}+c_{s}+c_{w} \ell_{w}\right] L_{1}\right. \\
& +\left[\left(t_{c}+t_{f}+t_{r}+t_{s}+t_{s^{\prime}}+t_{d}+\tau\right) v \cdot 10^{3} u L_{1}\left(1+\ell_{c}+\ell_{f}\right)\right] \\
& \left.+\left[L_{1}\left(1+l_{c}+l_{f}\right)-L_{2}\right] v \cdot 10^{3}+A c_{p} 10^{3}\right\} .
\end{aligned}
$$

The total fuel-cycle cost, $\mathrm{fc}_{\mathrm{t}}$, is the sum of all uranium and plutonium region costs. 
APPENDIX C

GENERAL OPERATING INSTRUCTIONS

704 PROGRAM 0908/RE224

USED NOT USED

READER: $72 \times 72$ board

PUNCH: not used

ORUM: $\square \square$

PRINTER: SHARE board \#2 if SS \#2 is down, not used otherwise

UF SWITCH:

SENSE SWITCH SETTINGS:

$$
\# 1 \text { - up \#2 - up - output on tape \#1 \#3,4,5,6 - not used }
$$

TAPES: Tape \#1 for output if SS \#2 is up

None used if SS \#2 is down

TIME BEFORE OUTPUT: negligible

RUNNING TIME: about 1 minute/problem with off-line output

OFF.LINE PRINTING: Print tape \#l (if used) off-line under program control.

RUNNING PROCEDURE:

1. READY tape \#l or printer.

2. Set sense switches.

3. READY binary program deck followed by data input (a blank card must separate problems) in reader.

4. CLEAR and LOAD CARDS.

STOPS (OCTAL): Final stop: HPR 0,1

FORTRAN ERROR STOPS 
APPENDIX D

FLOWCHART

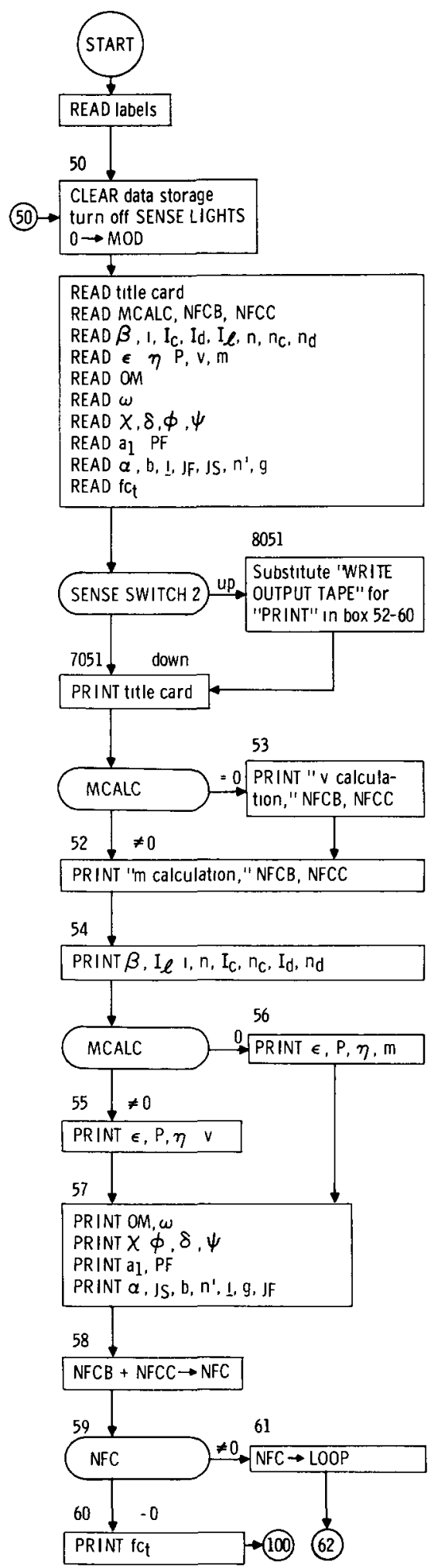

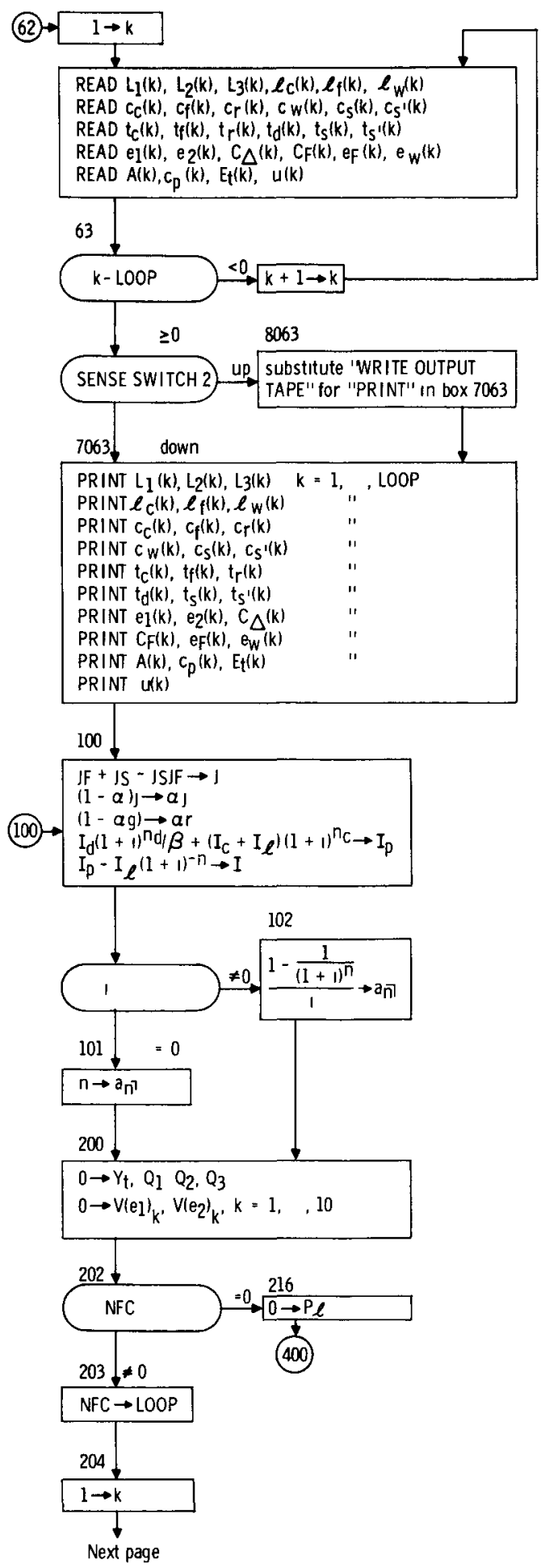




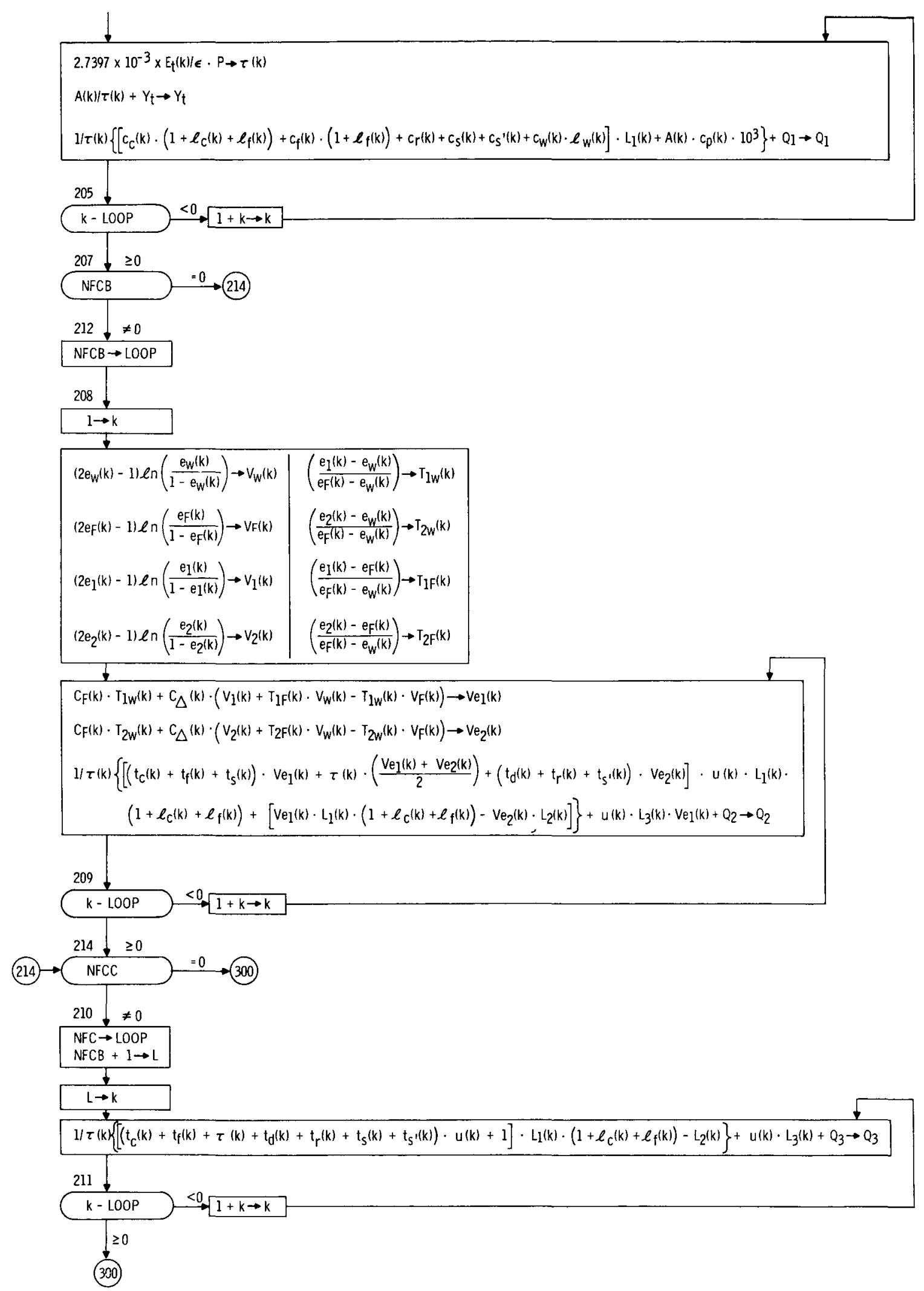




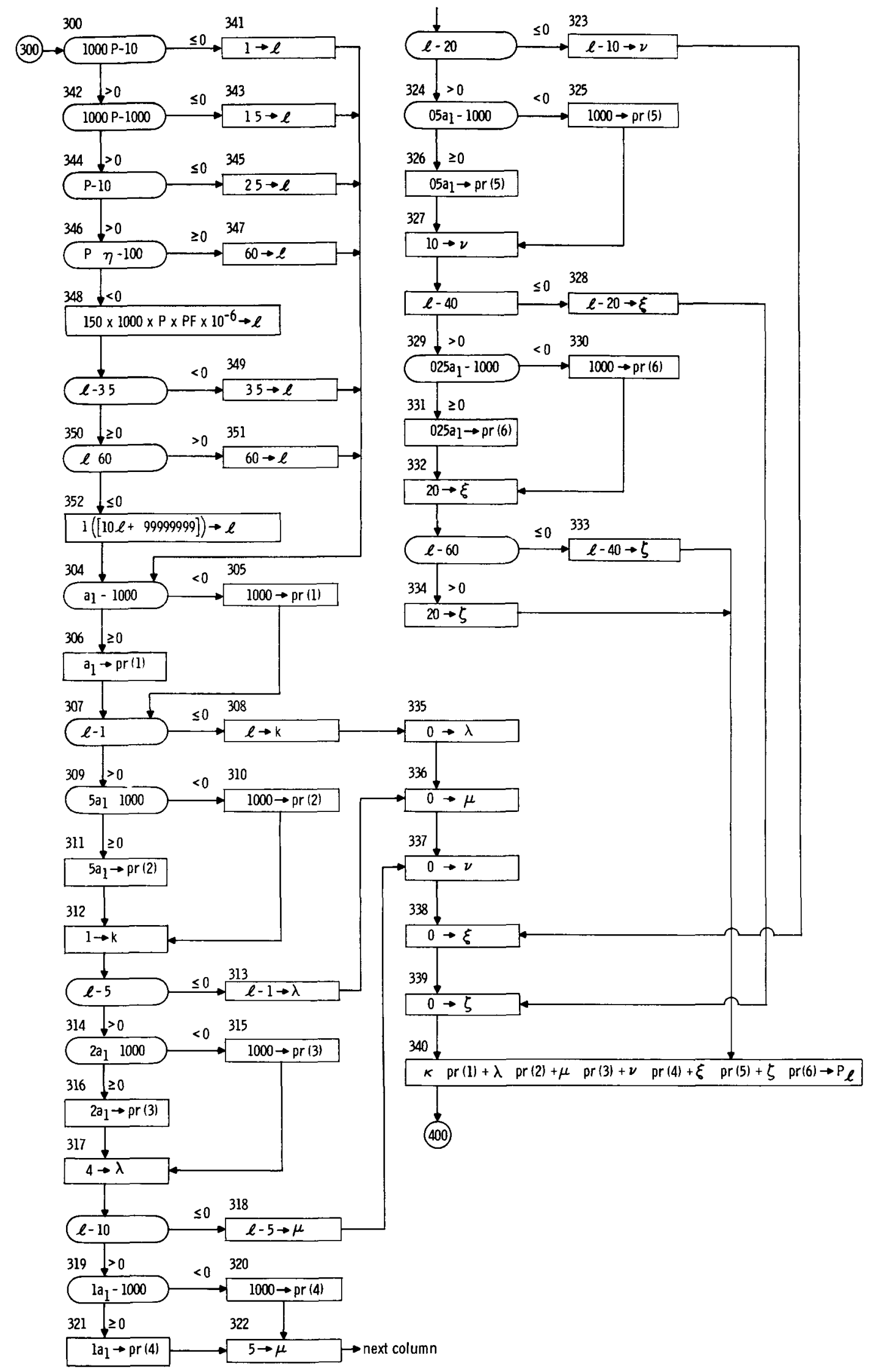



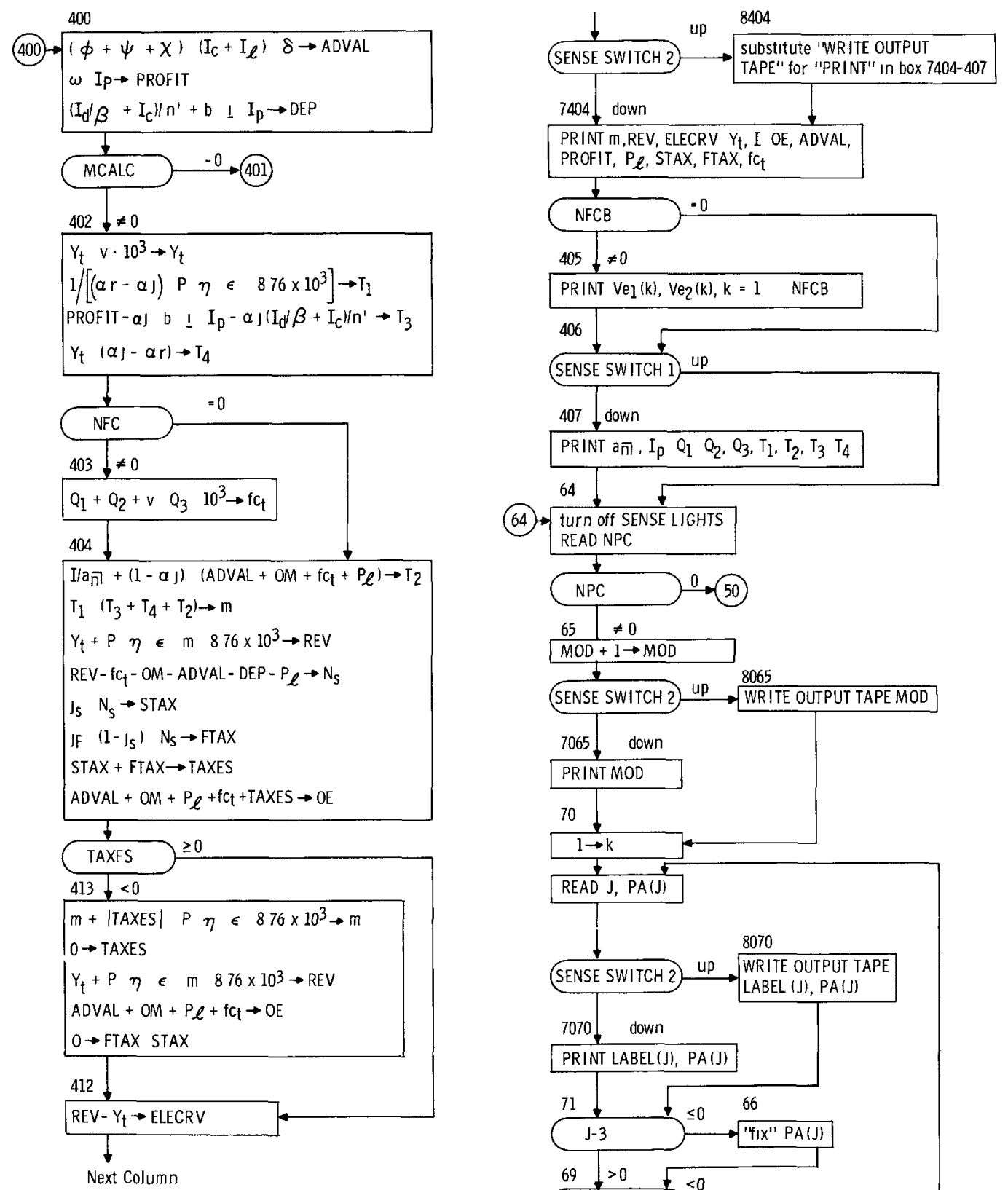

PROFIT, P ${ }_{\ell}$, STAX, FTAX, $\mathrm{fC}_{\mathrm{t}}$

$\frac{1}{\mathrm{NFCB}}=0$

$405 \neq 0$

PRINT Vel $(k), V_{2}(k), k=1 \quad$ NFCB

406

$106 \sqrt{5}$

SENSE SWITCH 1 UP

407 down

PRINT an, $I_{p} Q_{1} Q_{2}, Q_{3}, T_{1}, T_{2}, T_{3} T_{4}$

64

(64) $\rightarrow$ turn off SENSE LIGHTS

READ NPC

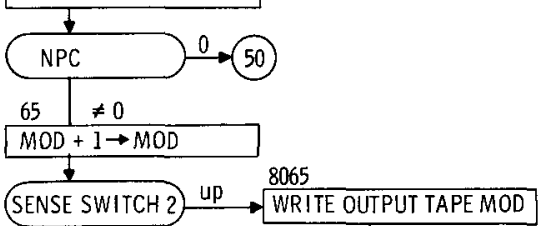

SENSE SWITCH 2) UP $\longrightarrow$ WRITE OUTPUT TAPE MOD

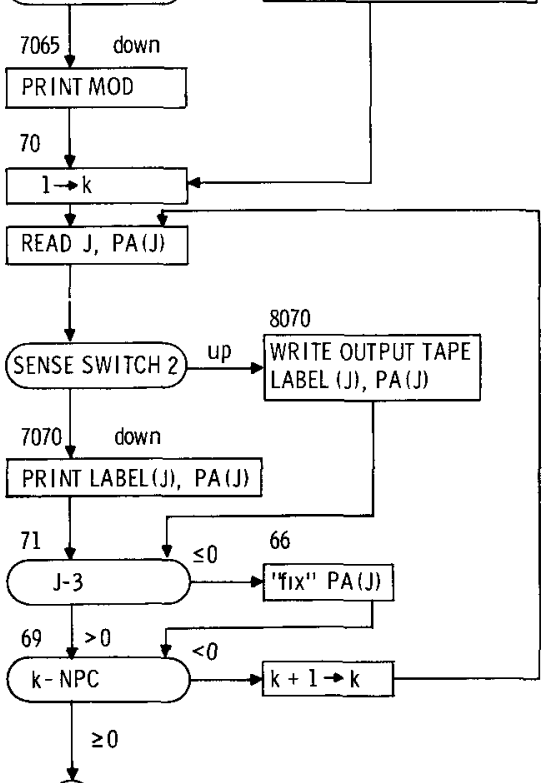

$100)$ 


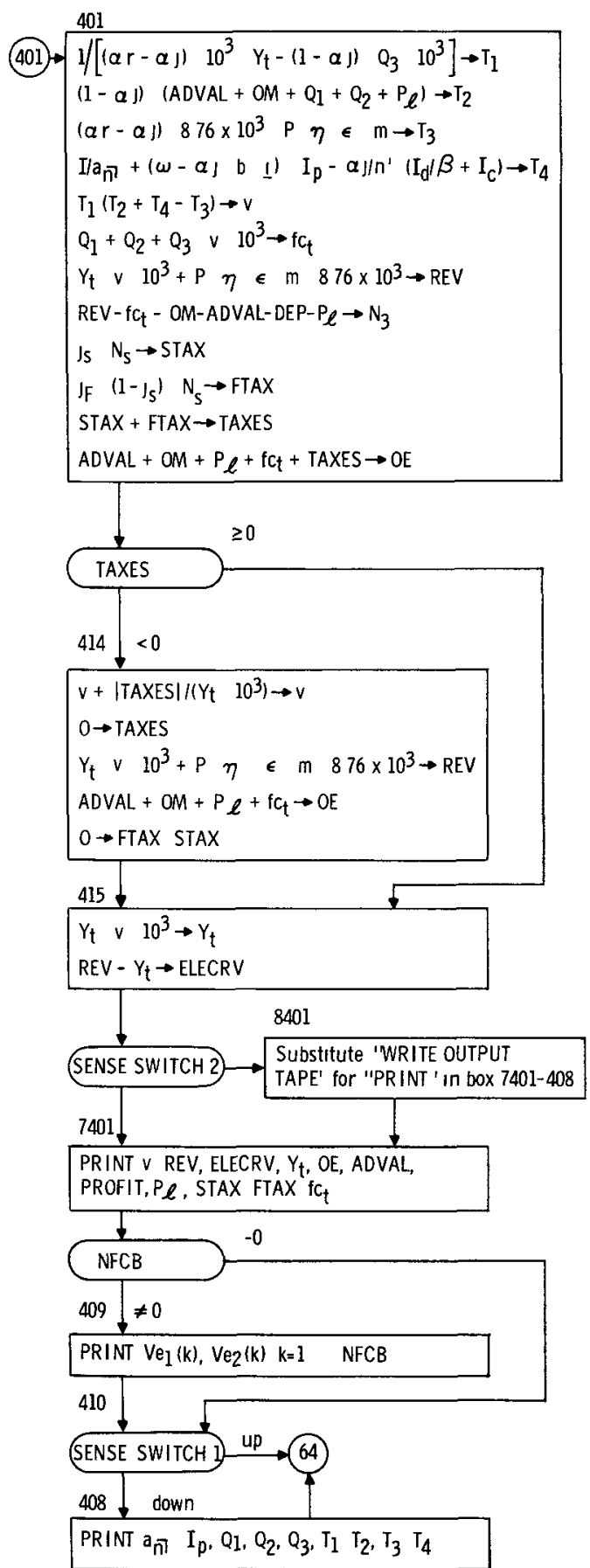


APPENDIX E CODE LISTING 
C 0908/RE224 REACTOR EEONOMICS CALCULATIONS J HEESTAND 7/5/61

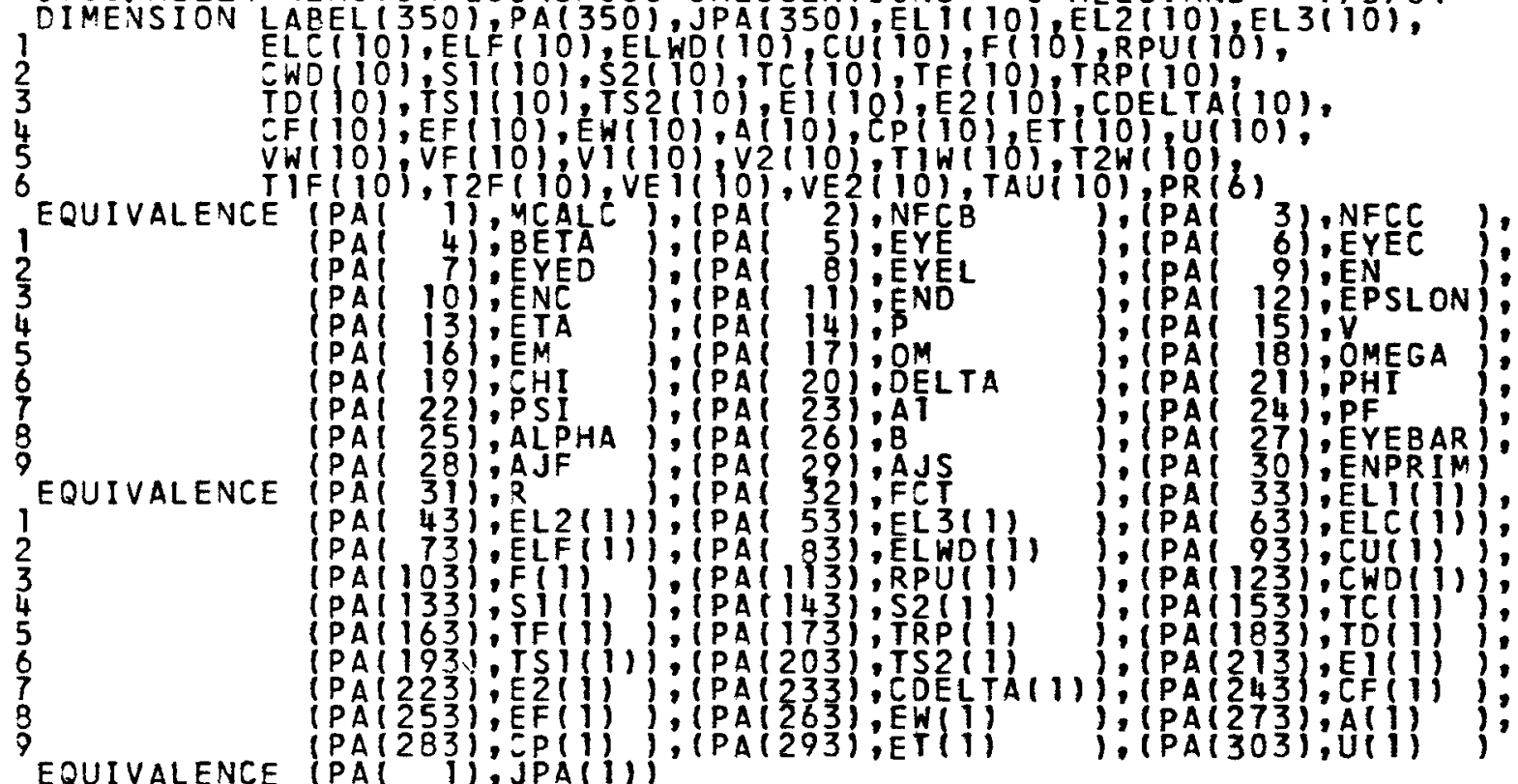
EQUIVALENCE (PAI I);JPA(II)

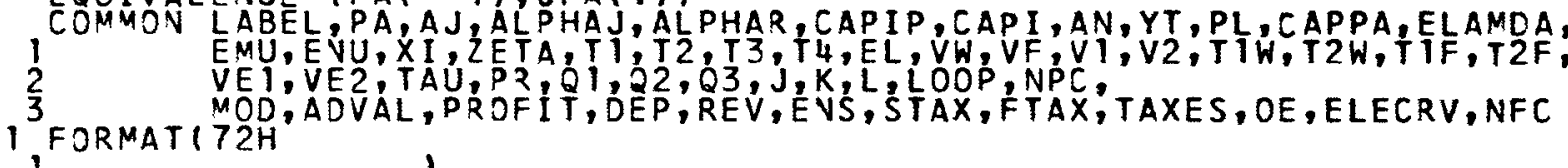

2 FORNAT (6E12.5)

3 FORMATI/7HO INPUT/16HO FIXED CHARGES/8H

1 IILIEI7.6/8H I E17.6,18H

2 I (C)E $17,6,18 \mathrm{H}$

4 FORMAT(IOHO-6) REVENUE/IIH

$17.6 / 8 \mathrm{H}$ ETA E $17.6,18 \mathrm{H}$

EPSILON IPE $14.6,184$,

BETAIPE $17.6,18 \mathrm{H}$
I (DIE $17.6,18 \mathrm{H}, \cdot 6 / 8 \mathrm{H}$

NICIE I7.6/8H

P E 1

5 FORNAT( $34 H O$ OPERATING AND
IPROFIT'SH ONEGAEIG.6)
6 FORMAT(2IHO AD VALOREM

6 FOR 1 PHI E17.6/9H DELTAE 16.6.18H

7 FORMATI $20 \%$ HO INSURANCE CHARGES/8H

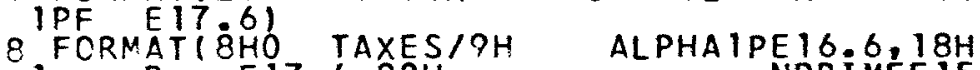

1 B E 17.6,20H NPRIMEE 15.6/8H IBARE IT.6.18\%

$9^{2}$ FORMAT(2OHO FUEL CYCLE COST $=1$ PE 13 . 6$)$

10 FORMAT (19HO FUEL CYCLE COSTS/7X,4HLi1)18X,4HL(2)19X,4HL(3)/(1PE 15

$1,6, E 22,6, E 23.6)$ )

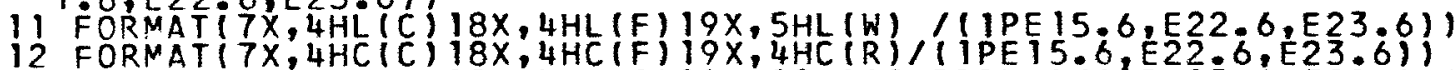

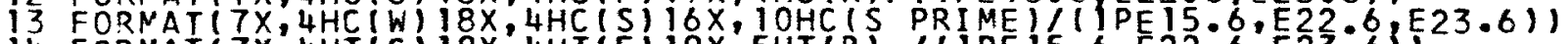

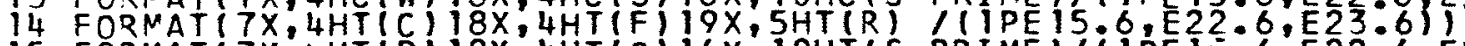

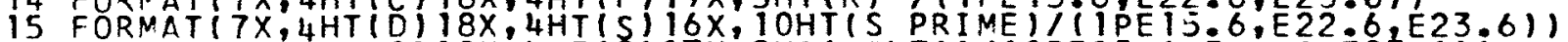

16 FORMAT $(7 X, 4 \mathrm{HE}(1) 18 \mathrm{X}, 4 \mathrm{HE}(2) 17 \mathrm{X}, 8 \mathrm{HC}$ (DELTA) (1PE 15.6, $22.6, \mathrm{E} 23.6)$

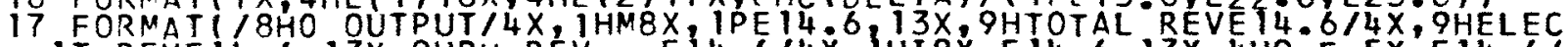

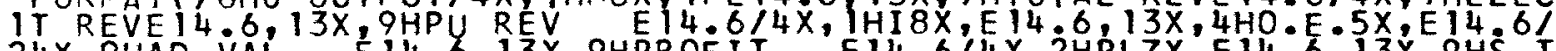

$24 X$, 9HAD VAL EI4.6, 13X,9HPROFIT E14,6/4X,2HPLTX, $14.6,13 X, 9 H S T$ $3 A X$ E 14.6/4X,9HF TAX E14.6,13X,9HTOTAL FC E14.6)

19 FORMATIIIZ, E12:5) 
20 FORMAT (12A6)

21 FORMAT $(4 H$

23 FORMAT (ITH M CALCULATION IUM REG (ONS)

24 FORMATI ITH V CALCULATION IUM REGIONS)

$1 A 6,1 P E 12.51$

25 FORMATI 10 OHO $17.6 / 8 \mathrm{H}$ REVENUE / $11 \mathrm{H}$

I 2, 19H URANIUM REGIONS

I $2,19 H$ URANIUM REGIONS

EPSILON IPE $14.6,18 \mathrm{H}$
$12,18 \mathrm{H}$ PLUTCNI

I $2,18 \mathrm{H}$ PLUTCNI

P El

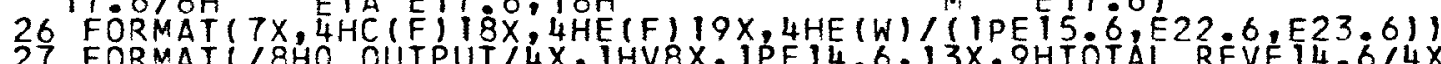

27 FORMAT ( $/ 8$ HO OUTPUT 4 X , IHV8X, IPE 14.6, 13X,9HTOTAL REVE 14.6/4X, 9HELEC

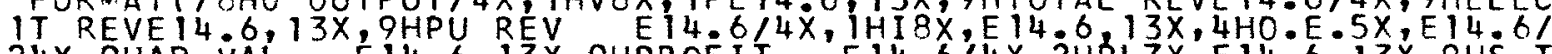

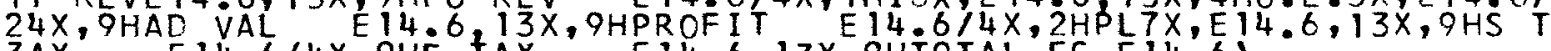
3 AX E $14.6 / 4 X$, 9HF TAX E 14.6,13X,9HTOTAL FC E14.6)

28 FORMAT ( / / 3 BHOMODIFICATIONI 6 )

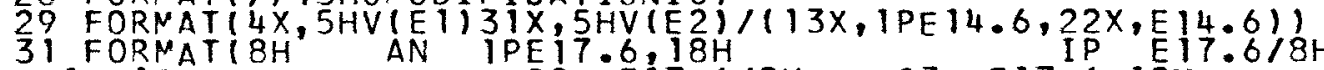

$16,18 \mathrm{H}$ Q2 218

Q3 E17.6, $18 \mathrm{H}$

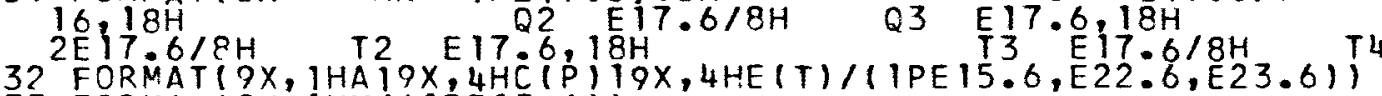

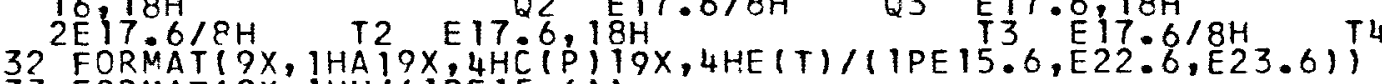

Q1 E 17 .

32 FORMAT ( $2 \times$, IHA I9X, 4 HC (P)

READ 20, (LABEL(K), $K=i, 312)$

50 DO $51 \mathrm{~K}=1,350$

51 PA $(K)=0$.

SENSE LIGHT 0

$M O D=0$

READ $12, M C A L C, N F C B, N F C C$

READ 2. BETA. EYE, EYEC, EYED, EYEL, EN, ENC, END

READ 2, EPSLON, ETA, P, V,EM

READ 2,OM

READ 2,OMEGA

READ 2, CHI, OELTA, PHI,PSI

READ 2,A I, PF

READ 2, ALPHA, B, EYERAR, AJF, AJS, ENPRIM, R

READ $2, F C T$

7051 PRINT I

IF ISNSE SWITCH 2) 7051,8051

52

IF (NCALC) $52,53,52$

$G O$ TO 54

53 PRINT 24 , NFCB, NFCC

54 PRINT 3 , BETA, EYEL, EYE, EN, EYEC, ENC, EYED, END

55 IF (MCALC) $55,56,55$

55 PRINT 4 , EPSLON, P, ETA, $V$

GO TO 57

56 PRINT 25, EPSLON,P, ETA, EN

57 PRINT 5,OM OMEGA

PRINT 6, CHI, PHI,DELTA,PSI

PR INT 7,AI,PF

PRINT 8 , ALPHA, AJS, B, EVPRIM, EYEBAR, R, AJF

$58 \mathrm{NFC}=\mathrm{NFCB}+\mathrm{NFCC}$

59 IF (NFC) $61,60,61$

60 PRINT $9, F C T$

GO TC 100

$61 \angle O O P=N F C$

62 DO $63 \mathrm{~K}=1, \mathrm{LOOP}$

READ 2,EL 1 $(K), E L 2(K), E L 3(K), E L C(K), E L F(K), E L W D(K)$

READ 2, CU(K), F(K), RPU (K), CWD (K), SI(K), S2(K)

READ 2, TC(K), TF(K), TRP(K), TD (K), TSI (K), TS2(K)

READ 2, El(K), E2(K),CDELTA $(K), C F(K), E F(K), E W(K)$

63 READ 2 , A $(K), C P(K), E T(K), U(K)$

7063 PRINTENSE SWITCH 2) $7063,8063, \mathrm{~K}$,

PRINT I1; (ELCIK), ELF(K):ELWD(K), K =1, LOOP)

PRINT 12, $(C U(K), F(K), R P U(K), K=1, L O D P)$ 


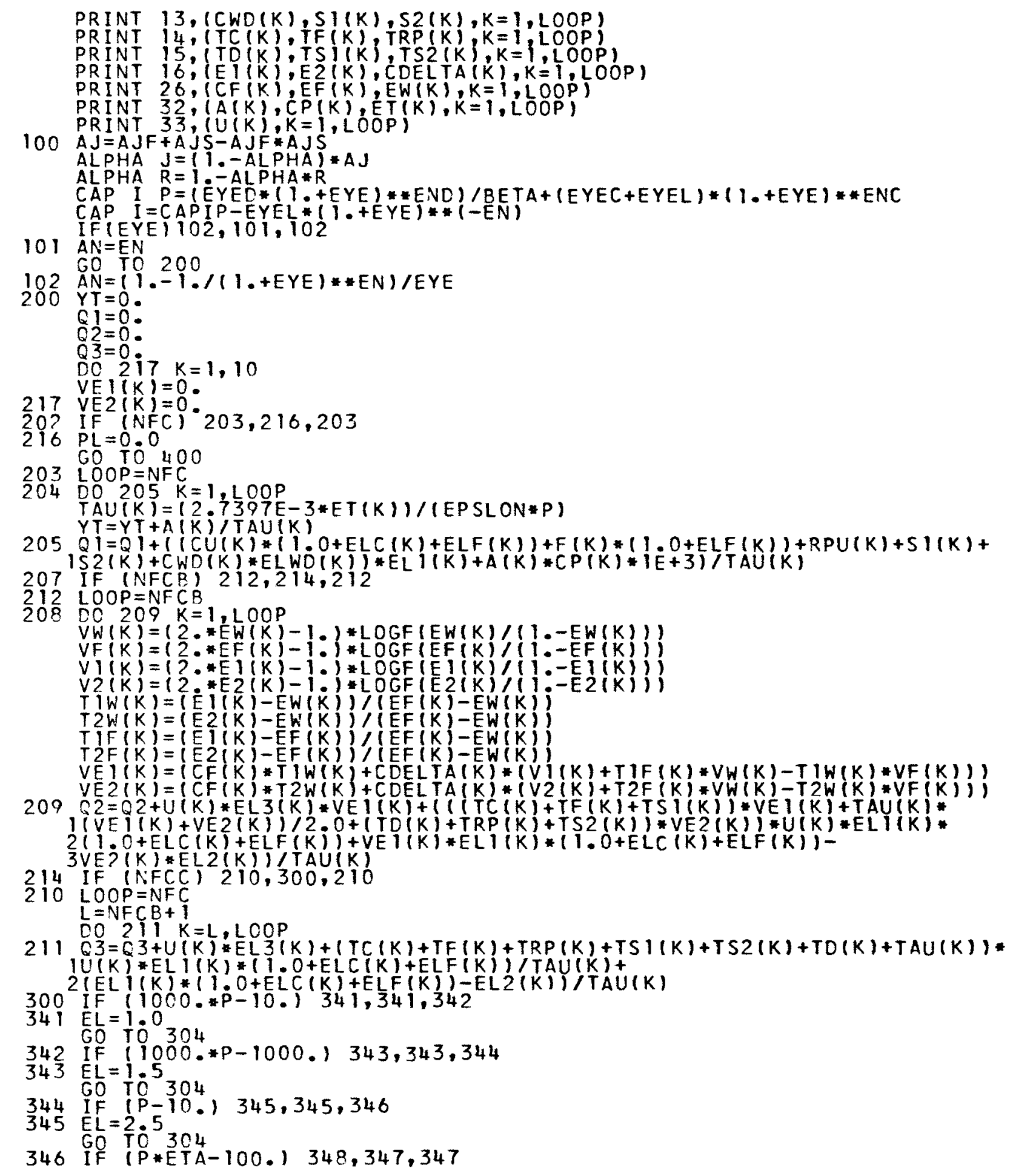




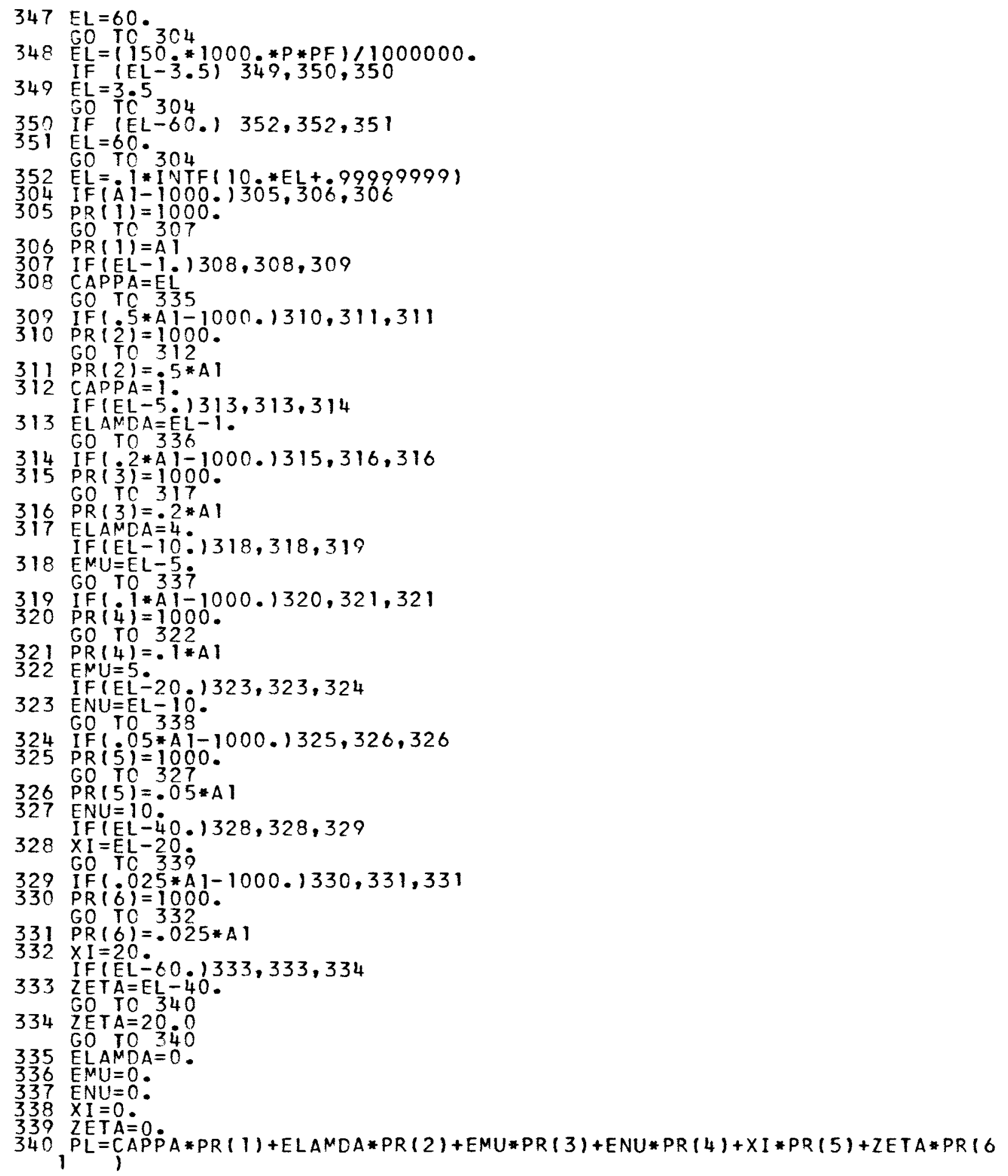


400 ADVAL $=(P H I+C H I+P S I) *(E Y E C+E Y E L) * U E L I A$

PROFI $T=O M E G A * C A P I P$

$D E P=1.0 / E N P R I N *(1.0 / B E T A * E Y E D+E Y E C)+B * E Y E B A R * C A P I P$

401 IF $1=1$ (NCALC) $402,401,402) * 1 E+3 * Y T-(1.0-A L P H A J) * Q 3 * 1 E+3)$

$T 2=(1$-ALPHAJ)* (ADVAL+OM+Q $1+Q 2+P L)$

$T 3=(A L P H A R-A L P H A J) * 8.76 E+3 * P * E T A * E P S L O N * E M$

$T 4=$ CAPI / AN+ (OMEGA-ALPHAJ *B *EYEBAR ) *CAPIP-

IALPHAJ $11.0 / B E T A * E Y E D+E Y E C) / E N P R I M$

$V=T) *(T 2+T 4-T 3)$

$F C T=G 1+Q 2+Q 3 * V * 1 E+3$

REV $=Y T * V * 1 E 3+P * E T A * E P S L O N * E M * 8.76 E+3$

ENS $=R E V-F C T-O M-A D V A L-D E P-P L$

$S T A X=A J S * E N S$

FTAX $=A J F *(1 .-A J S) * E N S$

TAXES $=S T A X+F T A X$

$O E=A D V A L+O M+P L+F C T+T A X E S$

IF (TAXES) $414,415,415$

$414 V=V+A B S F(T A X E S) /(Y Y * 1 E+3$ )

TAXES $=0.0$

$R E V=Y T * \dot{V} * 1 E 3+P+E T A * E P S L O N * E M * 8 \cdot 76 E+3$

$O E=A D V A L+O M+P L+F C T$

FIAX $=0.0$

STAX $=0.0$

$415 Y T=Y T * V * 1 E+3$

ELECRV =REV $-Y T$

IF (SENSE SWITCH 2) 7401.8401

7401 PRINT $27, V, R E V$, ELECRV, YT, CAPI, OE, ADVAL, PROFIT, PL, STAX, FTAX, FCT

IF (NFCB) $409,410,409$

409 PRINT 29 , (VE) (K), $V E 2(K), K=1, N F C P$ )

410 IF (SENSE SWITCH I) 408,64

408 PRINT $31, A N, C A P I P, Q 1, Q 2, Q 3, T 1, T 2, T 3, T 4$

GO TO 64

$402 Y T=Y T * V * 1 E 3$

$411 \mathrm{~T}=1=1$ ( (ALPHAR-ALPHAJ) *P*ETA*EPSLON*8.76E+3)

$T 3=P R O F I T-A L P H A J * B * E Y E B A R * C A P I P-A L P H A J *(1.0 / B E T A * E Y E D+E Y E C) / E N P R I M$

$T 4=Y T *$ (ALPHAJ-ALPHAR)

IF(NFC) $403,404,403$

$403 \mathrm{FCT}=\mathrm{C} 1+02+03 * V * 1 \mathrm{E} 3$

$404 \mathrm{~T} 2=C A P I / A N+(1 .-A L P H A J) *(A D V A L+O M+F C T+P L)$

$E M=T 1 *(T 3+T 4+T 2)$

$R E V=Y T+P * E T A * E P S L O N * E M * 8.76 E+3$

$E N S=R E V-F C T-O M-A D V A L-D E P-P L$

$S T A X=A J S * E N S$

FTAX $=A J F *(1 .-A J S) * E N S$

TAXES $=S T A X+F T A X$

$C E=A O V A L+O M+P L+F C T+T A X E S$

IF(TAXES) $413,412,412$

$413 E M=E M+A B S F(T A X E S) /(P * E T A * E P S L O N * 8 \cdot 76 E+3)$

TAXES $=0.0$

$R E V=Y T+\dot{P} * E T A * E P S L O N * E M * 8.76 E+3$

$C E=A D V A L+O M+P L+F C T$

FTAX $=0.0$

412 ELECRV = REV $-Y T$

STAX $=0.0$

IF ISENSE SWITCH 2) 7404,8404

7404 PRINT I7, EM, REV, ELECRV, YT, CAPI, OE, ADVAL, PROFIT, PL, STAX, FTAX, FCT

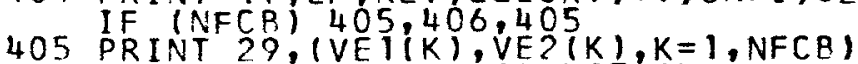

406 IF (SENSE SWITCH I) 407,64

407 PRINT 31 , AN, CAPIP,Q1,Q2,Q3,T1,T2,T3,T4

64 SENSE LIGHT O

REACIO,NPC

IF (NPC) $65,50,65$

65 MOD $=$ MOC +1

IF (SENSE SWITCH 2) 7065,8065 


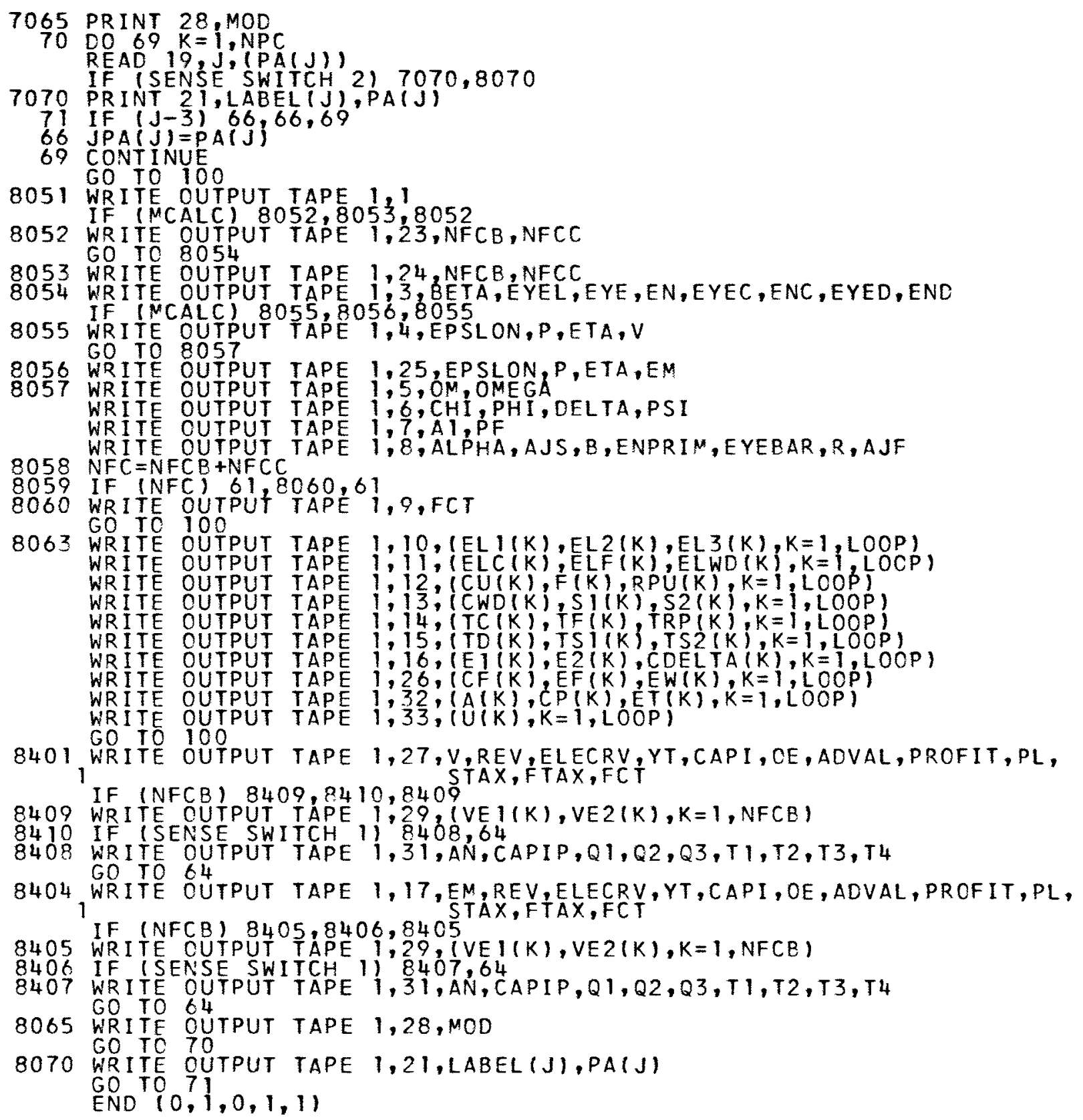


STCRAGE FOR VARIAPLES APPEARING IV COMMON SENTENCFS

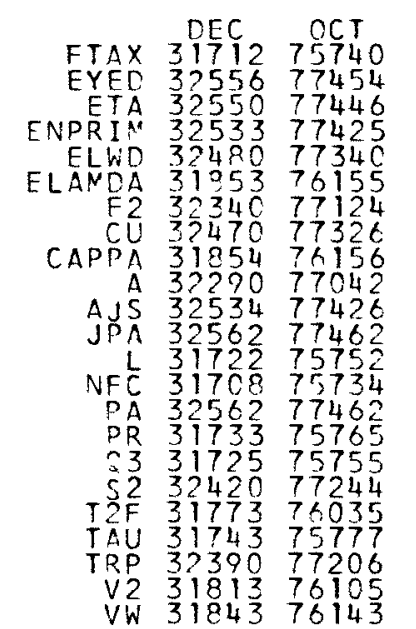

\begin{tabular}{|c|c|c|c|c|c|c|c|c|c|c|}
\hline $\begin{array}{r}\text { EFN } \\
1 \\
11 \\
11 \\
22 \\
27 \\
33 \\
52 \\
54 \\
57 \\
80 \\
7063 \\
200 \\
204 \\
209 \\
341 \\
346 \\
351 \\
307 \\
312 \\
317 \\
322 \\
327 \\
332 \\
337 \\
401 \\
409 \\
402 \\
412 \\
406 \\
7065 \\
71 \\
8052 \\
8054\end{array}$ & 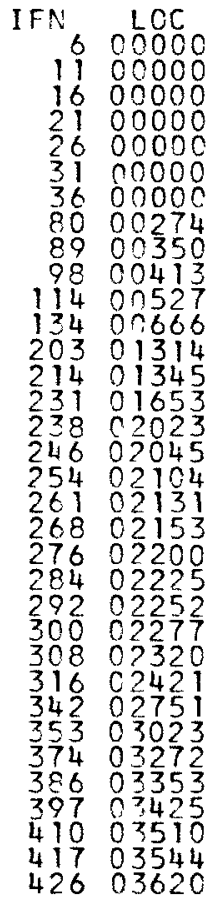 & $\begin{array}{r}E F N \\
2 \\
7 \\
12 \\
17 \\
23 \\
28 \\
50 \\
52 \\
55 \\
57 \\
81 \\
7063 \\
217 \\
205 \\
214 \\
342 \\
347 \\
352 \\
308 \\
313 \\
318 \\
323 \\
329 \\
333 \\
338 \\
414 \\
409 \\
411 \\
7404 \\
407 \\
7065 \\
66 \\
8052 \\
8055\end{array}$ & 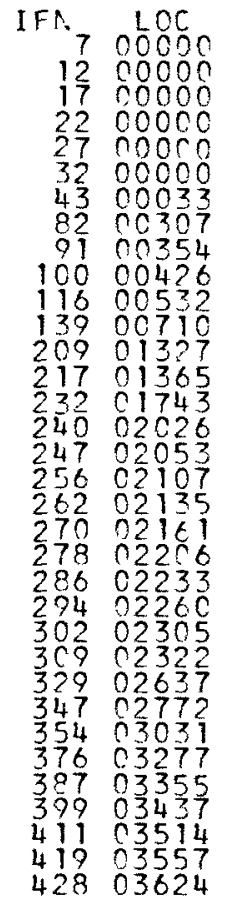 & $\begin{array}{r}\text { EFN } \\
3 \\
8 \\
13 \\
19 \\
24 \\
29 \\
51 \\
53 \\
55 \\
58 \\
62 \\
100 \\
202 \\
207 \\
210 \\
343 \\
348 \\
304 \\
309 \\
314 \\
319 \\
324 \\
329 \\
334 \\
339 \\
415 \\
410 \\
403 \\
7404 \\
407 \\
70 \\
609 \\
8053 \\
8055\end{array}$ & $\begin{array}{rc}\text { IFN } & L C C \\
8 & 00000 \\
13 & 00000 \\
18 & 00000 \\
23 & 00000 \\
28 & 00000 \\
33 & 00000 \\
44 & 00034 \\
84 & 003112 \\
93 & 00371 \\
110 & 00506 \\
117 & 00534 \\
194 & 01175 \\
210 & 01333 \\
210 & 01432 \\
233 & 1744 \\
241 & 02033 \\
249 & 02056 \\
257 & 02120 \\
264 & 02140 \\
272 & 02165 \\
280 & 02211 \\
208 & 02237 \\
296 & 02264 \\
304 & 02311 \\
310 & 02324 \\
335 & 02705 \\
344 & 02774 \\
358 & 03106 \\
378 & 03324 \\
389 & 0337 \\
400 & 03441 \\
412 & 03525 \\
421 & 03562 \\
430 & 03641\end{array}$ & $\begin{array}{r}E F N \\
4 \\
9 \\
14 \\
20 \\
25 \\
31 \\
7051 \\
53 \\
56 \\
59 \\
63 \\
101 \\
216 \\
212 \\
211 \\
344 \\
349 \\
305 \\
310 \\
315 \\
320 \\
325 \\
330 \\
335 \\
340 \\
7401 \\
408 \\
404 \\
405 \\
64 \\
7070 \\
8051 \\
8053 \\
8056\end{array}$ & $\begin{array}{rc}\text { IFN } & L O C \\
9 & 00000 \\
14 & 00000 \\
19 & 00000 \\
24 & 00000 \\
29 & 00000 \\
34 & 00000 \\
77 & 00261 \\
86 & 00335 \\
95 & 00374 \\
111 & 00511 \\
130 & 00643 \\
200 & 01273 \\
211 & 01337 \\
219 & 01434 \\
236 & 01755 \\
243 & 02036 \\
251 & 02074 \\
258 & 02124 \\
265 & 02145 \\
273 & 02172 \\
281 & 02217 \\
289 & 02244 \\
297 & 02271 \\
306 & 02314 \\
311 & 02336 \\
338 & 02720 \\
349 & 02776 \\
359 & 03116 \\
300 & 03330 \\
390 & 03401 \\
407 & 03473 \\
414 & 03531 \\
423 & 03575 \\
432 & 03644\end{array}$ & $\begin{array}{r}\text { EFN } \\
5 \\
10 \\
15 \\
21 \\
26 \\
32 \\
7051 \\
54 \\
56 \\
60 \\
63 \\
103 \\
203 \\
200 \\
300 \\
345 \\
350 \\
306 \\
311 \\
316 \\
321 \\
326 \\
331 \\
336 \\
400 \\
7401 \\
408 \\
413 \\
405 \\
605 \\
7070 \\
8051 \\
8054 \\
8056\end{array}$ & $\begin{array}{r}\text { IFN } \\
10 \\
15 \\
20 \\
25 \\
30 \\
35 \\
78 \\
87 \\
97 \\
112 \\
132 \\
202 \\
213 \\
220 \\
237 \\
244 \\
253 \\
260 \\
267 \\
275 \\
283 \\
291 \\
299 \\
307 \\
312 \\
340 \\
351 \\
368 \\
385 \\
395 \\
409 \\
415 \\
424 \\
434\end{array}$ & $\begin{array}{l}100 \\
00000 \\
00000 \\
00000 \\
00000 \\
00000 \\
00000 \\
00270 \\
00337 \\
00411 \\
00515 \\
00660 \\
01276 \\
01343 \\
01436 \\
02016 \\
02042 \\
02077 \\
02127 \\
02150 \\
02175 \\
02222 \\
02247 \\
02274 \\
02316 \\
02357 \\
02745 \\
03020 \\
03222 \\
03351 \\
03420 \\
03506 \\
03540 \\
03577 \\
03661\end{array}$ \\
\hline
\end{tabular}
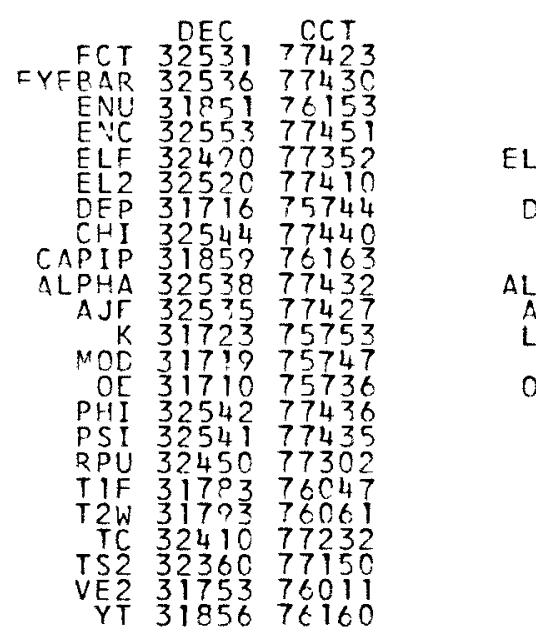

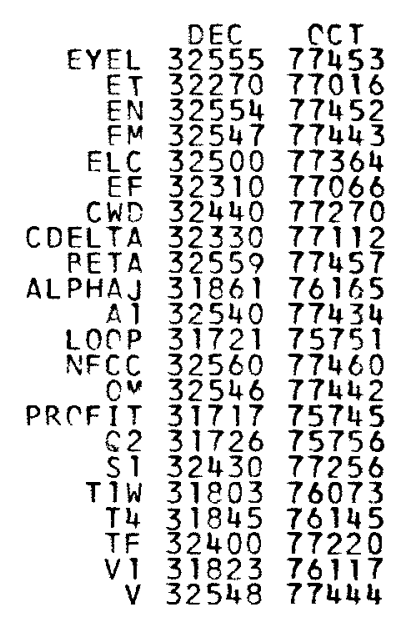

EXTERNAL FORMLLA NLWBERS WITH CORRESPONOING INTERNAL FORMULA NUMBERS ANR OCTAL LOCATIONS
EYE 32558 P 7 TCT EL 3253077422 A 3254377437 E $325 ? 7 \quad 7743$ 3186076164 $\triangle A R E$ 32212 76724 NFCP. 325617746 PL $31855 \quad 76157$ $R \quad 3253277424$ 13184876150 33184676146 3230077174 3226077004 VF 318337613
FNS 3170077054 ELECRU 3185276154

\section{,} EL3 3251077376 NPC $37762774 E 2$ RAX 3171375743 T2 3184776147 S1 3237077162 VEI 3176376023

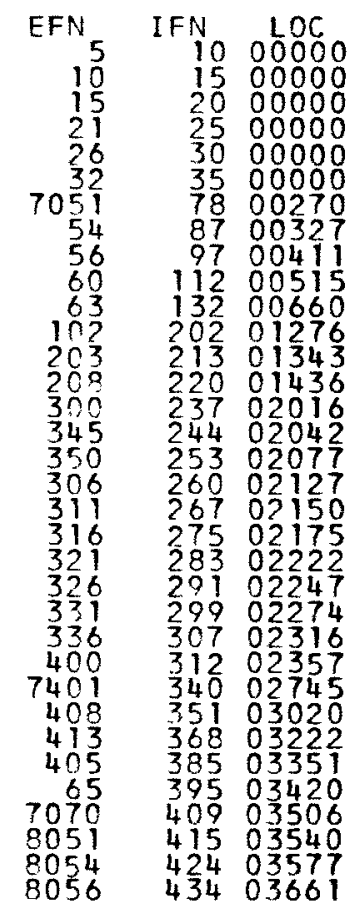




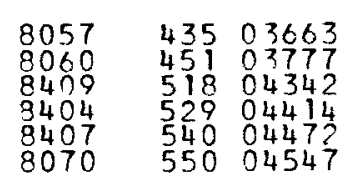

$\begin{array}{ll}\text { DEC } & \text { OCT } \\ 2868 & 05464\end{array}$

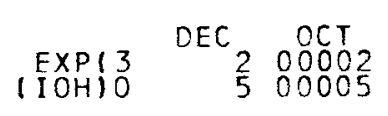

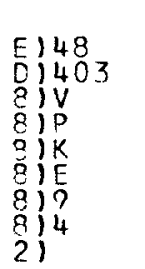

$\operatorname{CDBC}$

DEC OCT

1879
26
200032

248504065

259505043

667055

271405232

$\begin{array}{ll}2805 & 05365 \\ 2410 & 04552\end{array}$

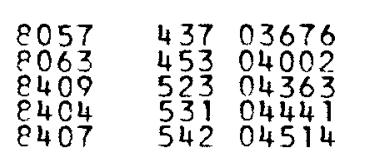

9058
8063
8410
8405
8065
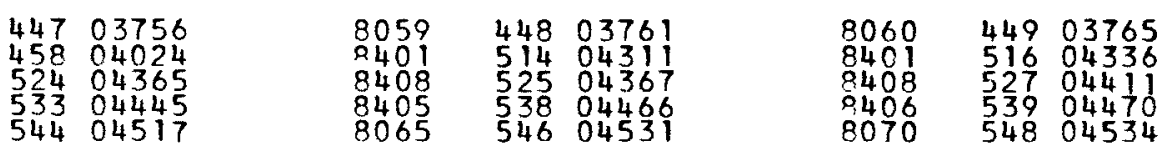

STORAGE NOT USED BY PROGRAN

3170775733

LOCATIONS OF NAMES IN TRANSFER VECTOR

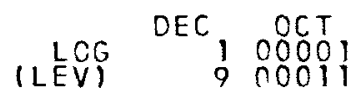

$\begin{array}{lll}\text { ICSH) } & \text { DEC } \\ \text { [RTNI } & 00007 \\ 6 & 00006\end{array}$

(FFH)

$\mathrm{CEC}_{3} \mathrm{OCT}$

$\begin{array}{ll}3 & 00003 \\ 4 & 00004\end{array}$

STCRAGE LOCATIONS FOR SYMBOLS NOT APPEARING IN SOURCE PROGRAM

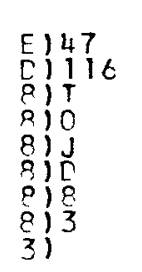

$\begin{array}{ll}\text { DEC } & \text { OCT } \\ 1876 & 03524\end{array}$

263601174

267705165
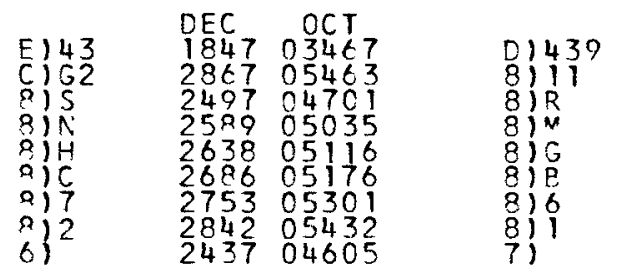

DEC 1262 OCT

277305325
257705021

274105265

2840
2413
245430

244404614

259005036

264805130

28550544

285605450

(RURROUTINES PUNCHED FRON LIPRARY

(SPH)

(CSH)

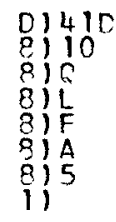

(EXP $(3)$
rLEV

\begin{abstract}
istir
\end{abstract}
$\begin{array}{rrr} & \text { DEC } & 0 C T \\ (I C H) & 800010 \\ \text { (STH) } & 0 & 00000\end{array}$

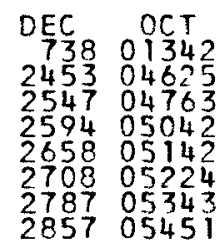

(BOC) 


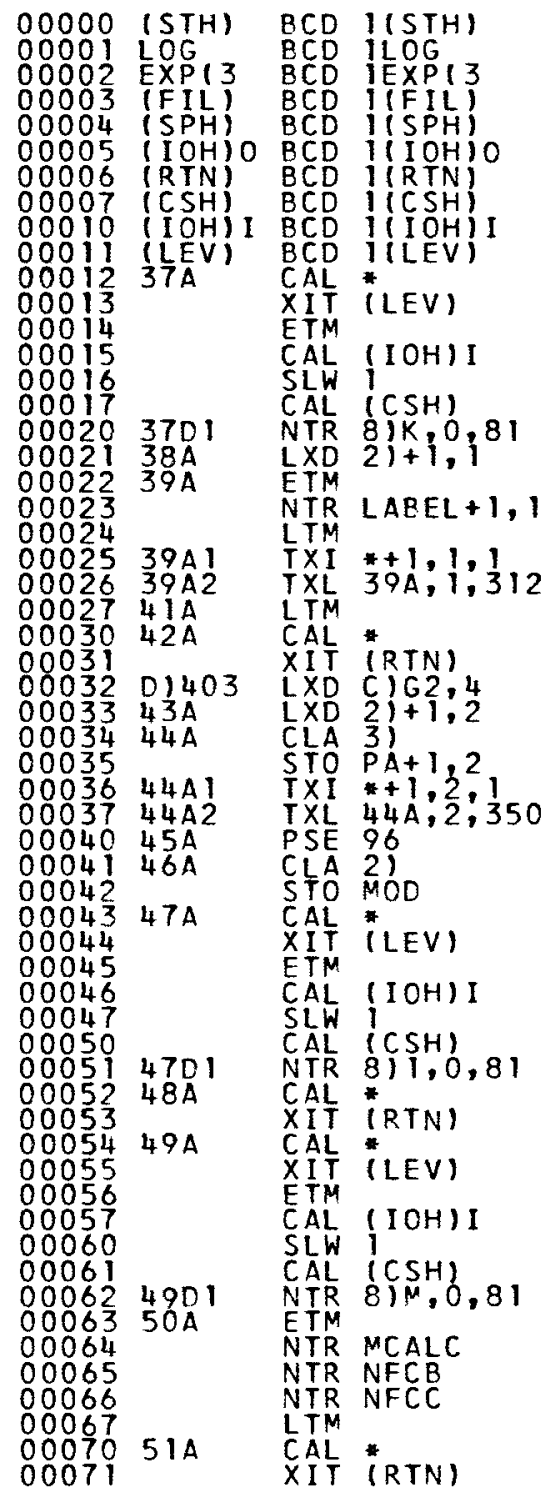

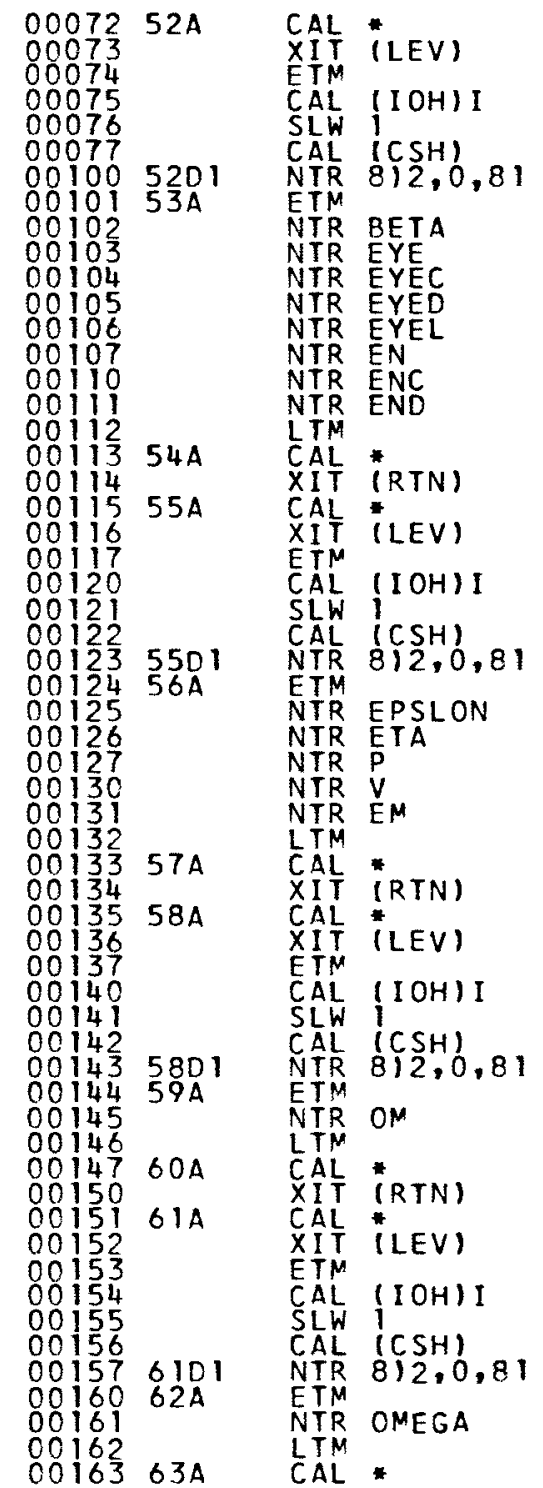

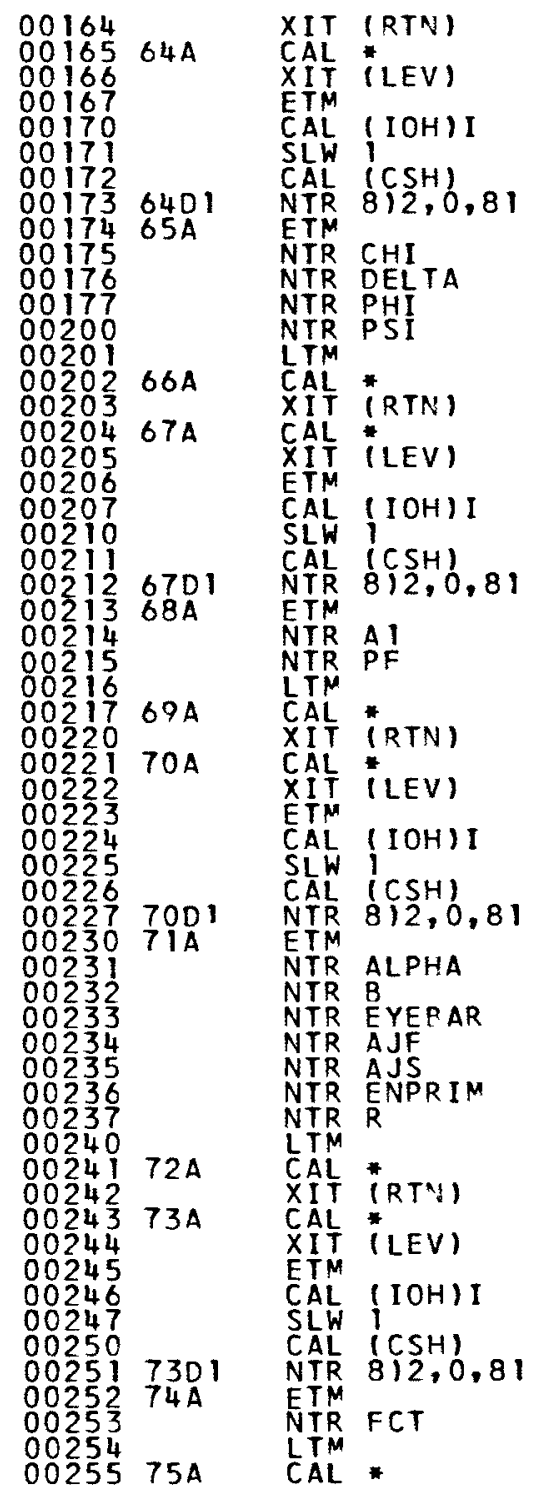




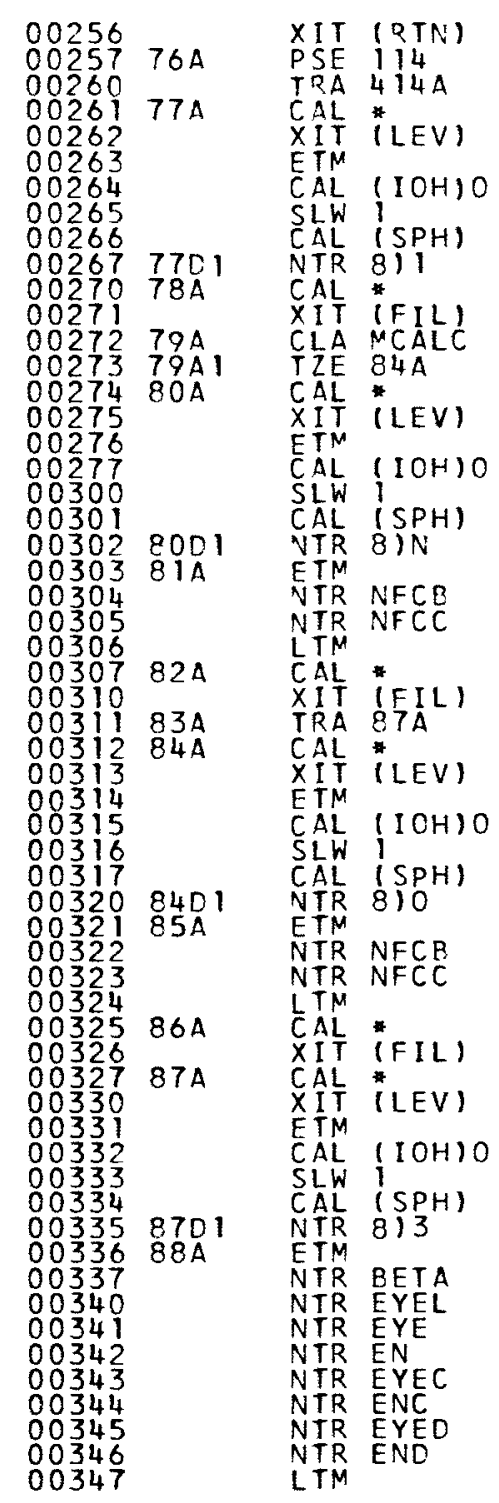

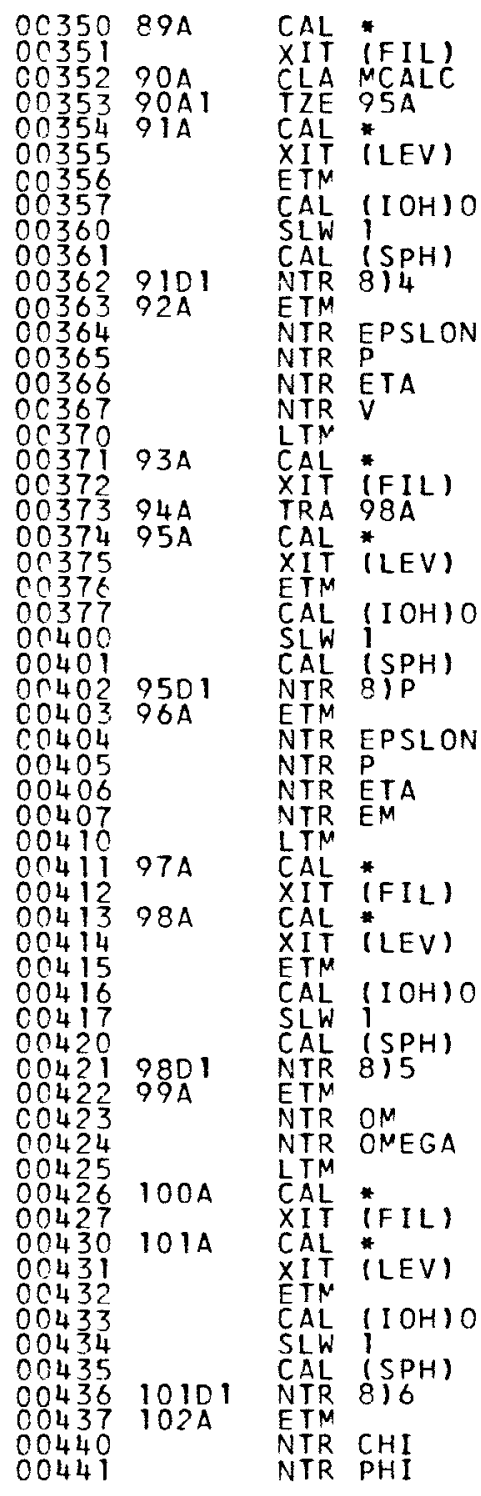

\begin{tabular}{|c|c|c|}
\hline 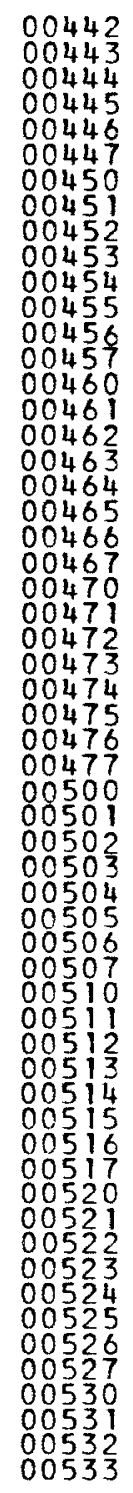 & 3A & \\
\hline
\end{tabular}




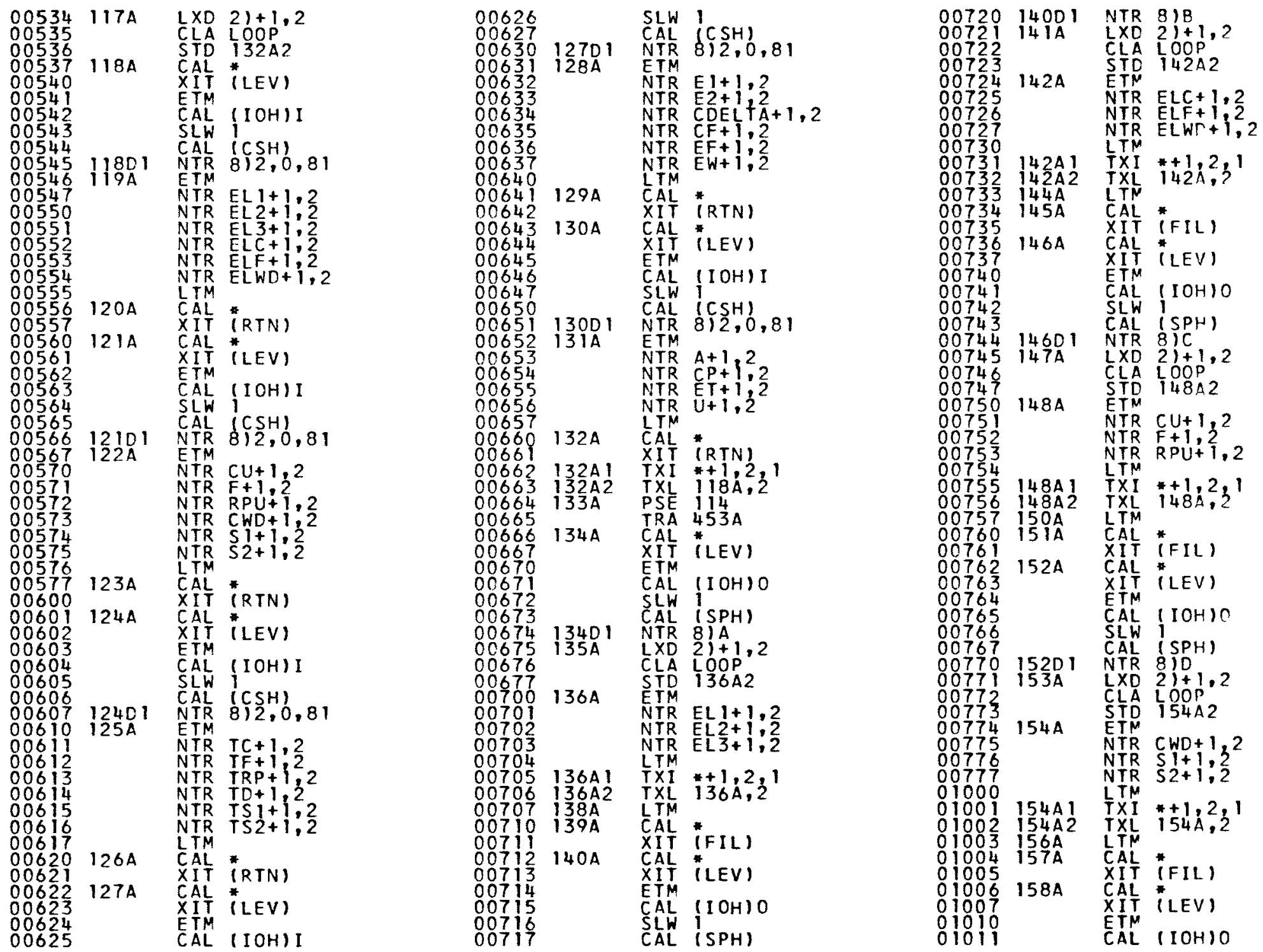




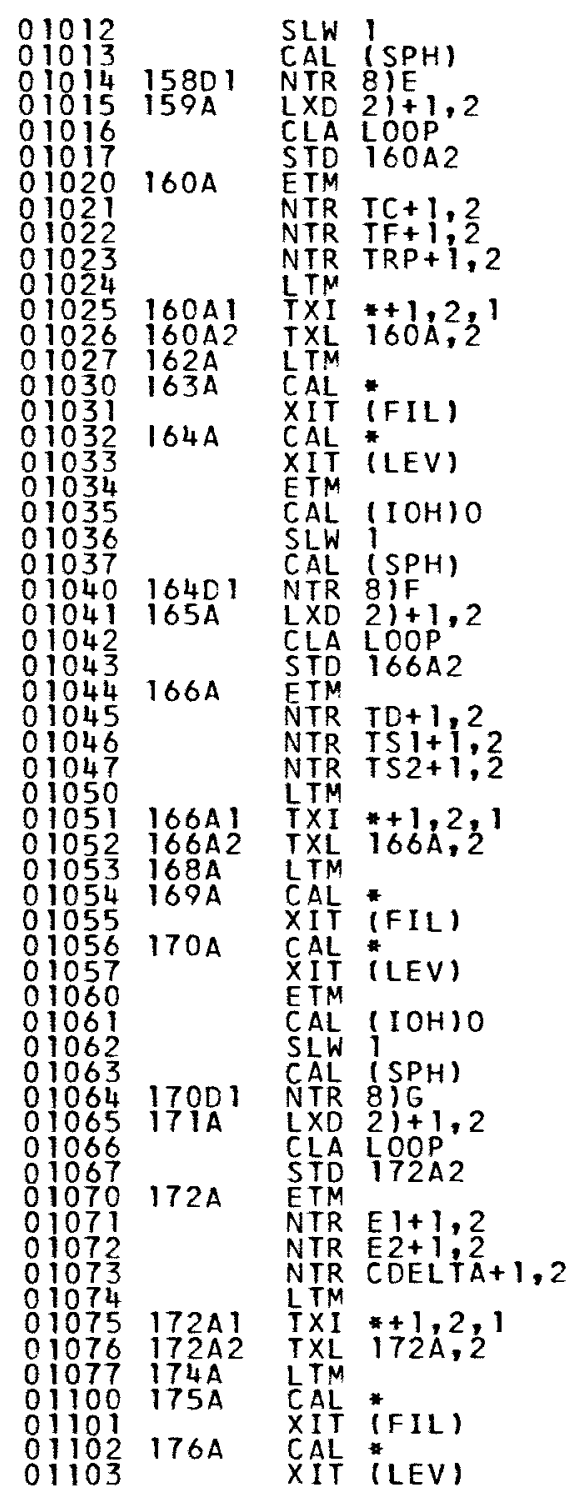

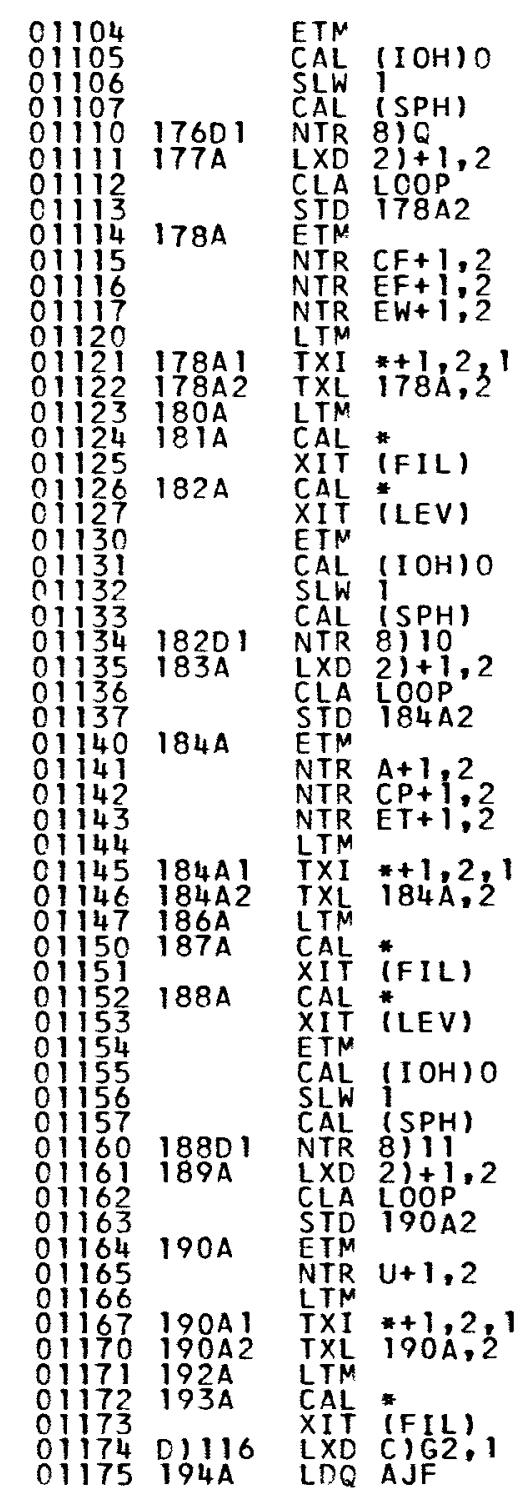

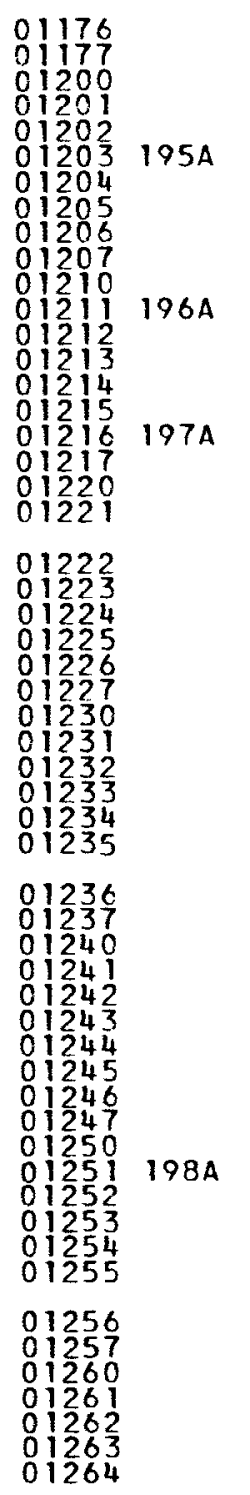

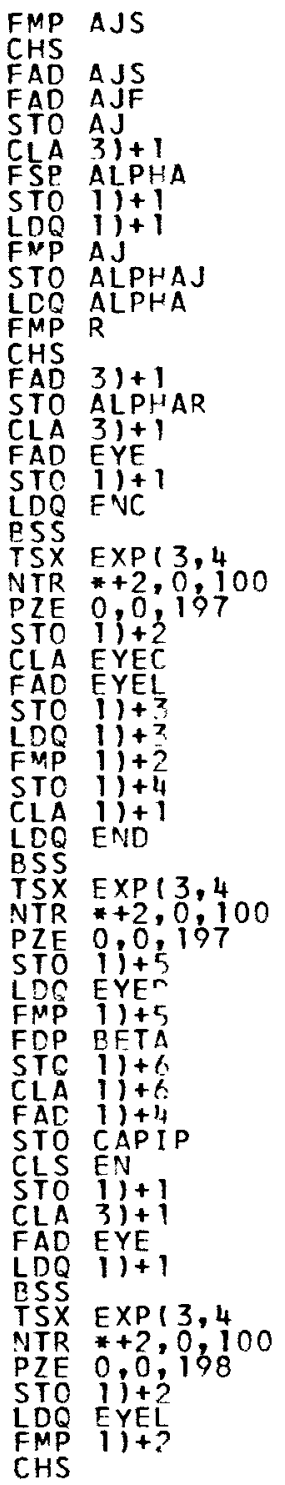




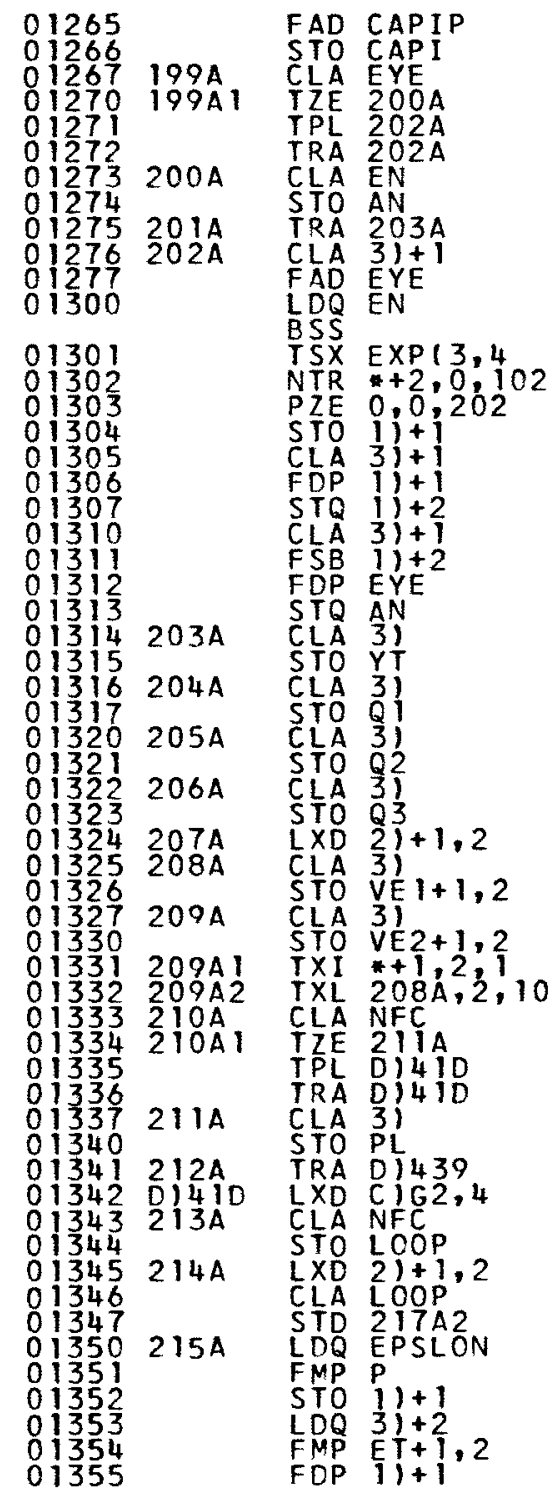

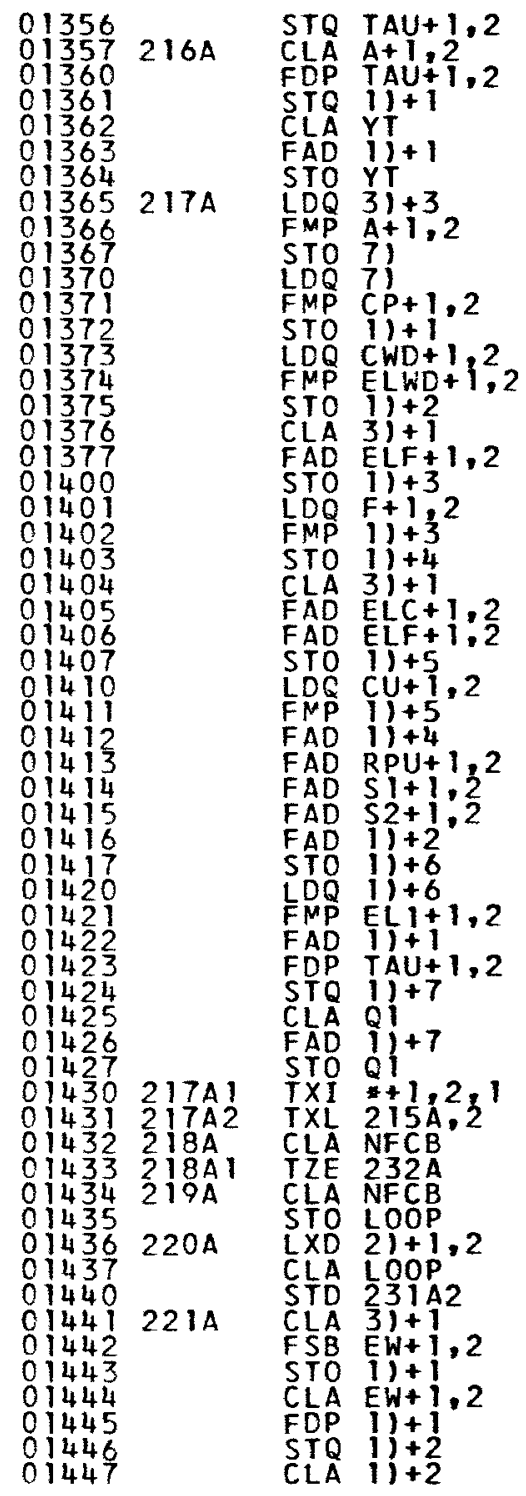

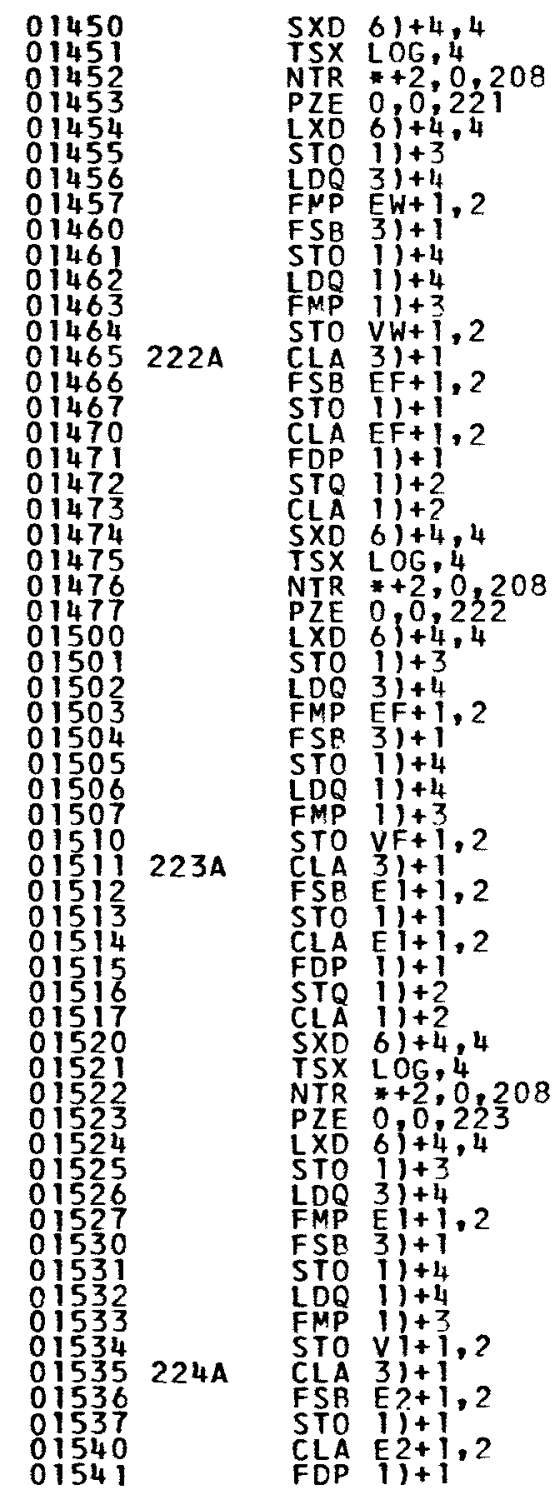




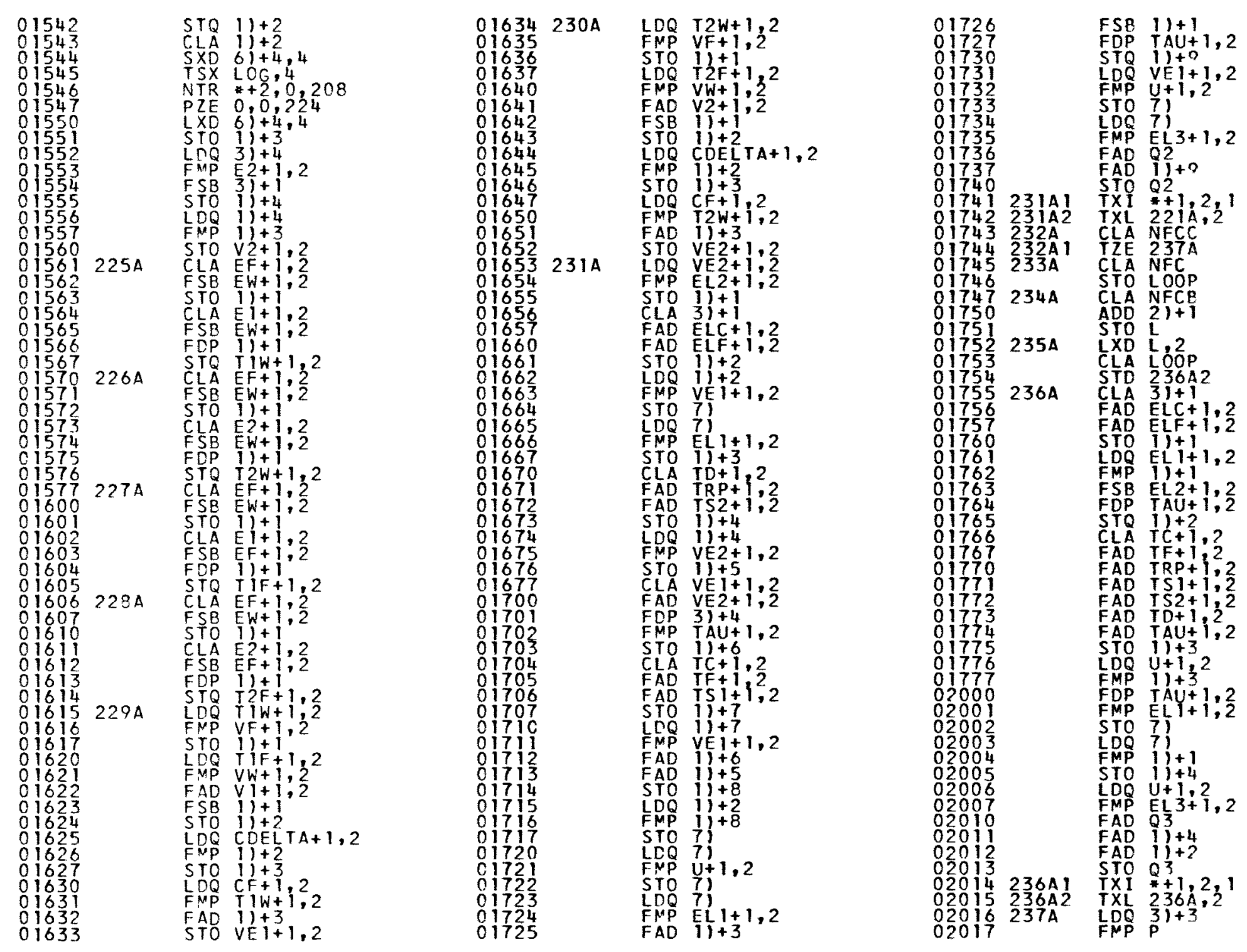




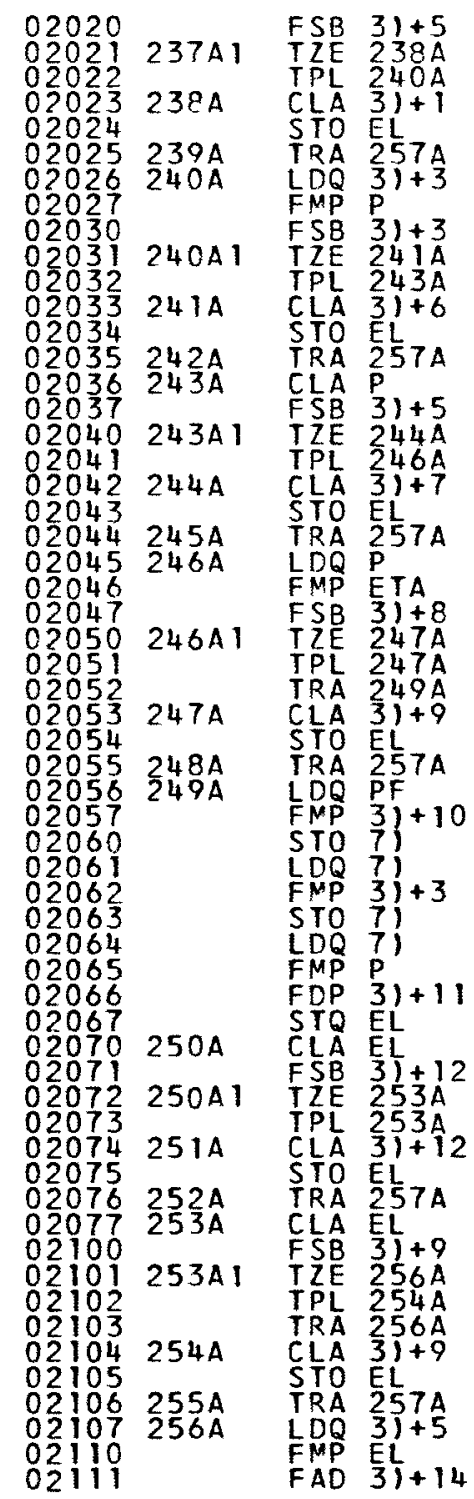

\begin{tabular}{|c|c|c|}
\hline & 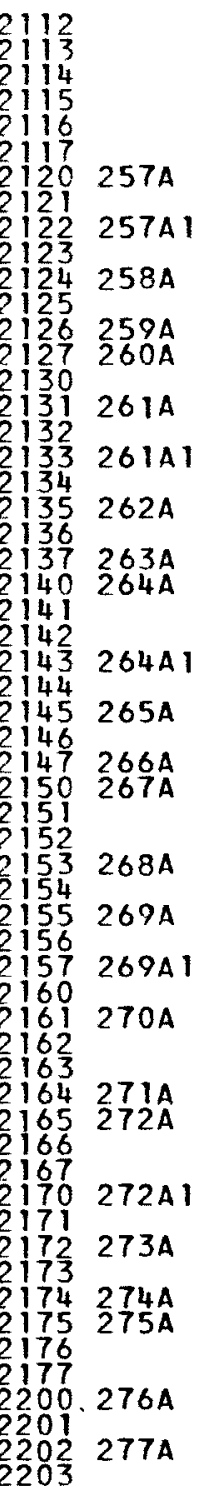 & 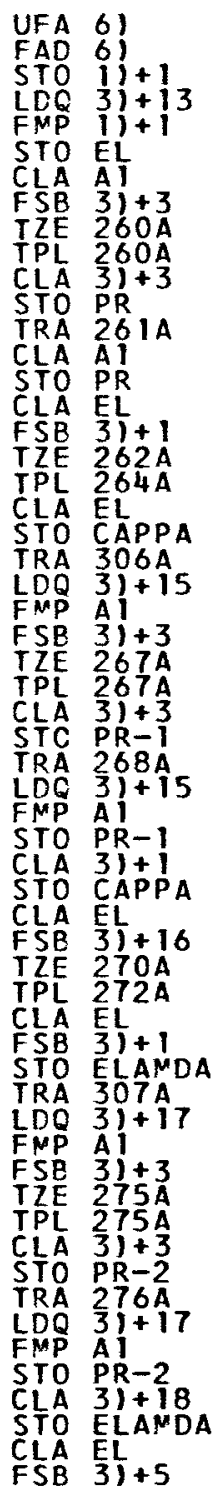 \\
\hline
\end{tabular}

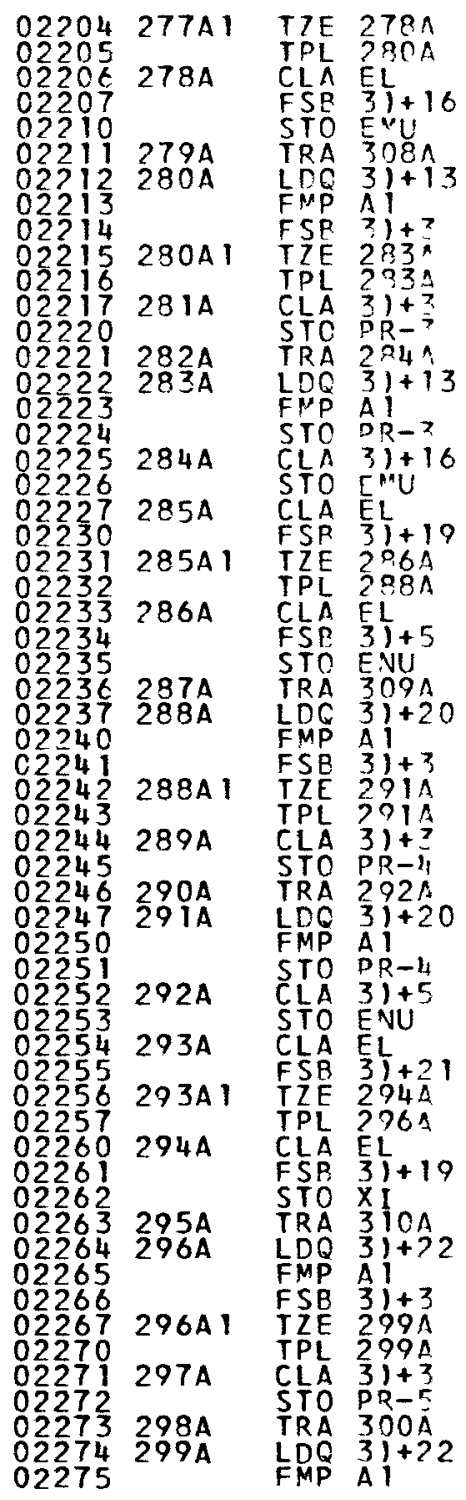




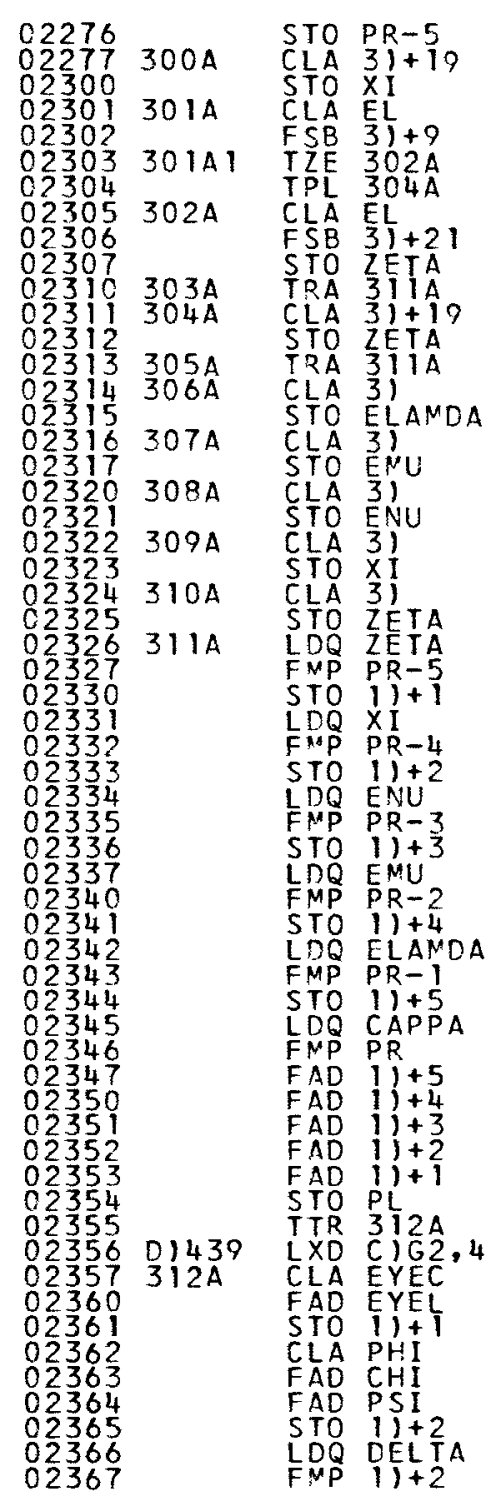

\begin{tabular}{|c|c|c|c|}
\hline $\begin{array}{l}02370 \\
02371 \\
02372 \\
02373 \\
02374 \\
02375 \\
02376 \\
02377 \\
02400 \\
02401 \\
02402 \\
02403 \\
02404 \\
02405 \\
02406 \\
02407 \\
02410 \\
02411 \\
02412 \\
02413 \\
02414 \\
02415 \\
02416 \\
02417 \\
02420 \\
02421 \\
02422\end{array}$ & $\begin{array}{l}315 \mathrm{~A} \\
315 \mathrm{~A} 1 \\
316 \mathrm{~A}\end{array}$ & 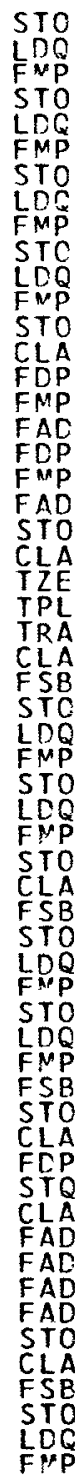 & 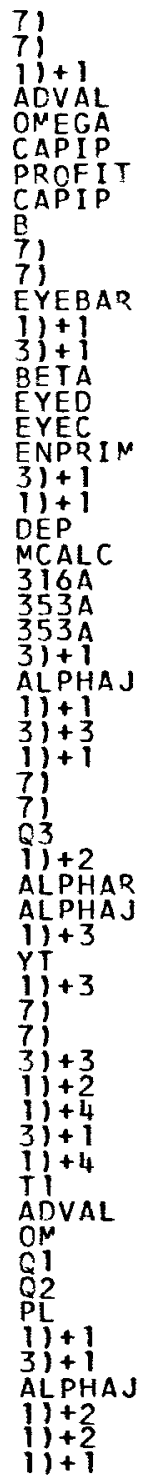 \\
\hline
\end{tabular}

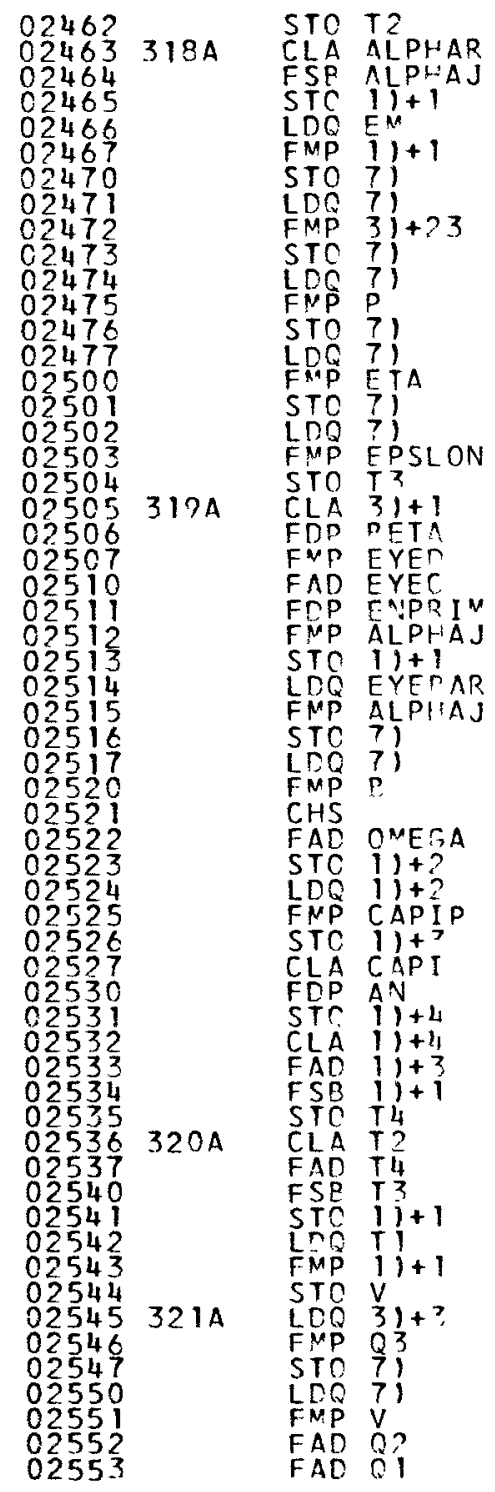




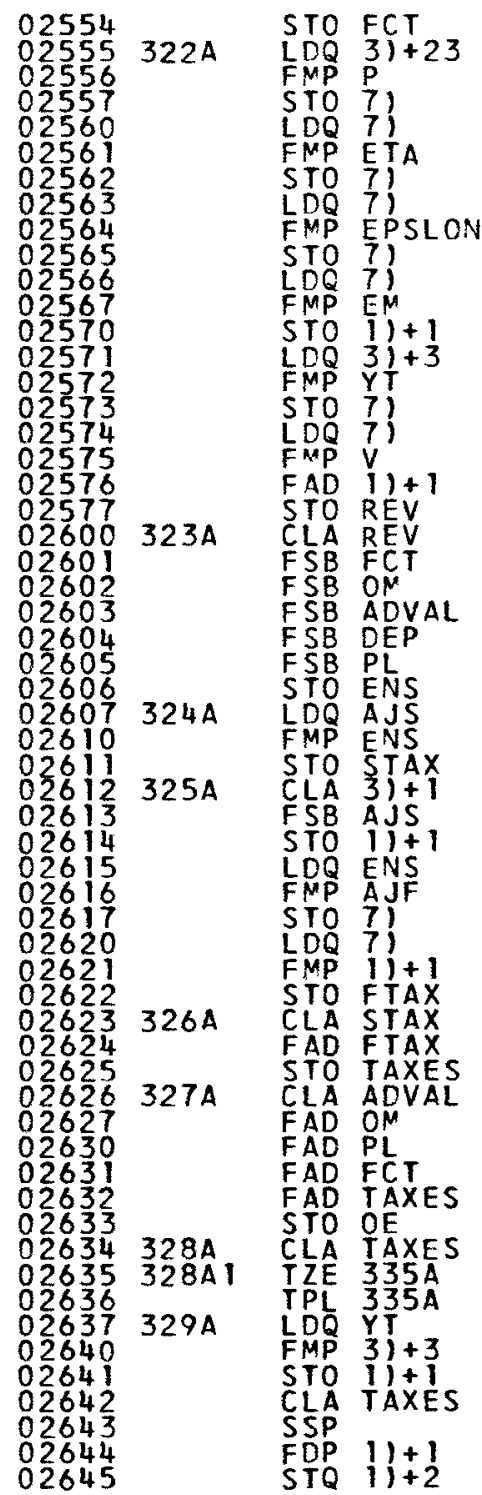

\begin{tabular}{|c|c|c|c|}
\hline $\begin{array}{l}02646 \\
02647 \\
02650 \\
02651 \\
02652 \\
02653 \\
02654 \\
02655 \\
02656 \\
02857 \\
02660 \\
02661 \\
02662 \\
02663 \\
02664 \\
02665 \\
02665 \\
02667 \\
02670 \\
02671 \\
02672 \\
02673 \\
02674 \\
07675 \\
02676 \\
02677 \\
02700 \\
02701 \\
07702 \\
07703 \\
02704 \\
02705 \\
02706 \\
02707 \\
02710 \\
02711 \\
02712 \\
02713 \\
02714 \\
02715 \\
02716 \\
02717 \\
02720 \\
02721 \\
02722 \\
02723 \\
02724 \\
02725 \\
02726 \\
02727 \\
02730 \\
02731 \\
02732\end{array}$ & $\begin{array}{l}333 A \\
334 A \\
335 A\end{array}$ & 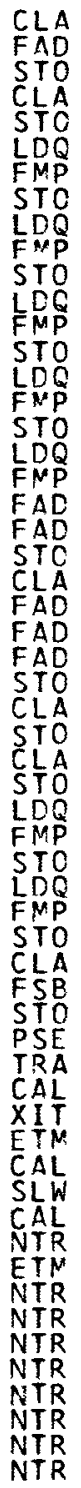 & 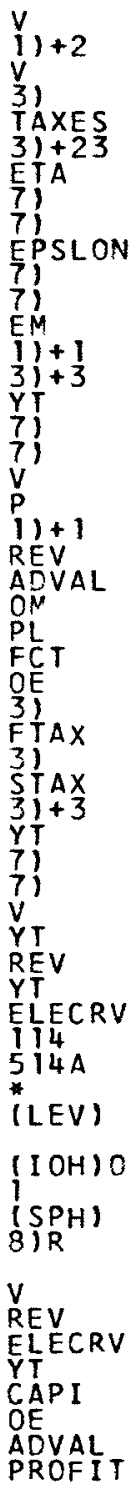 \\
\hline
\end{tabular}

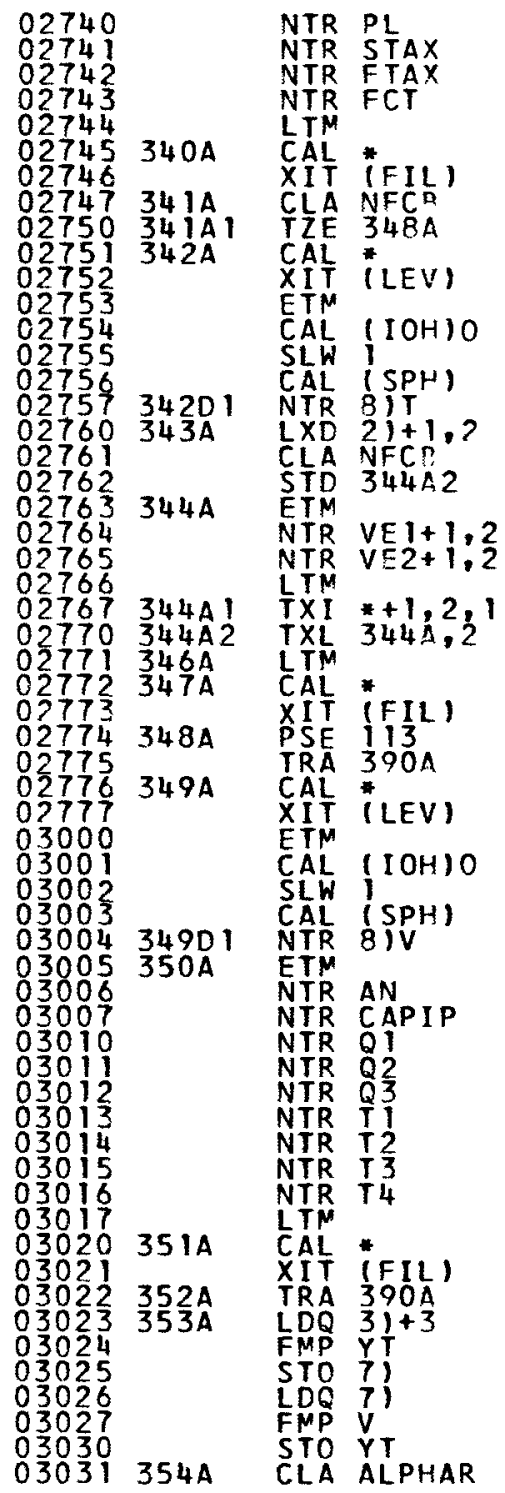




\begin{tabular}{|c|c|c|}
\hline 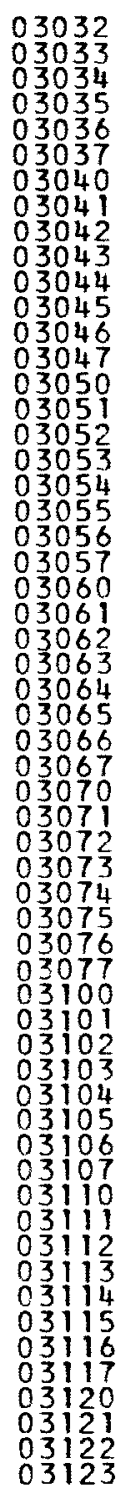 & $\begin{array}{l}357 A \\
357 A 1 \\
358 A\end{array}$ & $\begin{array}{l}\text { FSB } \\
\text { STO } \\
\text { LOO } \\
\text { FMP } \\
\text { STO } \\
\text { LOQ } \\
\text { FMP } \\
\text { STO } \\
\text { LDQ } \\
\text { FMP } \\
\text { STO } \\
\text { LDQ } \\
\text { FMP } \\
\text { STO } \\
\text { CLA } \\
\text { FDP } \\
\text { STQ } \\
\text { CLA } \\
\text { FDP } \\
\text { FMP } \\
\text { FAD } \\
\text { FDP } \\
\text { FMP } \\
\text { STO } \\
\text { LDQ } \\
\text { FMP } \\
\text { STO } \\
\text { LDQ } \\
\text { FMP } \\
\text { STO } \\
\text { LDQ } \\
\text { FMP } \\
\text { CHS } \\
\text { FAO } \\
\text { FSB } \\
\text { STO } \\
\text { CLA } \\
\text { FSB } \\
\text { STO } \\
\text { LDQ } \\
\text { FMP } \\
\text { STO } \\
\text { CLA } \\
\text { IZE } \\
\text { LDQ } \\
\text { FMP } \\
\text { STO } \\
\text { LOQ } \\
\text { FMP } \\
\text { FAD } \\
\text { FAD } \\
\text { STO } \\
\text { CLA } \\
\text { FAD } \\
\text { FAD } \\
\text { FAD } \\
\text { STO } \\
\text { CLA }\end{array}$ \\
\hline
\end{tabular}

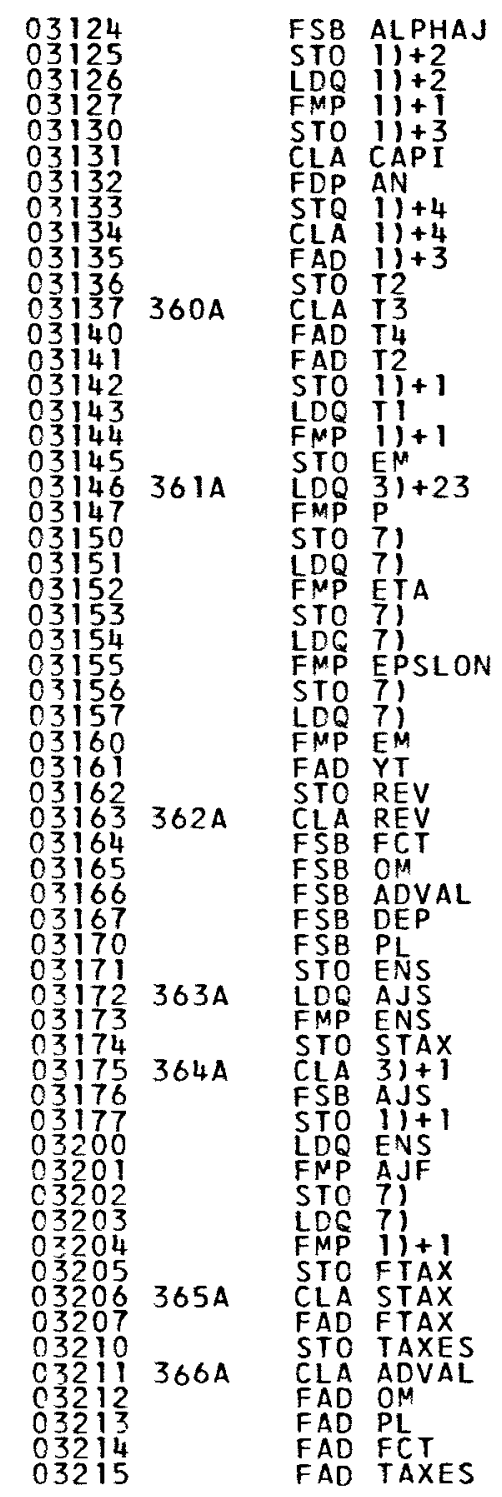

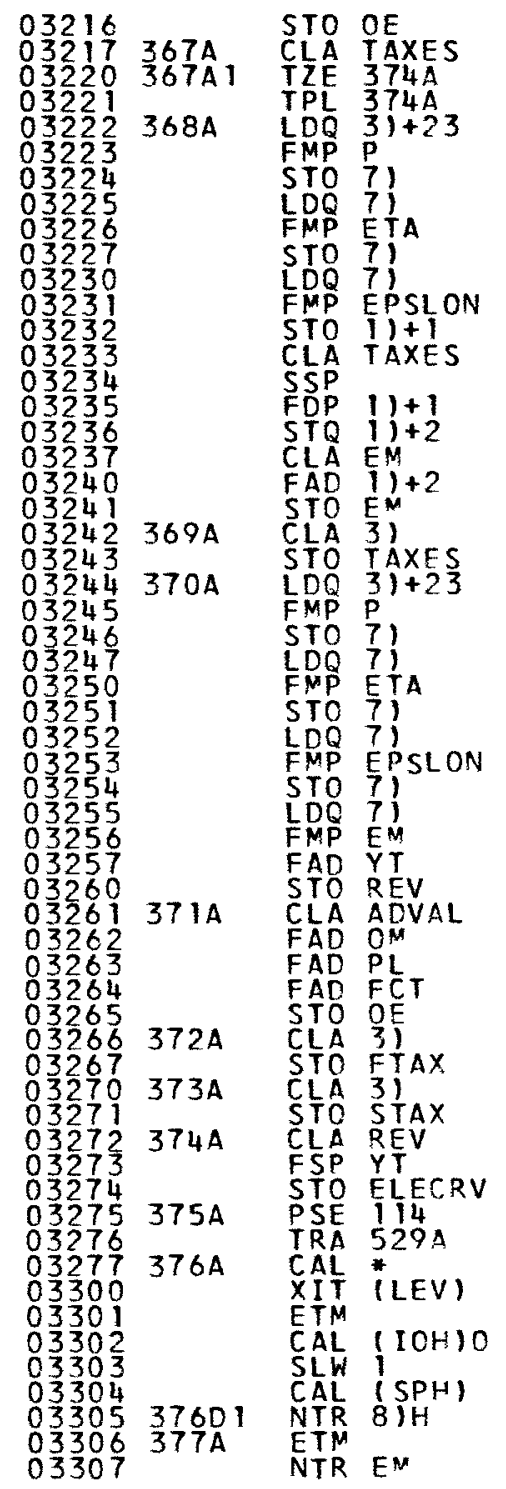




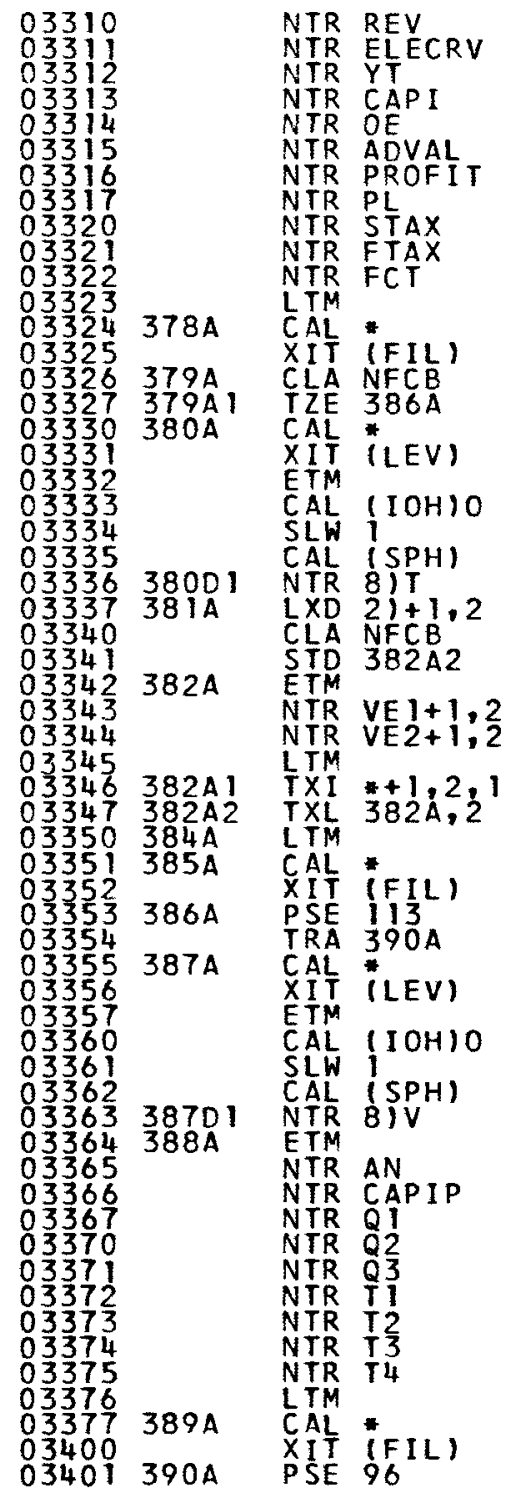

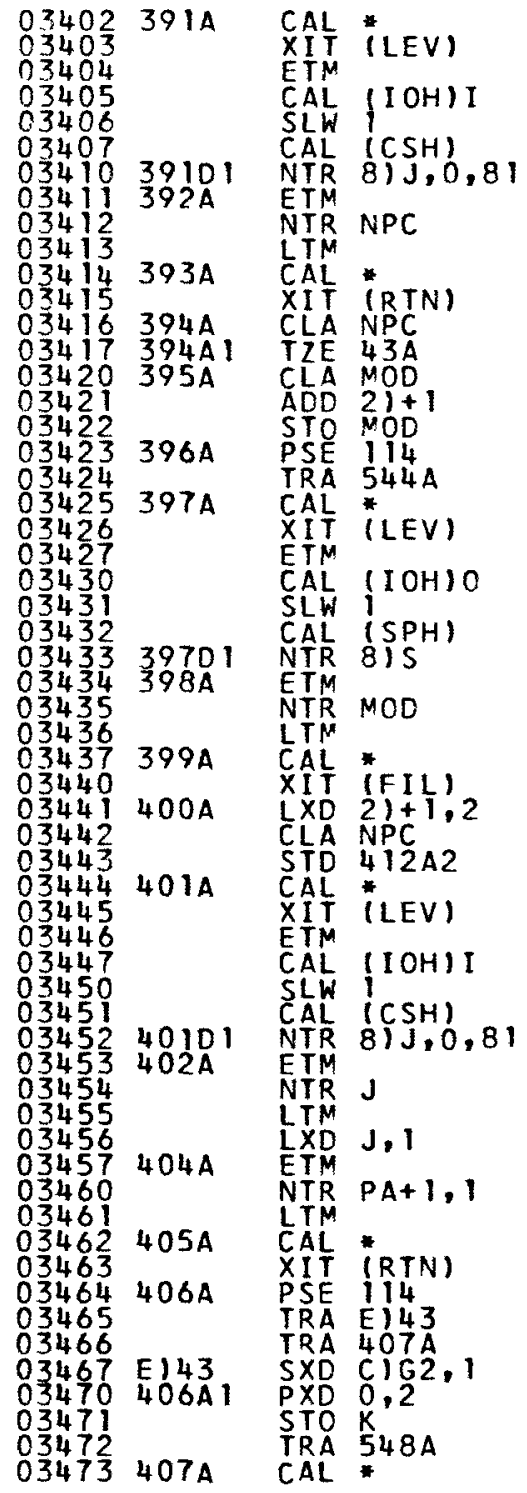

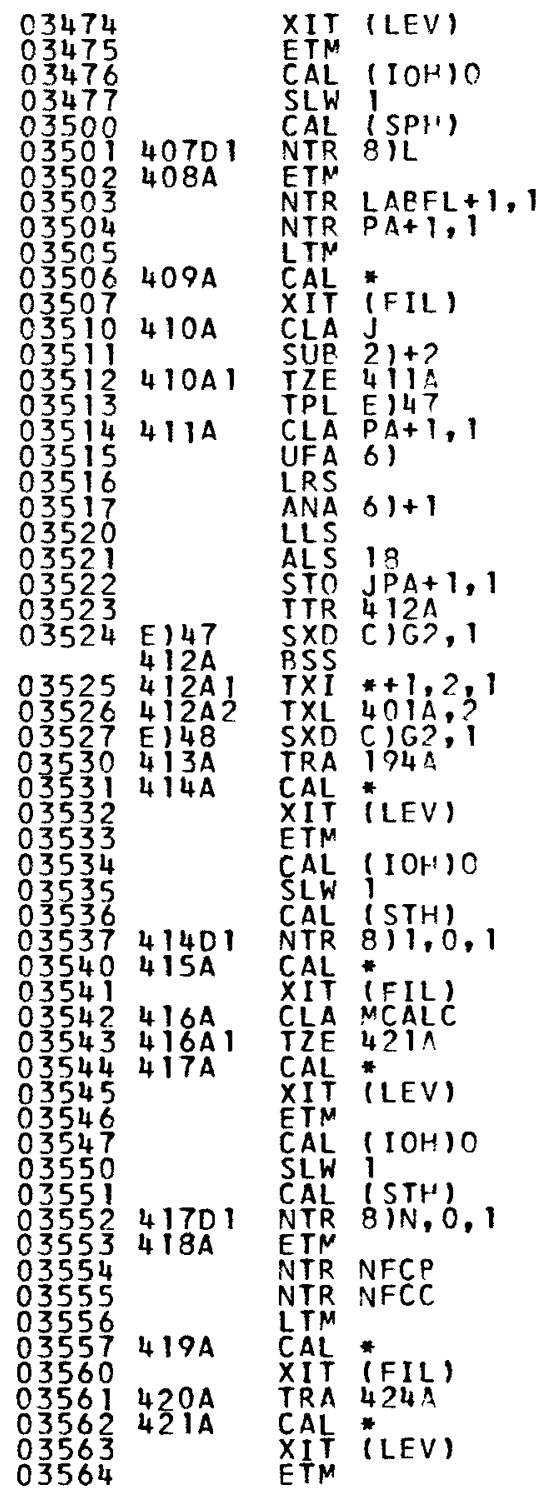




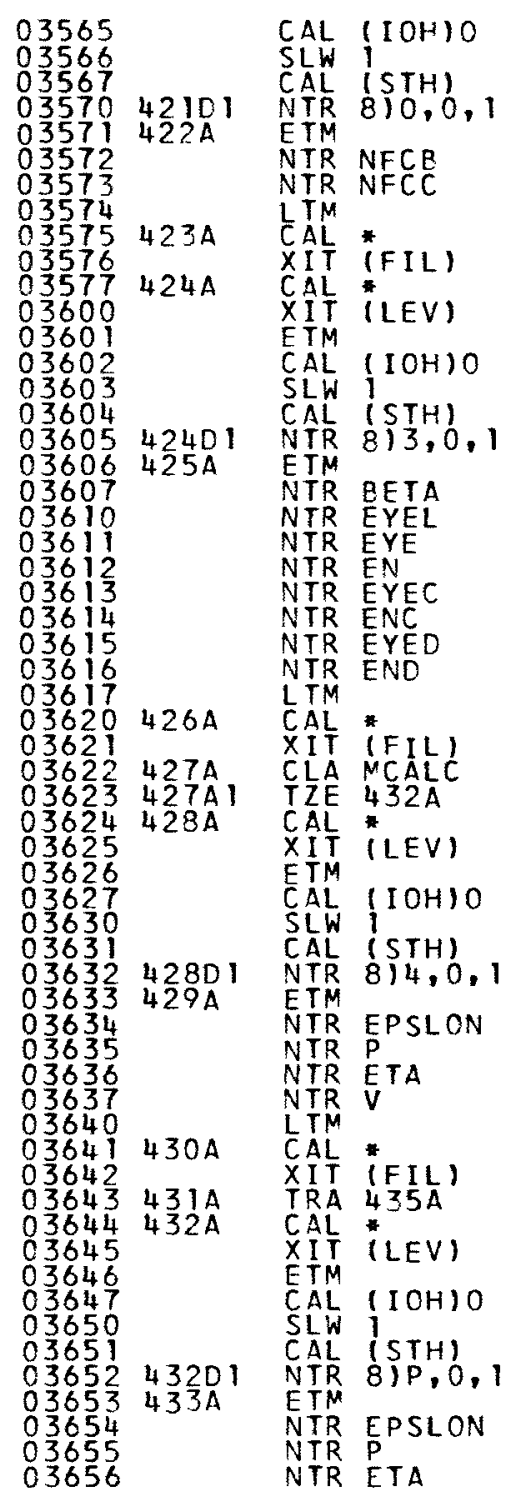

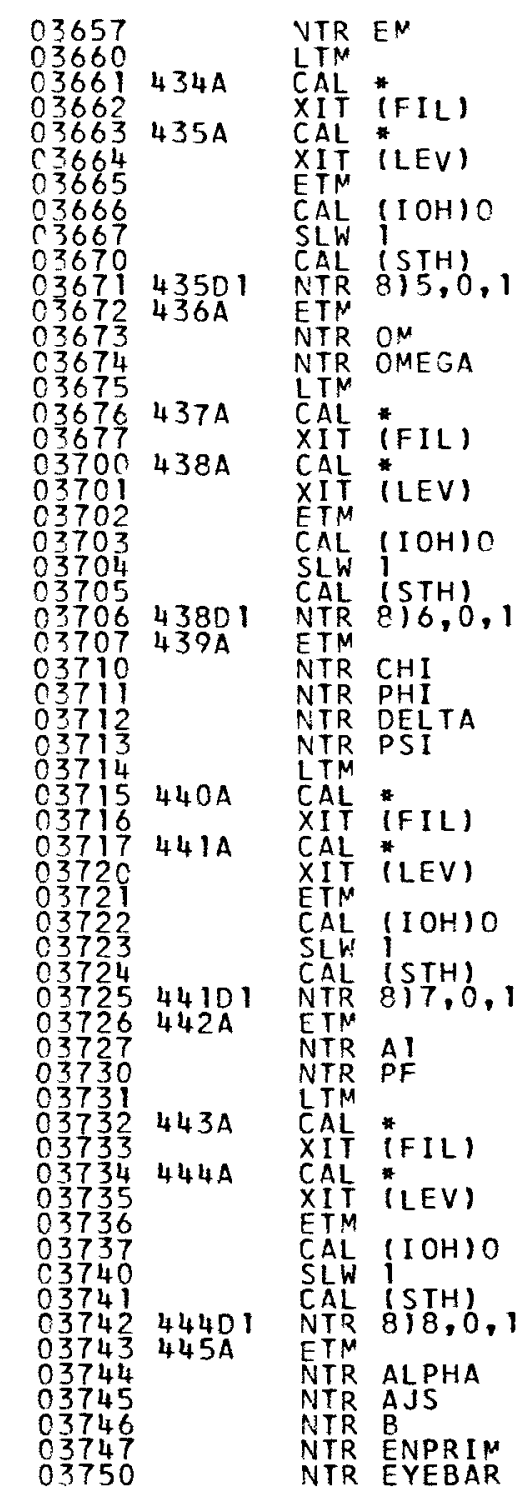

\begin{tabular}{|c|c|c|}
\hline & $\begin{array}{l}44901 \\
450 \mathrm{~A} \\
\\
451 \mathrm{~A} \\
452 \mathrm{~A} \\
453 \mathrm{~A}\end{array}$ & 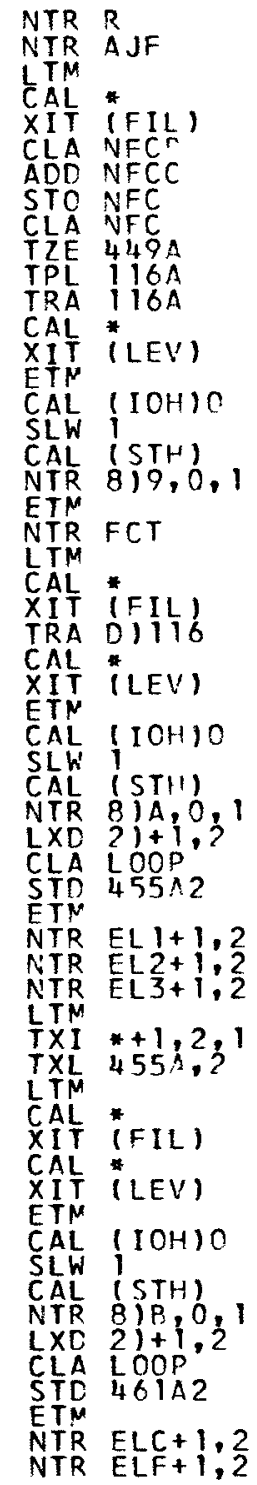 \\
\hline
\end{tabular}




\begin{tabular}{|c|c|c|}
\hline 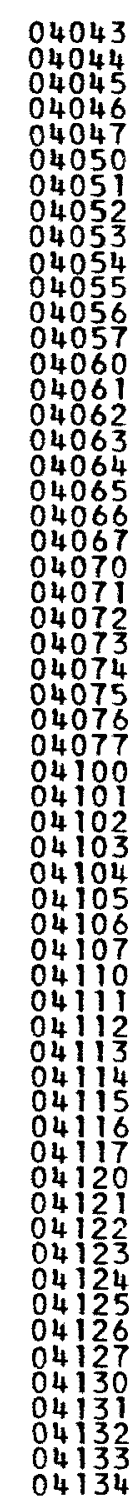 & 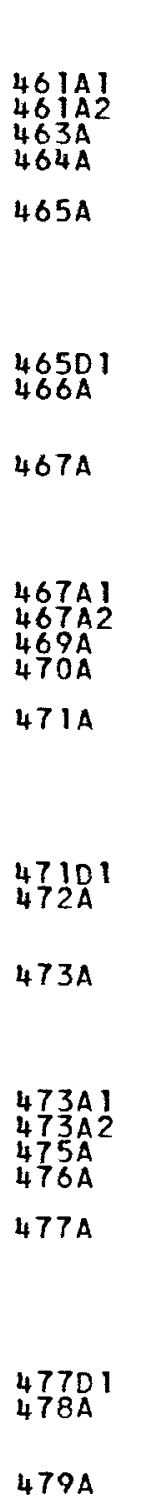 & $\begin{array}{l}?_{2}^{2} \\
2,1 \\
, 2 \\
1 \\
1 \\
10 \\
1 \\
0,1 \\
2^{2} \\
2\end{array}$ \\
\hline
\end{tabular}

\begin{tabular}{|c|c|c|}
\hline 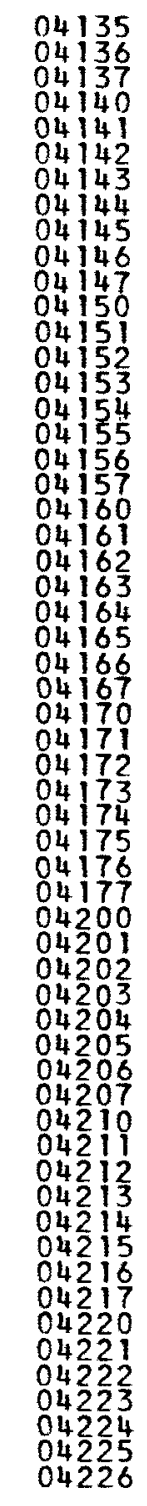 & $\begin{array}{l}9 A 1 \\
9 A 2 \\
\text { 9A }\end{array}$ & 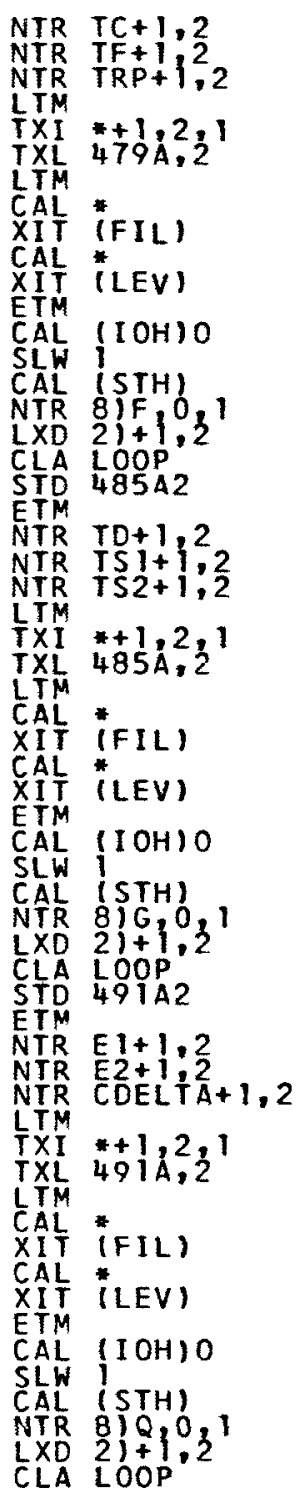 \\
\hline
\end{tabular}

\begin{tabular}{|c|c|}
\hline 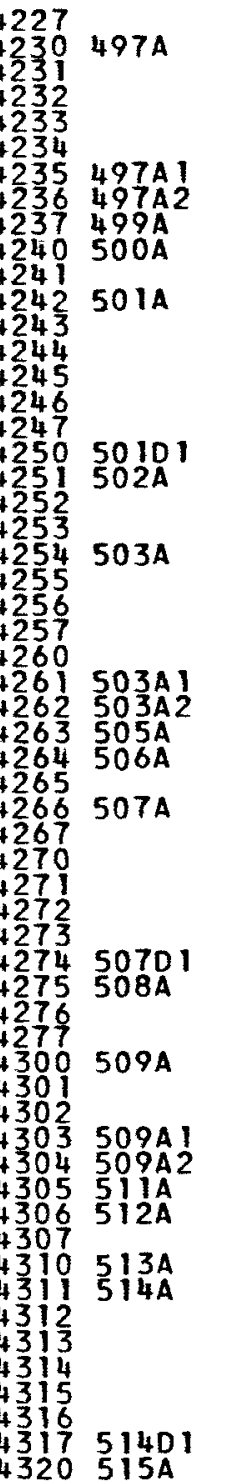 & $\begin{array}{l}0,1 \\
2 \\
2 \\
2 \\
2 \\
2 \\
2 \\
2\end{array}$ \\
\hline
\end{tabular}




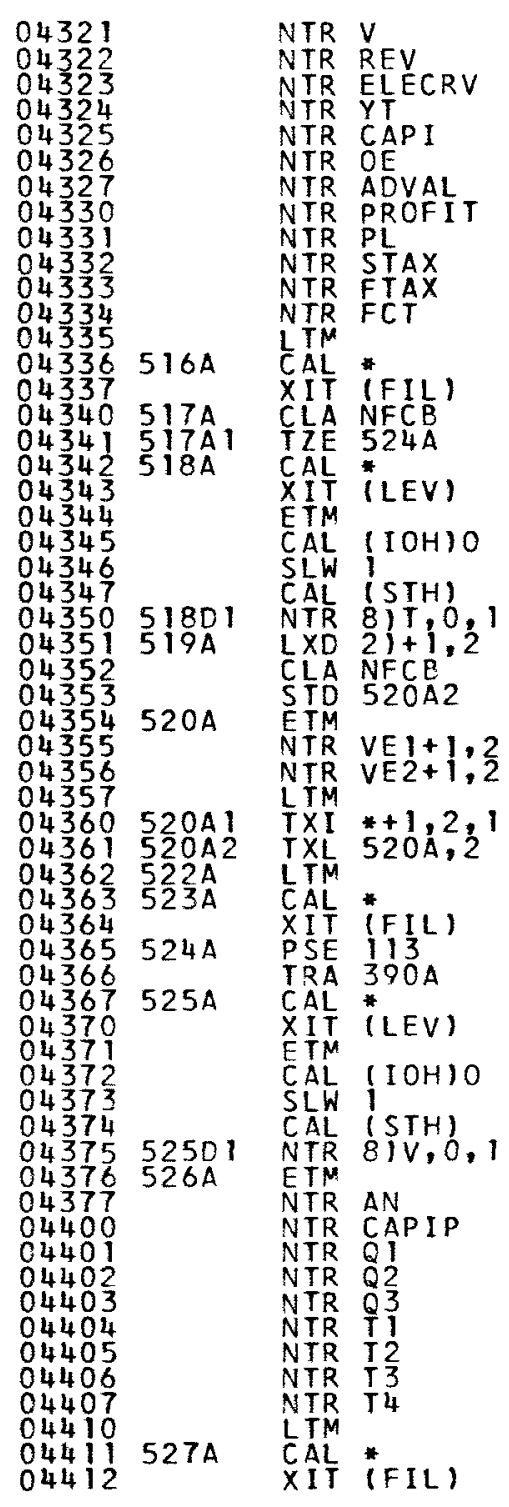

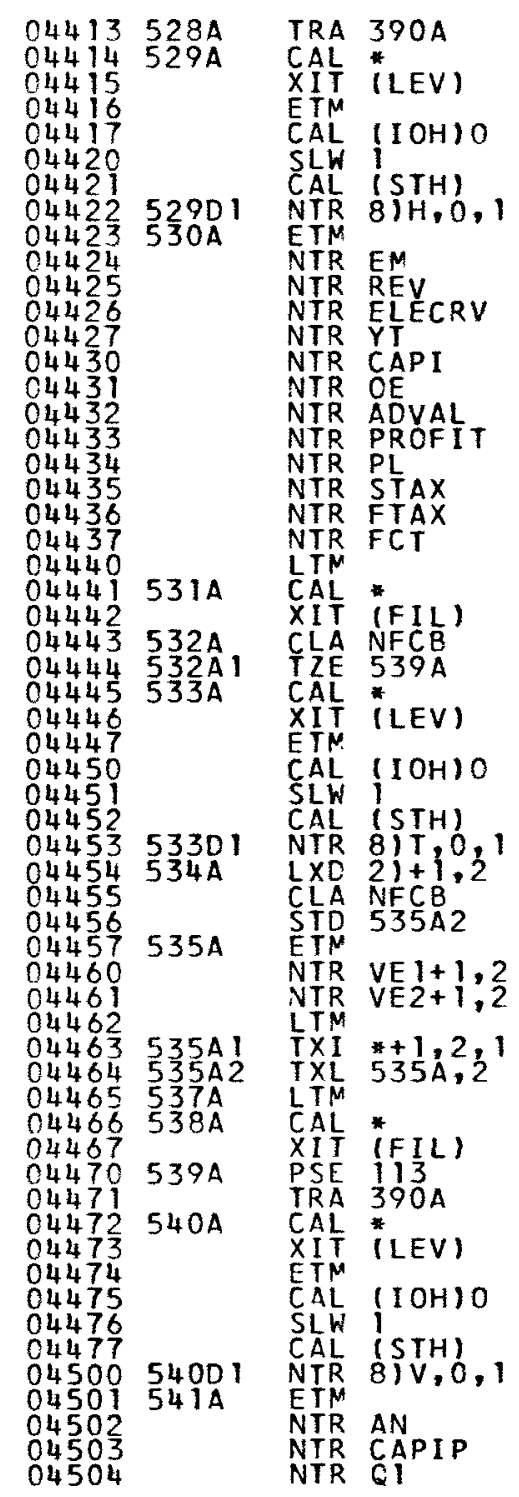

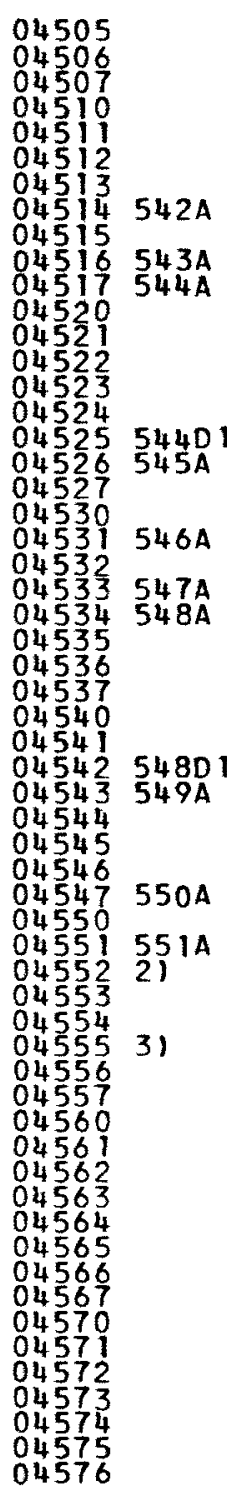

NTR Q?

TR

NTR T2

NTR T4

LTM

CAL *
XIT (FIL)
TRA 39OA

CAL *

ETM $(\mathrm{OOH})$

SLLW

CALL (STH)

ETM MOD

LTM

CAL * IFIL)

$400 \mathrm{~A}$

XIT iLEV

CAL $(\mathrm{IOH}) \mathrm{O}$

SLW (STH)

NTR BIL,0, 1

NTR LABEL +1 ,

NTR PA+1,

LTM

XIT iFIL)

OCT +000000000000

OCT +000001000000

CT +00000300000

CT +000000000000

C +201400000000

oct + 17054706211

OCT + 212764000000

0 + 20240000000

C +20150000000

T +202500000000

OCT + +207620000000

OCT + 206740000000

CT $T+210454000000$

OCT + 224750220000

OCT + 175631463146

OCT + 20077777776

OCT + +20350000000

OCT + 203500000000 


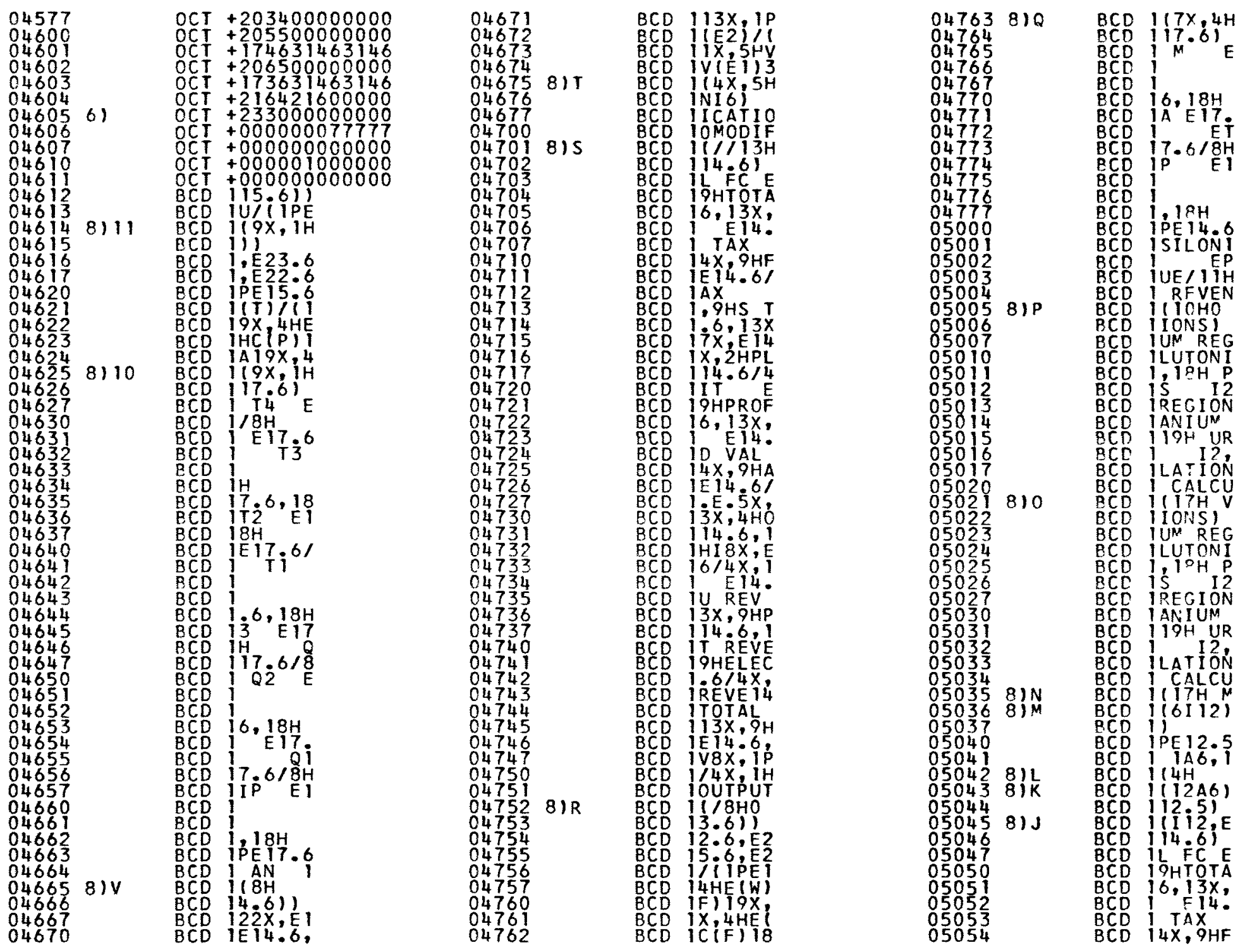




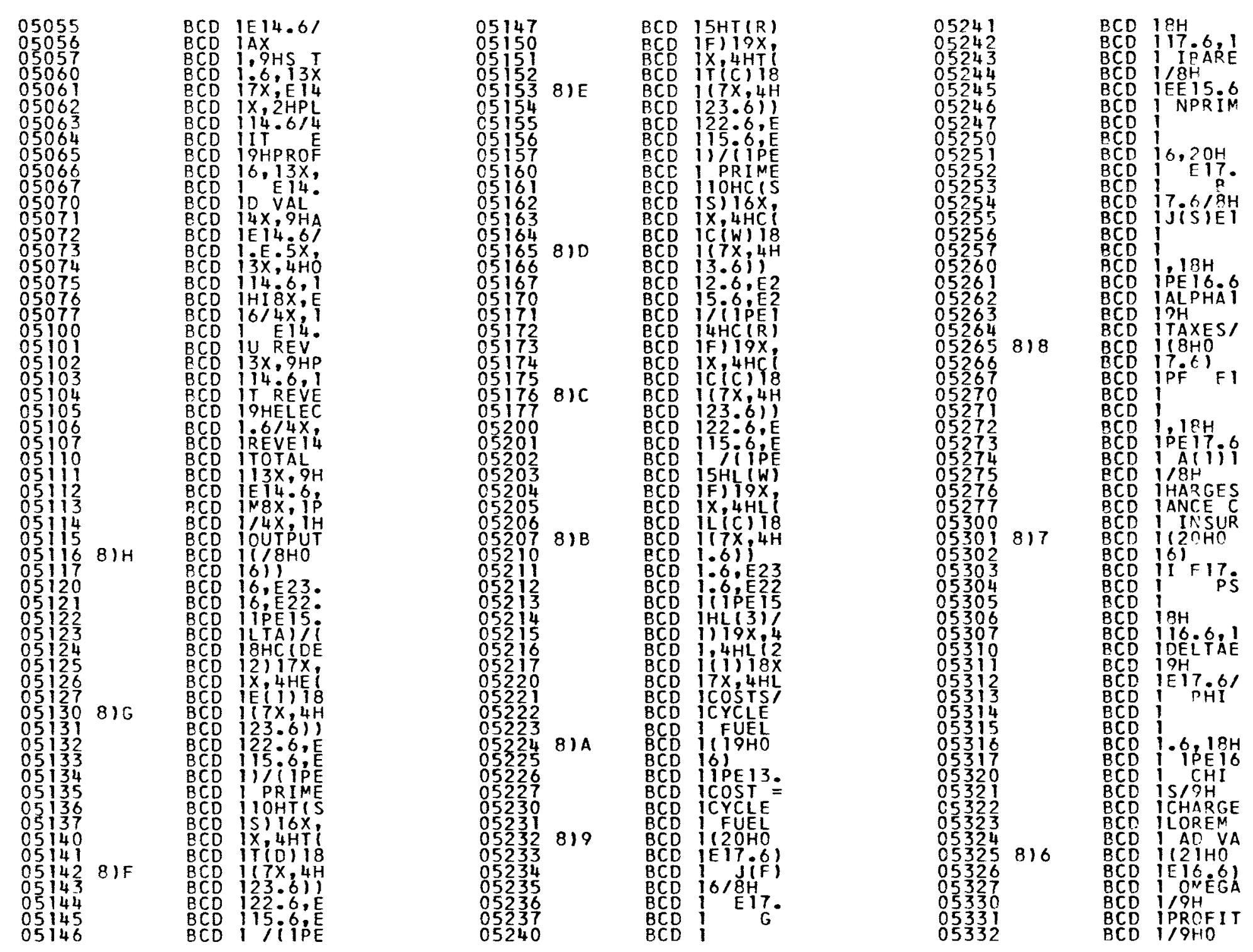




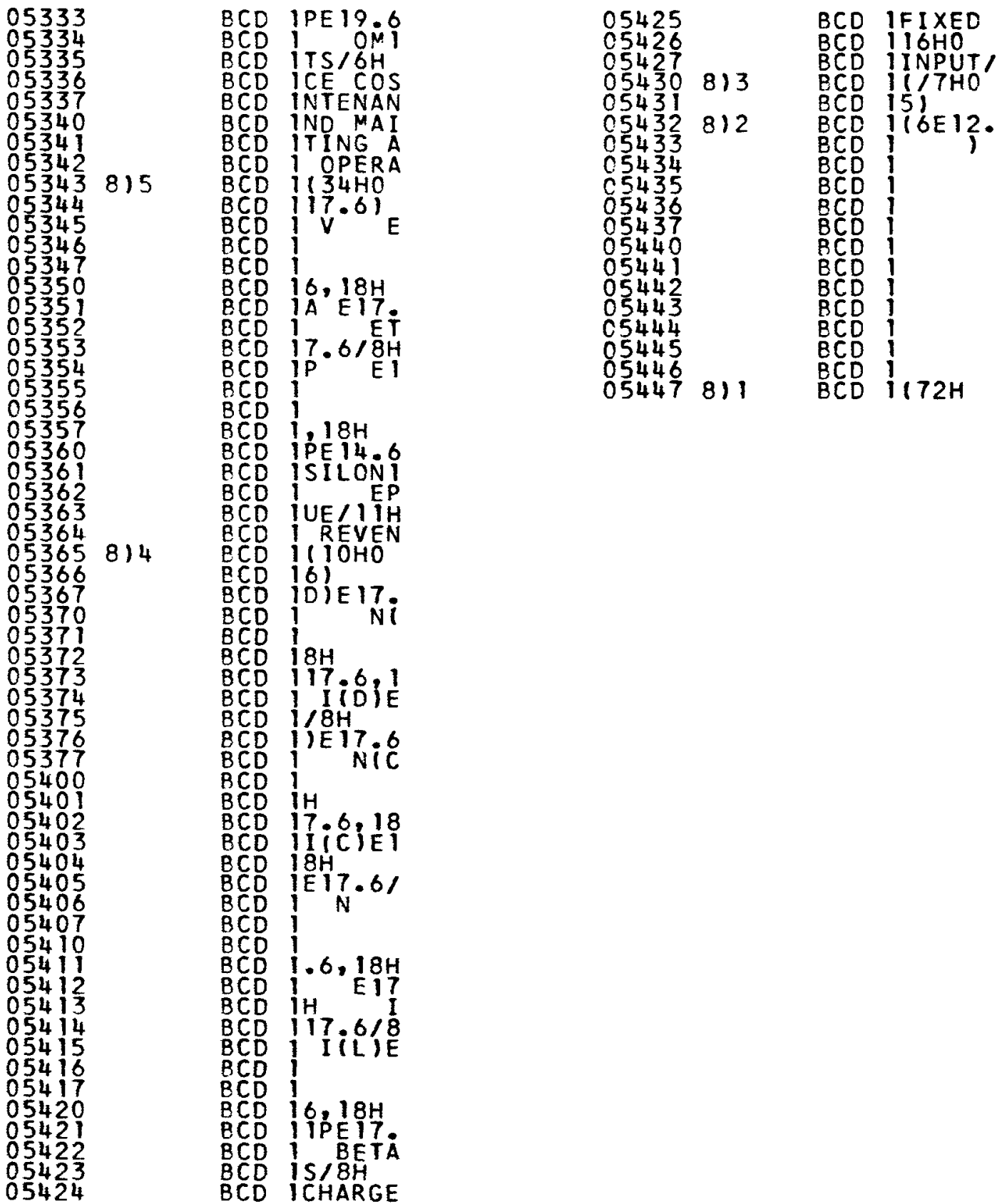


APPENDIX F

SAMPLE PROBLEM INPUT AND OUTPUT 
FORM I

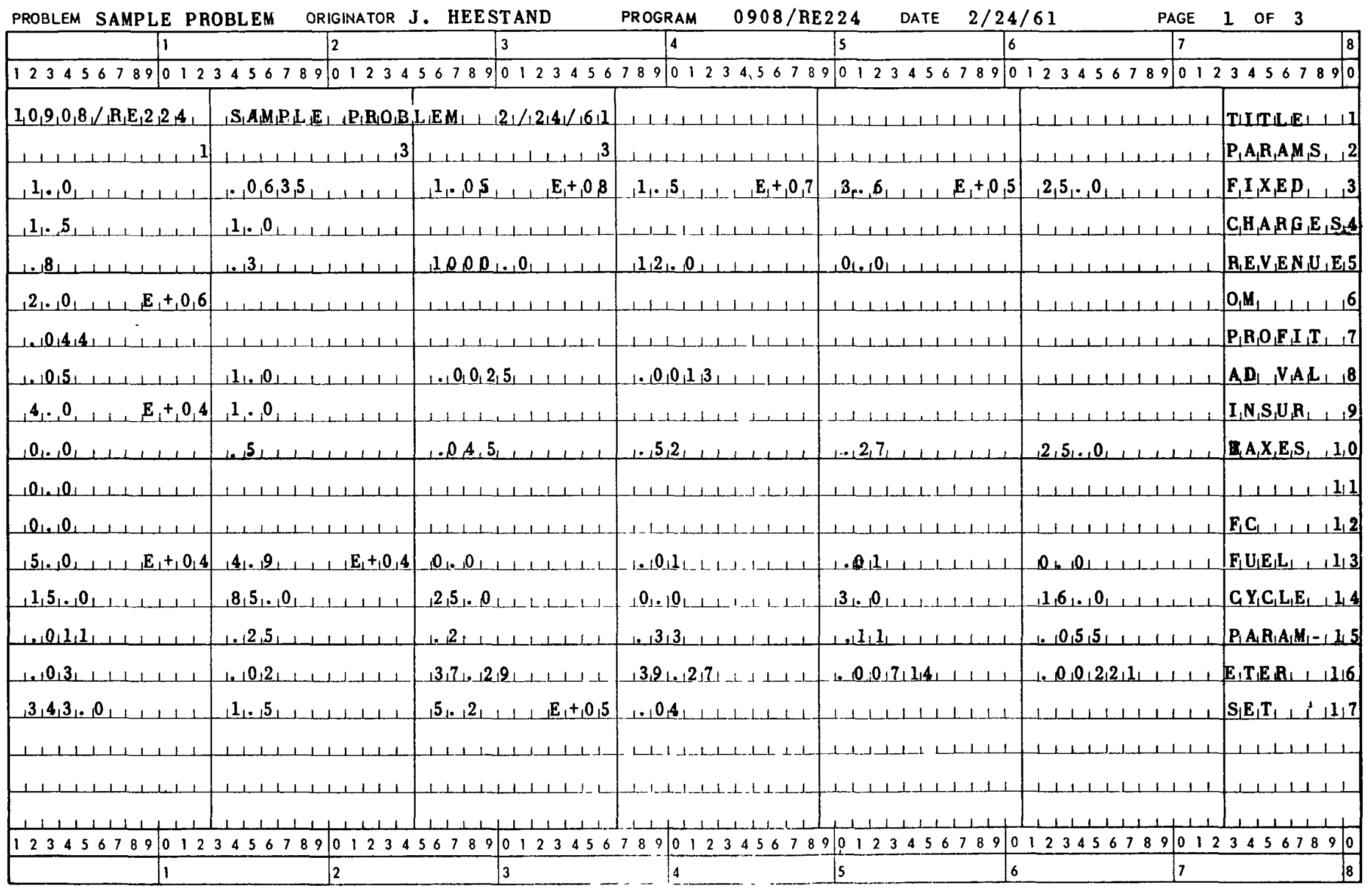

AMD-B (8-88) 
704 INPUT DATA

FORM I

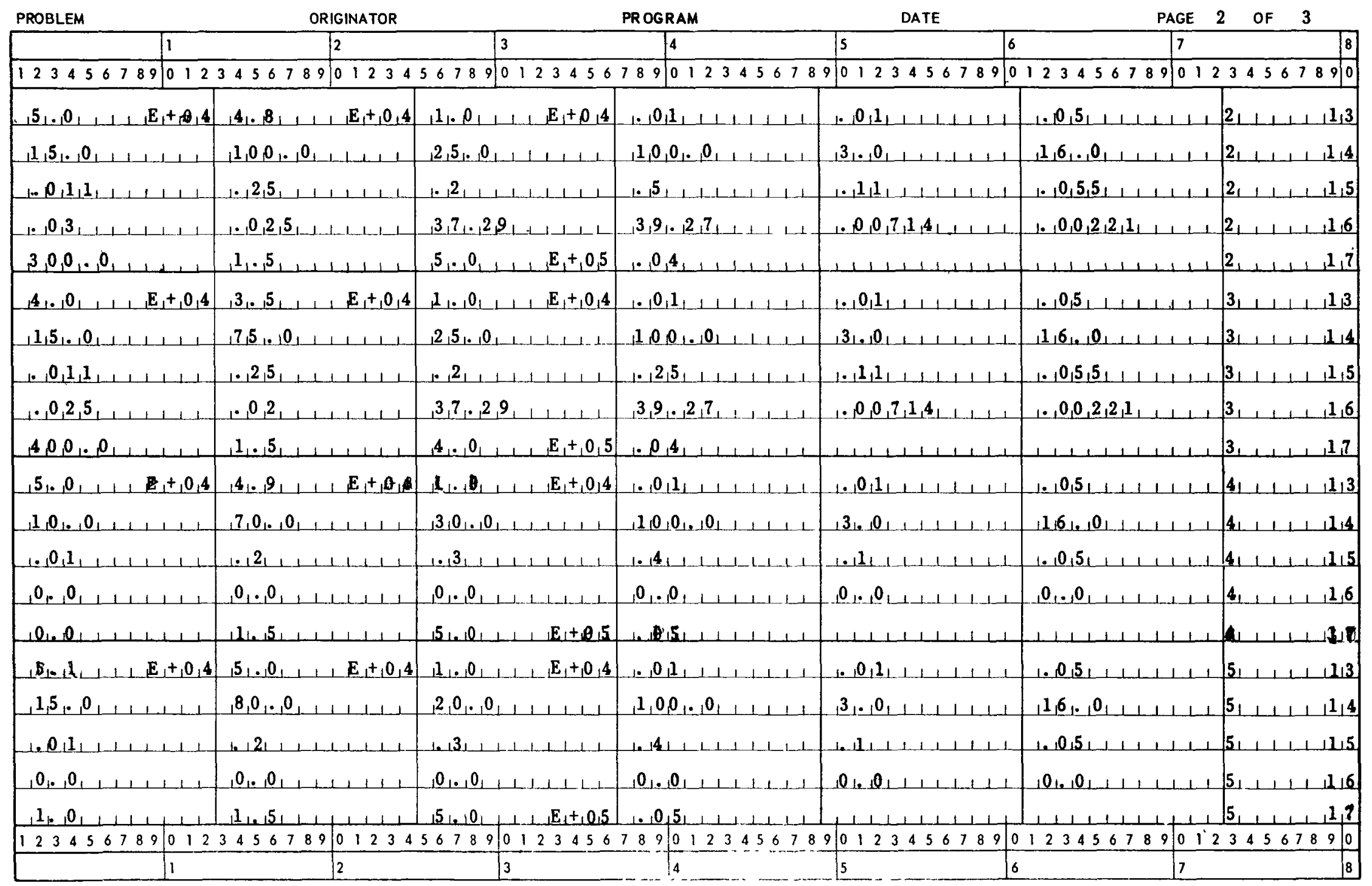


FORM I

PROBLEM

ORIGINATOR

PROGRAM

DATE

PAGE

of 3

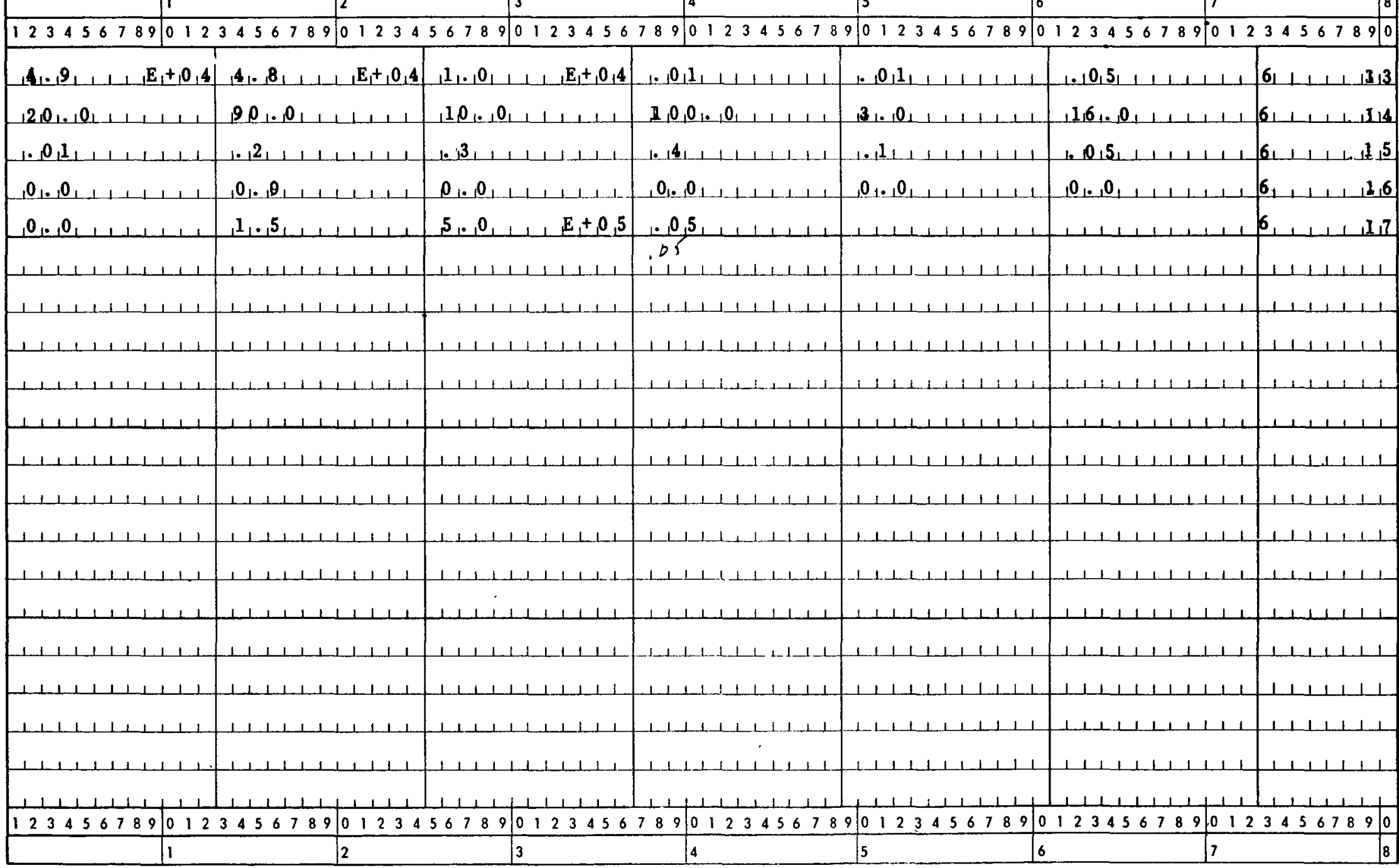

AMD-8 (8-58) 
0908/RE224 SAMPLE PROBLEM 2/24/61

$M$ CALCULATION 3 URANIUM REGIONS
3 PLUTONIUM REGIONS

\begin{tabular}{|c|c|}
\hline $\begin{array}{l}\text { FIXED } \\
\text { BETA } \\
I \\
I(C) \\
I(D)\end{array}$ & $\begin{array}{l}\text { CHARGES } \\
\begin{array}{rl}1.000000 E & 00 \\
6.350000 E-02 \\
1.050000 E & 08 \\
1.500000 E & 0 ?\end{array}\end{array}$ \\
\hline
\end{tabular}

REVENUE

$\begin{array}{ll}\text { EPSILON } & 8.000000 E-01 \\ \text { ETA } & 3.000000 E-01\end{array}$

OPERATING AND MAINTENANCE COSTS OM 2.00000OE O6

PROF IT

OMEGA $\quad 4.400000 E-02$

AD VALOREM CHARGES

CHI 5.000000E-02

DELTA 1.000000 EO

INSURANCE CHARGES

A(1) 4.000000E O4

TAXES

$\begin{array}{ll}\text { ALPHA } & 0 . \\ \text { B } & 5.000000 E-01 \\ \text { IBAR } & 4.500000 E-02 \\ \text { J(F) } & 5.200000 E-01\end{array}$

FUEL CYCLE COSTS

L(1)

5.000000E 04

5. 000000 E 04

4. $000000 E$ O4

5.000000E 04

$5.100000 E^{04}$

4. 900000 E 04

$L(C)$

10.000000E-03

$10.000000 E-03$

10.000000E-03

10.000000E-03

10.000000E-03

10.000000E-03

$C(C)$

$1.500000 E \quad 01$

$1.500000 E \quad 01$

1.500000 E OI
(12)
4.900000E 04
4.800000 E 04
3.500000 E 04
4. $900000 \mathrm{E}$ O4
5.000000 E 04
4.800000E O4
L(F)
$10.000000 \mathrm{E}-03$
$10.000000 \mathrm{E}-03$
$10.000000 E-03$
10.000000E-03
$10.000000 \mathrm{E}-03$
10.000000E-03
$C(F)$
8.500000E 01
$1.000000 \mathrm{E} 02$
7.500000 E 01

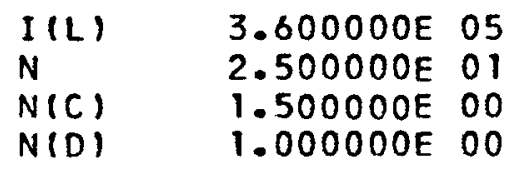

P $\quad 1.000000 E \quad 03$

$1.200000 E \quad 01$

$\begin{array}{ll}\text { PHI } & 2.500000 E-03 \\ \text { PSI } & 1.300000 E-03 \\ \text { PF } & 1.000000 E 00 \\ & \\ \text { JIS) } & 2.700000 E-01 \\ \text { NPRIME } & 2.500000 E 01 \\ \text { G } & 0 .\end{array}$

L(3)

0.

$1.000000 E \quad 04$

$1.000000 E^{04}$

1.000000 E 04

1.000000 E 04

$1.000000 E 04$

$L(w)$

0 .

5.000000E-02

5. $000000 E-02$

5. $000000 E-02$

5. $000000 E-02$

5. $000000 E-02$

$C(R)$

2.500000E 01

2.500000E O1

2.500000E OI 


$$
\begin{aligned}
& 1.000000 E \quad 01 \\
& 1.500000 E \quad 01 \\
& 2.000000 E \quad 01 \\
& C(W) \\
& 0.0 \\
& 1.000000 E 02 \\
& 1.000000 E 02 \\
& 1.000000 E 02 \\
& 1.000000 E 02 \\
& 1.000000 E 02 \\
& \text { T(C) } \\
& 1.100000 E-02 \\
& 1.100000 E-02 \\
& 1.100000 E-02 \\
& 10.000000 E-03 \\
& 10.000000 E-03 \\
& 10.000000 E-03 \\
& \text { T(D) } \\
& 3.300000 E-01 \\
& 5.000000 E-01 \\
& 2.500000 E-01 \\
& 4.000000 E-01 \\
& 4.000000 E-01 \\
& 4.000000 E-01 \\
& 3.000000 E-02 \\
& 3.000000 E-02 \\
& 2.500000 E-02 \\
& 0.0 \\
& 0 .
\end{aligned}
$$

$3.927000 E$ OI 3.927000 E 01 3.927000 E 01

0 .

0 .

0 .

$A$

3.430000 E 02

3. $000000 E 02$

4.000000E 02

0 .

1.000000 E 00

0 .

$\mathrm{U}$

4. $000000 E-02$

4.000000E-02

4. $000000 E-02$

5.000000E-02

5. $000000 \mathrm{E}-02$

5.000000E-02
7.000000 E 01

8.000000 E 01

$9.000000 E \quad 01$

C(S)

3. $000000 E$ DO

$3.000000 E$ OO

$3.000000 E$ OO

$3.000000 E$ OO

$3.000000 E$ OO

3.000000 E 00

$T(F)$

2.500000E-01

2.500000E-01

2.500000E-01

2.000000E-01

$2.000000 E-01$

2.000000E-01

$T(S)$

1. $100000 E-01$

$1.100000 E-01$

$1.100000 E-01$

$10.000000 E-02$

$10.000000 E-02$

$10.000000 \mathrm{E}-02$

$E(2)$

2. $000000 E-02$

$2.500000 \mathrm{E}-02$

$2.000000 E-02$

0 .

0 .

0 .

$E(F)$

7. $140000 E-03$

7. $140000 E-03$

7. $140000 E-03$

0 .

0 .

0 .

\section{$C(P)$}

$1.500000 E \quad 00$

$1.500000 E$ OD

1.500000 E 00

$1.500000 E$ OO

1.500000 E 00

I. 500000 E 00
$3.000000 E \quad 01$

$2.000000 E$ OI

$1.000000 E 01$

CIS PRIME)

$1.600000 E$ OI

1.600000 E 01

$1.600000 E 01$

$1.600000 E 01$

$1.600000 E$ OI

1.600000 E 01

$T(R)$

2.000000E-01

$2.000000 E-01$

2.000000E-01

3.000000E-01

$3.000000 E-01$

3.000000E-01

T (S PRIME)

5.500000E-02

5.500000E-02

$5.500000 E-02$

5.000000E-02

5.000000E-02

5.000000E-02 (DELTA)

3.729000E 01

3.729000 E 01

3.729000 E 01

0 .

0 .

0 .

$E(w)$

2.210000E-03

2.210000E-03

2.210000E-03

0 .

0 .

0 .

$E(T)$

5.200000E 05

$5.000000 E$ O5

4. 000000 E 05

$5.000000 E \quad 05$

5.000000E 05

$5.000000 E$ OS 


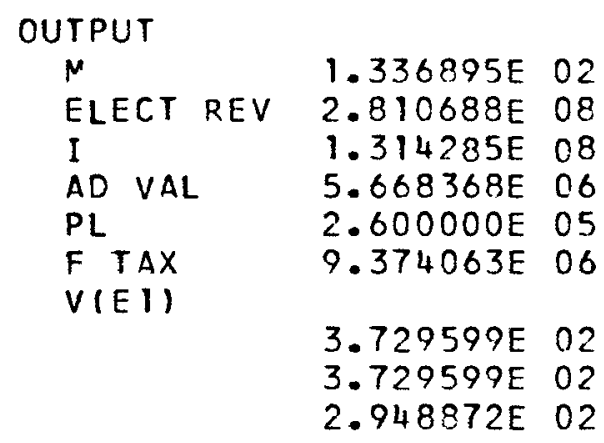

$\begin{array}{lll}\text { TOTAL REV } & 2.889936 E & 08 \\ \text { PU REV } & 7.924775 E & 06 \\ \text { O.E. } & 2.725817 E & 08 \\ \text { PROFIT } & 5.786251 E & 06 \\ \text { S TAX } & 6.667537 E & 06 \\ \text { TOTAL FC } & 2.486118 E & 08 \\ \text { VIE2I } & & \\ & 2.184147 E & 02 \\ & 2.948872 E & 02 \\ & 2.184147 E & 02\end{array}$


APPENDIX G

SAMPLE WORK SHEET

The following is a sample work sheet proposed by T. Heckman of the $\mathrm{AEC}$, to be of aid to the problem originator. 
0908/RE224 REACTOR ECONOMICS WORK SHEET

\begin{tabular}{|c|c|c|c|c|c|c|c|c|}
\hline \multicolumn{9}{|l|}{ ORIGINATOR - } \\
\hline \multirow[b]{2}{*}{ PARAMETER } & \multirow[b]{2}{*}{$\begin{array}{l}\text { IN) } \\
\text { INDEX }\end{array}$} & \multirow[b]{2}{*}{ UNITS } & \multicolumn{3}{|c|}{ PLANT___ PROBLEM NO. } & \multicolumn{3}{|c|}{ PLANT___ PROBLEM NO. } \\
\hline & & & VALUE & $\begin{array}{l}\text { REFERENCE } \\
\text { (AUTHOR } \\
\text { ANDIOR } \\
\text { DOCUMENT) }\end{array}$ & $\begin{array}{l}\text { ACCURACY } \\
\text { G GOOD } \\
\text { F FAIR } \\
\text { P POOR }\end{array}$ & value & $\begin{array}{l}\text { REFERENCE } \\
\text { IAUTHOR } \\
\text { AND/OR } \\
\text { DOCUMENTI }\end{array}$ & $\begin{array}{l}\text { ACCURACY } \\
\text { G GOOD } \\
\text { F FAIR } \\
\text { P POOR }\end{array}$ \\
\hline MCALC & 1 & - & & & & & & \\
\hline NFCB & 2 & - & & & & & & \\
\hline NFCC & 3 & - & & & & & & \\
\hline$\beta$ & 4 & - & & & & & & \\
\hline 1 & 5 & $\% \times 10^{-2}$ & & & & & & \\
\hline $\mathrm{I}_{\mathrm{c}}$ & 6 & $\$$ & & & & & & \\
\hline $\mathrm{I}_{\mathrm{d}}$ & 7 & $\$$ & & & & & & \\
\hline $\mathrm{I}_{\ell}$ & 8 & $\$$ & & & & & & \\
\hline $\mathrm{n}$ & 9 & yr & & & & & & \\
\hline $\mathrm{n}_{\mathrm{c}}$ & 10 & $\mathrm{yr}$ & & & & & & \\
\hline $\mathrm{n}_{\mathrm{d}}$ & 11 & yr & & & & & & \\
\hline$\epsilon$ & 12 & $\% \times 10^{-2}$ & & & & & & \\
\hline$\eta$ & 13 & $\% \times 10^{-2}$ & & & & & & \\
\hline$P$ & 14 & $\mathrm{TMW}$ & & & & & & \\
\hline $\mathrm{v}$ & 15 & $\$ / \mathrm{gm}$ & & & & & & \\
\hline $\mathrm{m}$ & 16 & mills / kwh & & & & & & \\
\hline $\mathrm{OM}$ & 17 & $\$ / \mathrm{yr}$ & & & & & & \\
\hline$\omega$ & 18 & $\% \times 10^{-2}$ & & & & & & \\
\hline$x$ & 19 & $\% \times 10^{-2}$ & & & & & & \\
\hline$\delta$ & 20 & $\% \times 10^{-2}$ & & & & & & \\
\hline$\phi$ & 21 & $\% \times 10^{-2}$ & & & & & & \\
\hline$\psi$ & 22 & $\% \times 10^{-2}$ & & & & & & \\
\hline$a_{1}$ & 23 & $\begin{array}{c}\text { \$per\$ } \\
\text { million }\end{array}$ & & & & & & \\
\hline
\end{tabular}




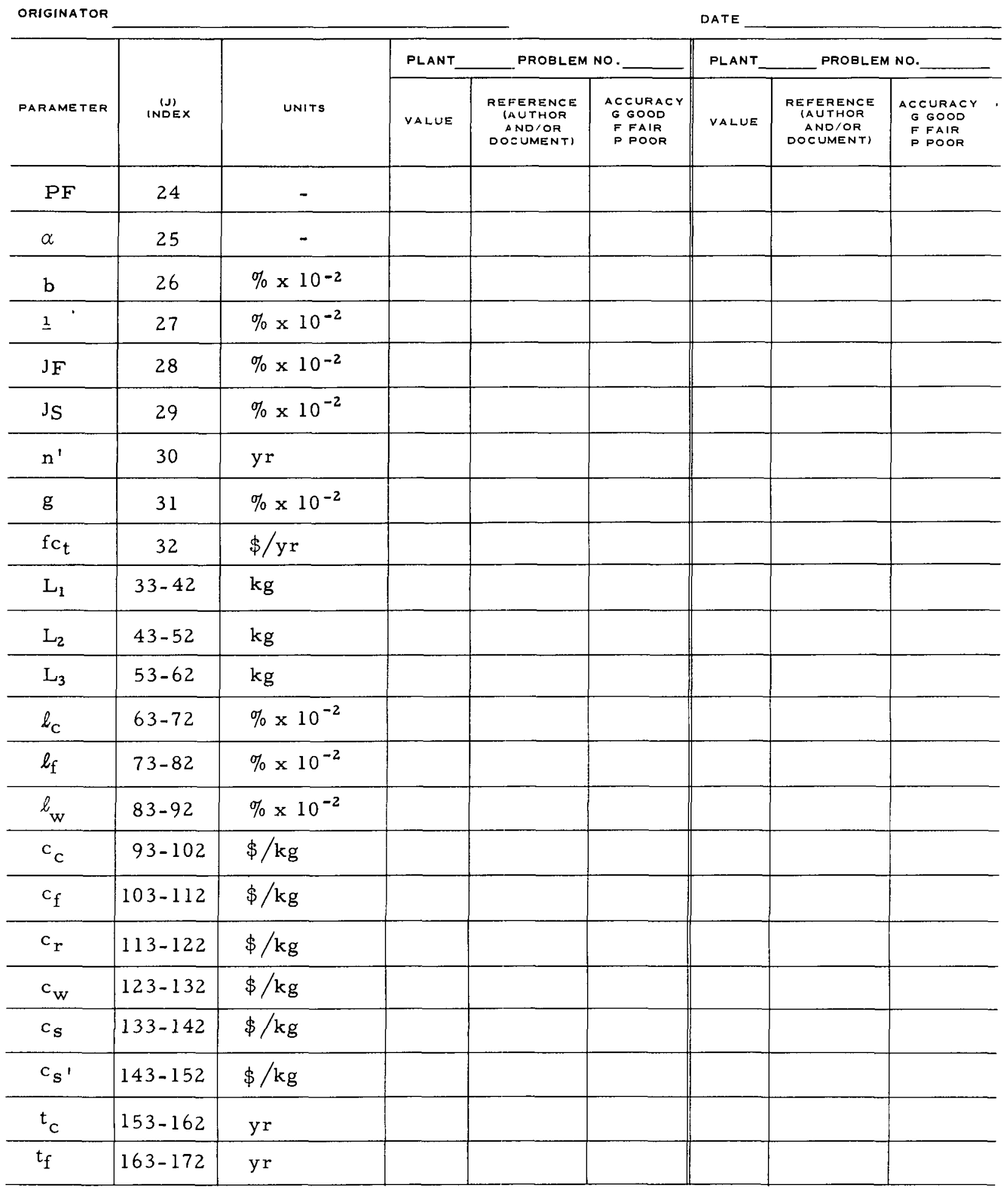




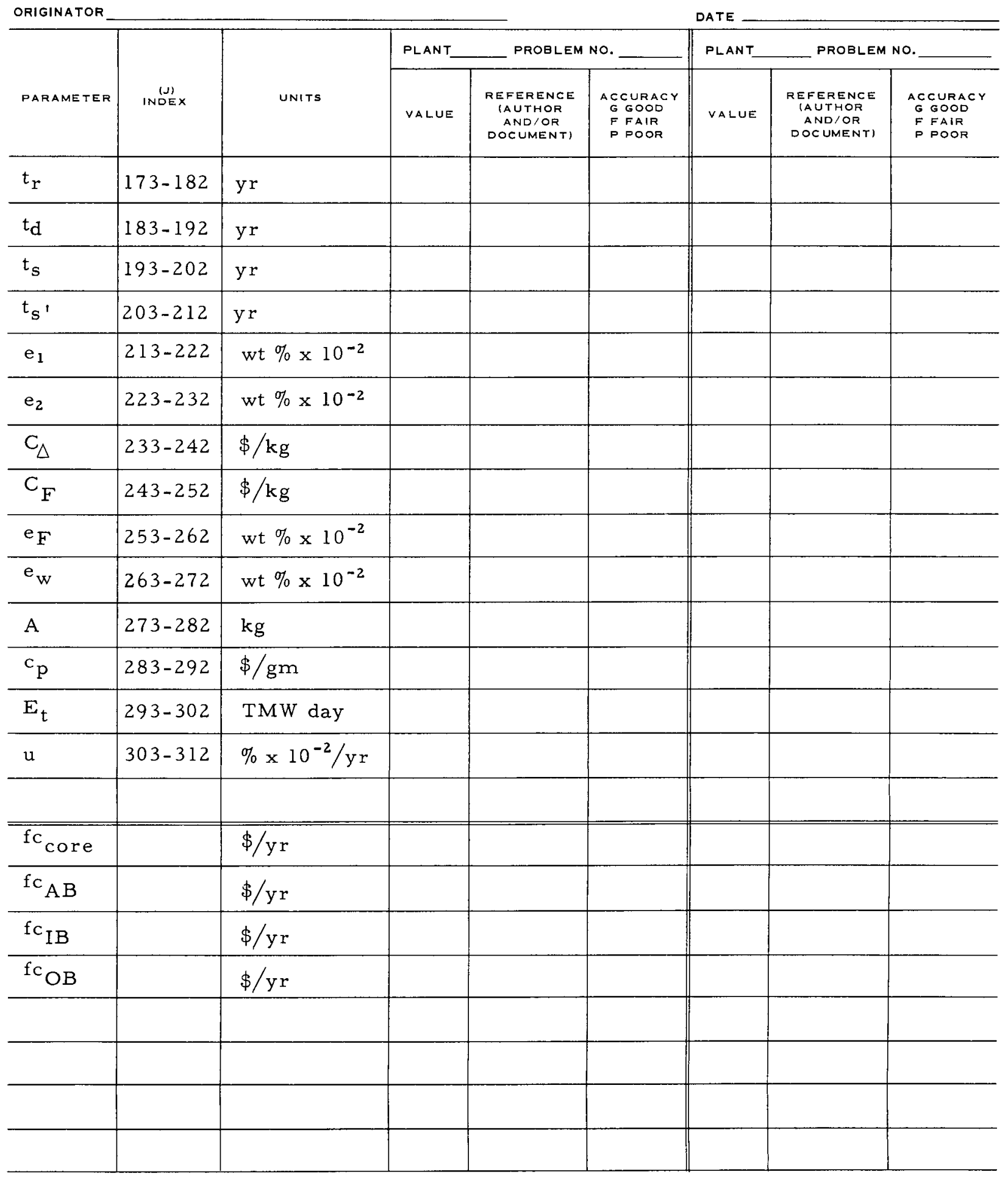


(a) J. M. McCampbell, Paper 16-6, Analytical Treatment of Power Reactor Economics, presented at the American Nuclear Society meeting in December, 1958.

(b) Indemnity regulations, 10 CFR 140, Federal Register, April 7, 1960.

(c) H. L. Hollister, and A. J. Burington, Pricing Enriched Uranium, Nucleonics, 16 (January 1958).

\section{ACKNOW LEDGEMENTS}

The authors wish to thank Mr. Leonard Link and Mr. Thomas Heckman for their contribution through discussion. 